

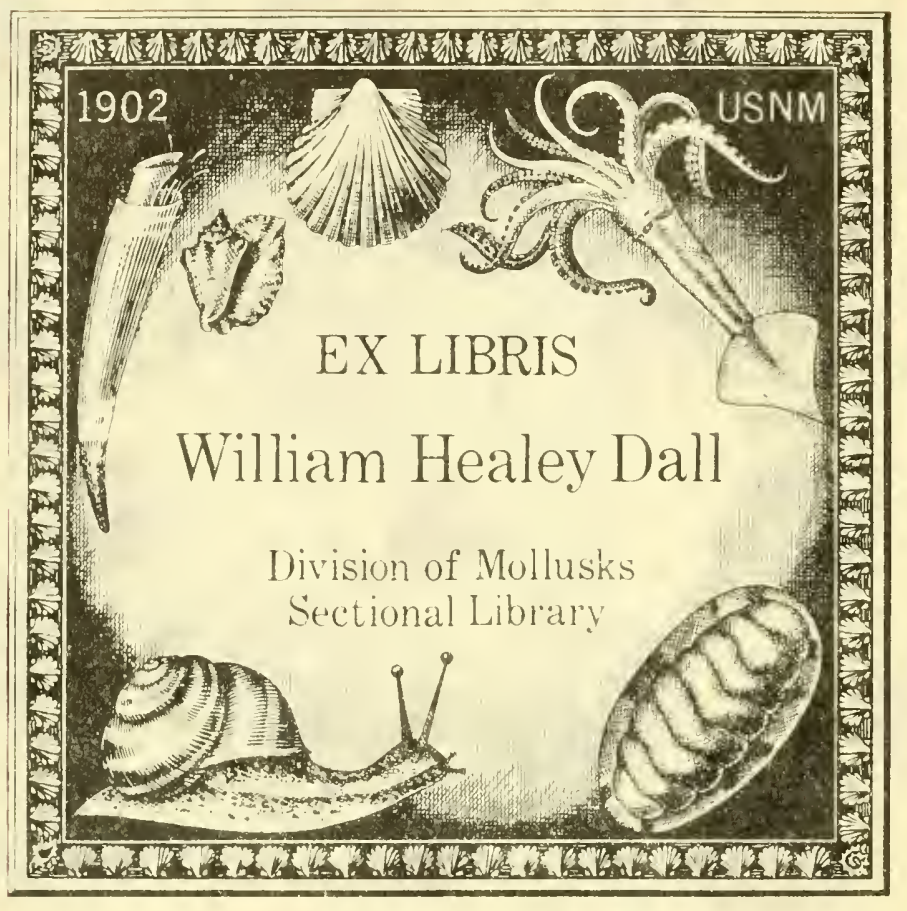

. 


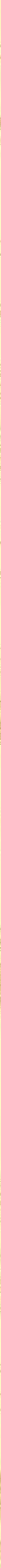





\section{Davitrion of Mollusates inational Librory}



IE des STIENCES
LES, H BéCUS

$M$ le l'rince

urles sciences

t achat de

eques, etc
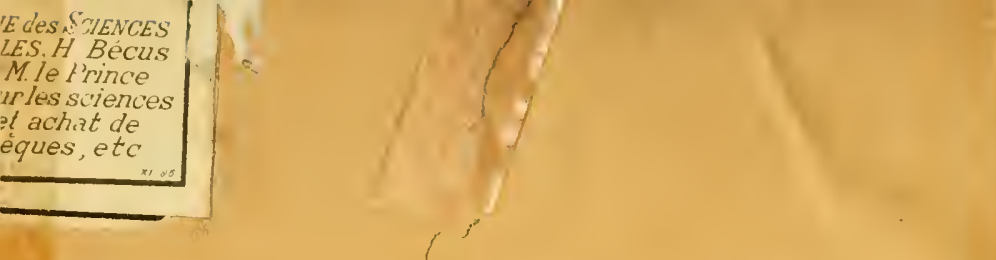


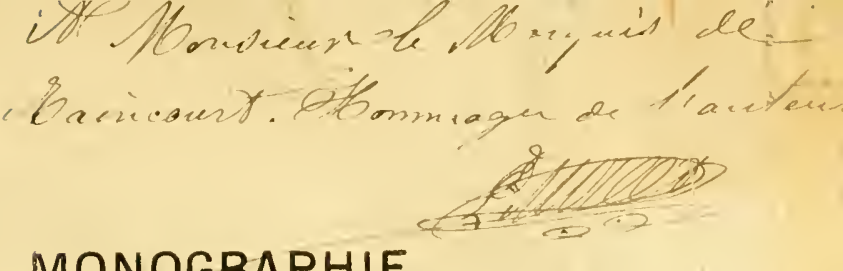

\section{MONOGRAPHIE}

DUU

\section{GENRE RINGIGULA}

ET DESCRIPTIONS

DE QUELQUES ESPẼCES NOUVELLES

PAR

LE COMMANDANT L. MORLET.

Avant - propos.

En cherchant à classer quelques espèces de Ringieules vivantes et fossiles, nous avons été frappé du nombre relativement assez grand de ces espèces et des difficultés que présente leur détermination. Ces raisons nous ont engagé à réunir tous les documents que nous avons pu nous procurer pour arriver à constituer une Monographie de ce genre si intéressant. Nous prions toutes les personnes qui nous ont aidé dans cetle tâche de vouloir bien accepter nos remercîments, et l'expression de notre sincère reconnaissance.

\section{Historique.}

Le genre Ringicula a élé créé, en 1\$38, par Deshayes. 
Jusqu'à cetıe époque, une grande confusion, relativement à ce genre, régnait parmi les conchyliologistes. Quelquesuns considéraient les espèces qui s'y rapportent, tantôt comm des Auriculina, tantôt comme des Marginella; enfin, d'autres les plaçaient parmi les Pedipes, les Voluta, les Auricula, les Nassa. etc.

Deshayes, dans la $2^{\circ}$ édition des Animaux sans vertèbres de Lamarck (VIII ${ }^{\circ}$ vol.), en traitant des Auricula. donna les caractères de son nouveail genre; il prit pour type le Ringicula ringens, espèce fossile da bassin de l'aris.

Genre RINGICULA, Deshayes, $18 \overline{8} 8$.

Nassa, Férussac, 1819 (pars).

Marginella, Ménard, 1811, Philippi, 1856 (pars).

Voluta, Brocchi, 1814 (pars).

Auricula, Lamarck, 1822 (pars).

Pedipes, Dujarlin, 1855 (pars).

Auriculina, Grateloup, 1858 (pars).

Caractìres génériques.

Coquille petile, ovale, globuleuse, ì spire assez courte, subéchancrée à la base. Ouverture parallèle à l'axe, longitudinale, étroite, calleuse. Columelle courte, arquće, ayant 2 on 5 plis presque égaux et une dent saillante, vers l'angle postérieur de l'ouverture. Bord droit trèsépais, renversé en dehors, presque toujours sans dent ou uridenté, simple ou finement plissé.

L'animal des Ringicules n'était pas connu jusqu'ici. M. Fischer a examiné quelques spécimens provenant du cap Breton (Landes), et qui nous ont été communiqués par M. de Folin. Voici ce qu’il a romarqué : 
“ L'animal, conservé dans l'alcool, rentre compléte" ment dans la coquille, mais, parfois, une porlion du " manteau reste appliquée sur la callosité de la colımelle. " Je n'ai pu distinguer la tête et je ne sais pas quelle est " la position des yeux. II n'existe pas d'opercule.

" J'ai trouvé deux mâchoires en forme de plaque sub. " trigune et à surface finement guillochée. Les mâ" choires de ce type existent chez un grand nombre de "Mollusques marins (Triton, Rissoa, Akera, Ceri" thium, etc.).

« Le ruban lingual est formé, de chaque côté, par une " rangée transverse de dents très-longues, aiguës au som" mel,où elles sont légèrement recourbées el bifides, à " leur insertion sur la plaque. Les dents se croisent de a telle sarte que la pointe de celles de la rangée de droite "alteint presque la base de celles de la rangée de gauche.

"Pas de dent rachiale ou centrale.

« La petilesse de ces dents est telle, qu'il m'est impos" sible d'affirmer s'il n'existe pas une dent transversale " plus petite entre deux dents de chaque côté, mais je " pense, néanmoins, que chaque rangéc de droite el de " gauche se compose de dents uniformes, semblables.

"Dans ce cas, les Ringicules auraient, par leur plaque " linguale, une grande ressemblance avec les Philine " (Bullae, Lamarck), et les Scaphander, dont on peut les “ rapprocher provisoirement, jusqu'au moment où l'ob" servation des individus vivants indiquera leur place " définitive, en faisant connaître la manière dont les " yeux sont disposés (Fischer)."

Distribution géographique.

Les Ringicules, à l'état vivant, se trouvent dans presque toutes les mers du globe, il l'exceptiou des mers froides. 
Nous les répartissons en 4 régions :

$1^{0}$ Océan Indien, ner Rouge, lirand Océan, Océan Pacifique, 16 espèces ;

$2^{\circ}$ Côle E. d'Amérique el Antilles, 2 espèces;

$5^{\circ}$ Cóte 0 . d’Afrique, 5 espèces;

$4^{\circ}$ Mers d'Europe, 4 espèces.

Quelques espèces vivantes ont été signalées à l'état fossile. Nous les indiquerons également dans la liste des fossiles. Quant à celles-ci, nous les énumérons d'après leur horizon géologique.

\section{A. Lisle des Espèces vivantes.}

1. Ringicula acuta, Philippi.

R. acuta, Philippi, Zeitsch. für Malak., vol. VI, p. 55, 1849.

- Issel, Malac. mar Rosso, p. 157, 1869.

- Nevill, Journ. As. Soc. of Bengal, vol. XLIV, part. 1I, p. 101, 1875.

Var. Ringicula minuta, H. Adams, Proc. Zool. Soc. London, p. 11, pl. 111, fig. 16, 1872 .

Tesla ovato-oblonga, acuminala, transversim striata, anfractu uliimo spiram parum superante; apertura ad labrum intus valde incrassatum, medio productum, coarctala, ringente (Philippi). - Long. max., 4 mill.; diam., 3 mill. - Long. min. 13 mill.; diam. 1 mill.

Ilab. Aden (Th. Philippi); Java (Dupuy); golfe d'Oman, Gwadar, littoral de la Perse, Bombay, Ceylan et Arakan. Très-commun dans toules ces localités (Nevill); Singapore (Stoliczka). La variété minuta habite les mêmes localités et se trouve aussi dans la mer Rouge, à Suez (Mac-Andrew). 
Obs. Forma angusla, acula, fere exacle eadem alque in R. striata, Philippi, fossili, sed stria conferta, minus conspicue et labrum, in allultis, intus valde incrassatum, medio in dentem obtusum, productum, unde apertura coarctala et ringens evadit (Philippi).

Une forme voisine a élé trouvée par M. Nevill, à Natal.

Il existe également un R. acuta fossile de Wilhemshöhe, décrit par Nl. Sandberger, mais qui est différent et que nous décrirons plus loin sous le nom de R. Sandbergeri.

On cite, dans les synonymies de cette espèce, l'ouvrage de Savigny (Description de l'Égypte, Coq., pl. vı, fig. 7, 1817), mais cette figure représente une coquille lisse et globuleuse, que nous considérons comme très-différente et que nous décrirons ci-dessous.

2. Ringicula Savignyi, L. Morlet (pl. V, fig. 1). Savigny, description le l'Égypte, coq., pl. VI, fig. 7, 1817.

Testa parva, ovato-globosa, lavigata; spira brevis, acuta; anfractus 5 convexi, sutura simplici discreti, ultimus $2 / 3$ longitudinis requans, basi rotundalus; apertura coarctala, marginibus callo junctis; margine columellari arcuato, triplicato, plica superna valida, plicis infernis crassis, callo immersis, canali callo partim tecto; labro lavi, rectilineo, extus murginato, intus ad $2 / 3$ longitudinis dilatato, subdentato._Long. 3 mill.; diam. $21 / 2$ mill.

Coquille petite, ovale, globuleuse et lisse. Spire comrte et aiguë, composée de ̋̋ tours convexes, sépares par une suture simple, le dernier formant les $2 / 5$ de la coquille et arrondi a la base. Ouverture resserrée. Bords rémnis par un léger dépôt calleux; bord columellaire, arquué; garni 
de 5 plis, le supérieur très-fort, les inférienrs très-épais et paraissant courts, à cause de l'épaisseur de la callosité qui descend très-bas et couvre, en partie, le canal dı siphon; bord droit lisse, parallèle à l'axe de la coquille, épais, formant une dent, aux $2 / 5$ de la hauteur, et renversé en dehors.

Hab. Baie de Suez, mer Rouge.

Obs. Nous donnons à cette espèce le nom de Savigny qui l'a fait figurer dans son ouvrage (Description de l'Égypte, Coq., pl. vi, fig. 7, 1817), sans dénomination spécifique (Coll. L. Morlet).

5. Ringicula prismatica, de Folin (pl. V, fig. 2). R. prismatica, de Folin, Les fonds de la mer, vol. I, partic I, p. 87, pl. xı, fig. 1, 1867-1871. R. apicata, Nevill, Journ. Asiat. Soc. Bengal, vol. XL, part. I1, p. 5, pl. I, fig. 12, 12a (non $\left.10,10^{a}\right), 1871$.

- Nevill, Journ. Asiat. Soc. Bengal, vol. XLIV, p. 102, 1875.

Testa parvula, ovato-globosa, crassa, solida, albida, nitida, interdum subdiaphana, anfractibus quinis, subcarinatis, rapide angentibus, ultimo permagno, 3/4 testa equante, ad basin sulcato, sutura simplice, apertura elonguta, obliqua, superne canaliculata, margine dextro tridentato, super busin reflexo, dentibus subacutis (de Folin). - Long. 2,5 mill.; diam., 1,3 mill.

Hab. Port-Louis, île Maurice : très-rare (Nevill); les rivages de l'île Maurice (de Folin); iles Andaman, Ceylan (Nevill).

Obs. Espèce trouvée récemment par M. Nevill, aux iles Andaman. On pent lit distinguer du R. acnta, Philippi, 
var. minuta, H. Alams, par son aspect lisse et poli, et par son dernier tour ayant seulement $\overline{5}$ stries à la base, au lieu d'être strié en totalité, comme chez d'autres especes. Elle est légèrement étroite et plus contractée, moins calleuse, avec la dent plus aiguë (Nevill).

II. Nevill n'ayant publié son R. apicata qu'en 1871 , il est équilable de restituer à cette espèce le nom de R. prismatica, qui lui avait été imposé, antérieurement, par M. de Folin.

4. Ringicula Folini, I. Morlet (pl. V, fig. 5).

Testa minutissima, ventricosa, crassa, regulariter et valide striata; anfractus \& 1/2 convexiusculi, sutura parum canaliculata discreit, ultimus dimidium longitudinis (equans, basirotundatus; spira elongata, sensim crescens ; apertura angusta, marginibus callo valido junctis, columellariarcuato, triplicato, plicis cquidistantibus et cequalibus ; labrum fere rectum, incrassatum, medio prominens, extus varicosum (de Folin). - Long. 2,7 mill.; diam. 1 mill.

Coquille petite, légèrement ventrue, épaisse, régulièrement et fortement striée; tours, au nombre de 4 1/2, légèrement convexes, séparés par une suture un pen canaliculée, le dernier formant la ınoitié de la coquille et arrondi à la hase. Spire allongée, angmentant graduellement. Duverture étroite : bords réunis par un dépôt calleux assez fort, bord columeliaire fortement arqué, garni de 5 plis à peu près à égale distance l'un de l'autre et égaux: labre presque droit, épais, surtont au milieu, saillant en dehors.

Hab. Carimata (de Folin); Singapore Ćllection de Folin). 
5. Ringicula Goujoni, de Folin (pl. V, fig. 4).

R. Goujoni, de Folin, Les fonds de la mer, vol. I, partie I, p. 67, pl. vi, fig. 4, 1867-1871.

Testı minuta, ovata, subelongata, crassa, solida, alba, nitida, spiraliter et regulariter sulcata; anfractibus quinis, satis rapide crescentibus, sutura simplice junctis, ultimo permagno, 2/3 testee cquante; apertura angusta, paululum obliquc margine dextro labrato, labro crasso, bidentato; sinistro valde reflexo, incrassato, tridentato (de Folin). - Long. 2,1 mill.; diam. 1,1 mill.

Hab. Côte septentrionale de Java (de Folin); NouvelleCalédonie (R. P. Lambert).

6. Ringicula canaliculata, de Folin (pl. V, fig. 6). R. canaliculata, de Folin, Les fonds de la mer, vol. I, partie I, p. 67, pl. vi, fig. 6. 1867-1871.

Testa minuta, ovato-globosa, crassa, solida, alba, nitida, dimidia parte testce minutissime transversim sulcata; spira brevi, subacuta; anfractibus quinis, subconvexis, rapide augentibus, sutura sat profunda separatis, ultimo permagno, 3/4 testce cxquante; apertura angusta, canali lato antice truncata, margine dextro valde labrato, labro crasso, latissino, ultimum anfractum superante, intus valde unidentato, sinistro lato, reflexo, incrassato, sulcato, intus tridentato, dentibus prominentibus elongatisque (de Folin). — Long. 3,8 mill.; diam. 2,8 mill.

Hab. Pointe de Pamaling, Ilong-Kong (de Folin;, Java (Desliayes).

Obs. L'exemplaire de Java de la collection Deshayes constitue une variété de taille plus petite. 
7. Ringicula encaipoferens, de folin (pl. V, fig. 5).

R. encarpoferens, de Folin, Les fonds de la mer, vol. I, partie 1, p. 66, pl. vi, fig. 5, 1867-1871.

R. abbreviata, G. et H. Nevill, Journ. Asiat. Soc. Bengal, vol. XLIV, partie 11, p. 102, 1875.

Testa minuta, globosa, alba, interdum subdiaphana, nilida, spiraliter el regulariter sulcata; anfractibus quaternis, rapide crescentibus, ultimo permagno, 4/5 testee rquante; sutura simplice; apertura elongata, margine dextro valide labrato, liris subrotundatis, crenulato, extus super ultimum unfractum late extenso, intus mediam partem versus tumido, ad basin emarginato, sinistro valde reflexo et incrassato, intus valde denticulato, extus irregulariter crenulato (de Folin). - Long. 2,3̈ mill.; dium., 2, 2 mill. (de Folin). — Long. 3 mill. (sur lesquels le dernier tour seul mesure $21 / 2$ mill.); diam. 2 1/2 mill. (Nevill).

Hab. Pointe de Pamalang, Batavia, et la côte septentrionale de Java (de Folin); Balapiti, Ceylan (Nevill).

Obs. D'après les dimensions données par M. Nevill, les échantillons recueillis par lui seraient un peu plus grands que ceux des localités indiquées par M. de Folin.

M. Nevill n'ayant publić son R. abbreviata qu'en 1875 , il y a lieu de restituer à cette espèce le nom de R. encarpoferens, qui lui avait été improsé, antéricurement, par II. de Folin.

8. Ringicula Caron, Hinds (pl. V, fig. 7).

R. Caron, Ilinds, Zool. Voy. of II. it. S. Sulpluur. vol. II, 1. 47, 11. xv1, tig. 15, 16, 1814. 
R. Carou, Hinds, Proceerl. Zool. Suc. London, p. 97, 1844, et p. 98, $n^{\circ} 85,1871$.

- Lischke, Japanische Ifeeres Conch., vol. II, p. $78,79,1871$.

- Nevill, Journ. Asiat. Soc. Bengal, vol. XILIV, part. II, p. 101, 102, $187 \%$.

Testa ovala, acuminatu, striata, nitida; anfractibus rolundatis, ultimo subtransverso, rotundato, distanter striato; spira exserta; apertura subabbreviala, labro corrugato (Hinds). - Long. 3,5 mill.; diam. 2,5 mill.

Hah. Détroil de Malacca, par 17 brasses de profondeur, vase (Gould); île Goat, Port-Jackson, Australie; Gwadar (Blanford).

Obs. Cette espèce a été aụssi Iraguée par N. Blanford, à Gwadar; elle est parfaitement distincte, par tous ses caractères, du R. acuta. Son bord droit, particulièrement, est très-différent : le léger développement de la dent pariétale, sa texture différente et sa striation constituent autant de caractères qui la distingueut de l'acuta.

9. Ringicula propinquans, Hinds.

R. propinquans, Hinils, Proceed. Zool. Soc. London, p. 96,1844 .

- Smith, Proceed. Scientific Meetings of the Zool. Soc. London, partie I, p. $75 \overline{5}, 1871$.

- Lischke, Japanische Meeres Conch., vol. II, p. 78, 79, 1871 .

Testa ovata, relusa, striaia, nilida; anfractibus rotundatis, ultimo magno, valide rotundato, concinne striato (Hinds). - Long. 1 ligne $1 / 2$. 
liab. Sual, Philippines, par 5 à 7 brasses de profondeur, sable vaseux (Hinds).

10. Ringicula exserta, Ilinds.

R. exserta, Hinds, Proceed. Zool. Soc. London, p. 17, 1844.

- Angas, Proceed. Zool. Soc. London, p. 98, $n^{\circ} 87,1871$.

Testa ovata, acuminata, leviguta, polita; anfractibus rotundatis, levigatis; spira elongata, labro pone valide incrassato (Hinds). - Long. 1 ligne 2/3.

IIab. Comiguig, par 40 brasses, sable vasenx; Sorsogon, ile de Luzon, par 6 brasses, sable grossier; Philippines (Hinds): Port-Jackson, Australie (Angas).

11. Ringicula grandinosa, Hinds (pl. V, fig. 8).

R. grandinosa, Hinds, Proceed. Zool. Soc. London, 1.: 96,1844 .

- Smitl, on West African shells, Proceed. Zool. Soc. London, p. 755, 1871.

Testa ovata, retusa, lavigata, polita; anfractibus rotundatis, ultimo magno, subquadrato, rotundato; columella superne valde callosa, denticulatu (Hinds)._Long. 5 mill.; diam. 3,8 mill.

IIab. Bais, île de Negros, par 6 brasses de profondeur, sable grossier; Cagayan, ile de Mindanao, 25 brasses, sable vasenx; Catbalonga, île de Samar, de 10 à 50 brasses, sable vaseux; Sorsogon, île de Luzon, l'hilippines (Hinds).

La mème espère est indiquece à Whydal, côte 0 . d'A. 
frique, par 11. E. Smilh, mais cette identification est-elle exacte?

Cette coquille est petite, ovale, lisse, brillante, un pen bombée en dessus, presque aplatie en dessous. Spire courte, aiguë, composée de 5 tours légèrement convexes, séparés par une suture très-prononcée, le dernier formant presque les $4 / 5$ de la coquille, arrondi à la base. Ouverture étroite; bords réunis par un dépôt calleux trèsfort, qui couvre la moitié de l'avant-dernier tour de spire; bord columellaire oblique par rapport à l'axe de la coquille, garni de $\overline{\mathbf{j}}$ plis très-épais : callosité trèsrenflée et formant, à sa jonction, le long de la coquille, un léger sillon; bord droit très-épais, très-renversé en dehors, et formant, à sa partie supérieure, un petil canal.

Nous complétons la trop courte diagnose de H. Hinds, d'après des échantillons qui se rapportent à son type.

12. Ringicula arctata, Gould (pl. V, fig. 9).

R. arctata, Gould, Otia, p. 122, 1871.

- Angas, Proceed. Scient. nieet. Zool. Soc. London, p. 98, $\mathrm{n}^{\circ}$ 88, 1871.

- Lischke, Japanische IJeeres Conch., vol. II, p. 78,79 , pl. v, fig. $16,17,18 \% 1$, et vol. III, p. 59,1875 .

Testa solida, ovata, acuminata, alba; spira anfiact:bus 4, convexis, ultimo striis volventibus (10-12) insculpto; sulura profunda; apertura auricuiata, labro incrassato, intus tumido, plicis ad columellam conspicuis; dente parietuli robusto, usque ad angulum posticum aperturce protracto; callo labiali lato, sinum siphonalem transeunte. (Gould). - Long. 4. mill.; diam. 4 mill.

Ilab. Ile de Goat, Port-Jackson, Australie (Brazier); Hong-Kong (Gould); Nangasaki (Lischke). 
Ofs. Culte espice est voisine des R. Caron et propinquans, mais les lignes transverses sont plus serrées.

15. Ringicula australis, Hinds (pl. V, fig. 10).

R. australis, Ilinds, Proceed. Zool. Soc. London, p. 97, 184.4 .

- Angas, On the marine Molluscan fauna of South Australia, p. 130, 1865.

- Crosse, Journ. de Conchyl., vol. XIII, p. 44, pl. II, fig. 5, 1865.

Testa ovata, acuminata, lavigata, polita; anfractibus rotundatis, penultimo sensim minore; spira elongata, infra suturam fascia subalbida cincta (Hinds). - Long. 3 mill.; diam. $12 / 3$ mill.

Hab. Port-Lincoln (Hinds), Golfe de Spencer (Angas), Australic; Nouvelle-Calédonic (R. P. Lambert).

Obs. M. Hinds n'ayant pas fait figurer cette espèce et I'en ayant donné qu'une description très-succincte, M. Crosse l'a décrite de nouveau et l'a fait figurer.

14. Ringicula denticelata, Gould.

R. denticulata, Gould, Otia, p. 121, 1871 .

Angas, Proceed. Zool. Soc. London, p. $98,{ }^{\circ} 86,1871$.

Testa ovata, acuminata, solida, lactea, striis confertis transversim (exilioribus interdum intervenientibus) insculpta; anfractibus 5 ventricosis; apertura angusta, labro admodum incrassato, intus denticulato, fere ad sinum siphonalem interrupto, plicis aculis, transversis, callo modico, haud appresso, dente parietali morlico (Gould). Long. '5 mill.; diam. 3,5 mill. 
Hab. Port-Jackson, Australie (Angas).

Obs. Celte espèce est caractérisée par ses nombreuses stries et par l'exiguilé de la callosité, qui passe au-dessus de l'échancrure siphonale.

15. Ringicula fossulata, de Folin (pl. V, fig. 11). R. fossulata, de Folin. Les fonds de la mer, vol. I, partie II, p. 251, pl. xxxı, fig. 9, 186 -1871.

Tesla ovato-globosa, apice acuminata, alba, nitida; anfractus 5 , valde rapide accrescentes, laves, ultimi minutissime spiraliter sulcati, ultimus maximus, 4/5 testa cquans; apertura paulum elongata, dentibus majusculis sinuata: margo dexter valde incrassatus, superne fossulatus' (margines fossulce super dentem satis prominentem conjuncti, postea costulam unicam simulantes, quce ad. basin cunalem parvum, rotundatum cingit et super dentem sinistrum inferiorem porrectum intus penetrat; margo sinister super basin in reflexione lala et crassa valde expansus, dentibus tribus ornatus, dens superior tricostulatus (de Folin). - Long. 3,6 mill.; diam. 1,8 mill.

Hab. Port de Nouméa, Nouvelle-Calédonie (de Folin).

16. Ringicula dolianis, Gould.

R. doliaris, Gould, Proc. Boston Soc., v. VII, p. 524, 1860.

- Gould, Otia, p. 121, 1862.

Testa majuscula, tenuis, ventricosa, ovata, albida; spira acuminata; anfractibus 4 rotundatis, sulcis transversis, remotis, insculptis, ultimo amplo; sutura profunda, apertura magna, labio angusto, haud incrassato, plicis columella tenuibus, acutis, plica parietali parva, tenui, callo siphonali modico (Gould). - Long. 5 mill.; diam. 3 mill. 
Hab. Hakodarli (Gould).

17. Risgicola nitiba, Verrill.

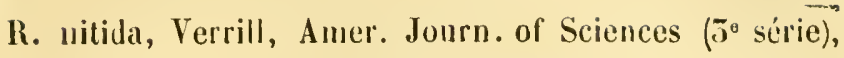
vol. $\mathrm{Y}, \mathrm{p} .6,16,1875$.

- Tryon, Amer. Journ. of Sciences, Amer. ma *rine Conchology, p. 100, 1875.

Coquille petite, blanche, lisse, ovale-élargic, avec 5 tours à spire régulièrement conique, subarquée, croissant régulièrement, et plus courte que l'ouverture; tours de spire très-convexes, arrondis, séparés par des sutures Irès-prononcées ; une ligne infra-suturale, bien distincte, se voit à leur parlie supérieure; la surface des tours est presque lisse, mais on peut y distinguer quelques stries spirales microscopiques, plus évidentes en avant; ouverturé un pen en forme de croissant; lèvre externe uniformément arquée, formaut un segment de cercle, son bord, régulièrement épaissi. se retirant un peu en arrière, près le la suture; callosilé étroite, presque unie, mais un peu bombće au milien et légèrement saillante; culumelle forte, recourbée à son extrémitć avec des plis spiraux très-prononcés et égaux; le pli antérieur projeté au-dessus du canal, avec son extrémité arrondic (Verrill). - Long. 4, 5 mill.; diam. 5,1 mill.

Hab. Sur les côtes de la Nouvelle-Angleterre (EtatsUnis), oủ deux spécimens ont été dragués, dans un fond de vase, par 110 et 150 brasses de profondear (Verrill).

18. Rixgicula semistriata, d'Orbigny.

R. semistriata, d'Orbigny, Hist. de l'île de Cuba (Ramon de la Sagra), Mlollusques, vol. II, p. 105, ,1. xxı, fig. 17, $19,1855$. 
Testa orato-conica, crassa, albida, postice levigala, antice transversim striata; spirce conica, acuta; sutura ımpressa; apertura oblonga; columella incrassata, biplicata, callo repando, postice instructa, labro crassissimo, in medio subtuberculato (d'Orbigny). - Long. 2 mill.; diam. 1 mill.

Hab. Jamaïque (D’Orbigny.)

Obs. Cette espèce se rapproche beaucoup du R. marginata par sa forte callosité, mais elle s'en distingue par sa surface striée seulement en avant, caractère qui la fait différer des espèces décrites, qui, toutes, sont entièrement striées (d'Orbigny).

19. Ringicula suturalis, Smith.

R. suturalis, Smith, Proceed. Scient. meet. Zool. Soc. London, p. 755, pl. Lxxv, fig. 12, 1871.

Testa ovata, alba, polila; spira acuminata; sutura chorda callosa cincta; anfractibus $\ddot{5}$, convexis, spiraliter sulcalis, in anfractu ult. sulci 10 ; apertura piriformis; columella callosa, triplicata; labrum extra valide incrassatum (Smith). - Long. 2 3/4 mill.

Hab. Whydah (côte 0 . d'Afrique).

Obs. Petile espèce très-striée, appartenant au groupe des Ringicula propinquans et Someri, mais beaucoup plus petite, et se distinguant facilement par le nombre et la position des dents, ainsi que par le cordon de la suture.

20. Ringicula Someri, de Folin (pl. V, fig. 12).

R. Someri, de Folin. Les fonds de la mer, vol. I, partie I, p. 14, pl. 1, fig. 7, 1867-1871.

Testa parvula, ovalo-globosa, crussu, solida, candida, 
transversim minute et regulariter sulcata: anfractibus 6-7, subcarinatis, prioribus rapide crescentibus, ultimo permagno, globoso, 7-10 testa cequante; sutura simplici; apertura elongata, obliqua; marginibus valde incrussatis, dentatis, dextro latissimo, sinistro inflato, late reflexo, dentibus majoribus (de Folin). - Long. 4 mill.; diam., 2,6 mill.

IJab. Rade de Saint-Vincent, Cap-Vert (de Folin).

21. Ringicula Mloritzi, de Folin (pl. V, fig. 15).

R. Moritzi, de Folin. Les fonds de la mer, vol. I, partie II, p. 212, pl. xxvi (non xxvili), fig. 10 (non 14), 1867-1871.

Testa ovato-globosa, subvitrea, aliquando magis crassu et candida, spiraliter el regulariter sulcata; sulciminuti, scepe evanidi; anfractus 4, rapide crescentes, ultimus permagnus, globosus, dimidiam partem testo cequans; sutura simplex; apertura semilunaris ; margo sinister incrassatus, canali rotundato terminatus, dexter super basin valde reflexus, inflatus, dentatus; dentes 3 ; superne margines canali satis profundo juncti(de Folin).-Long. 21/2 mill.; diam., 1 1/2 mill.

Hab. Cagnabac, côte 0. d'Afrique (de Folin).

Obs. Cette espèce, qui se rapproche beaucoup du R. Someri, s'en distingue par sa taille plus petite, par ses tours de spire moins nombreux, et par le canal qui sépare, i la base, les deux bords de l'ouverture, canal bien plus large et moins arrondi que dans l'autre espèce. Il y a aussi quelques différences dans la réllexion dı bord droit et dans la dentition. Le bord gauche, lui-mème, est beancoup moins épaissi; enfin, le canal supérieur n'est pas non plus tout à fait le même. 
22. Ringicula auriculata, Ménard (pl. V, fig. 14). Marginella auriculata, Ménard, Ann. dı Mus., vol. X VII, p. $551,1811$.

- Philippi, Enum. Moll. Sicilix, vol. 1, p. $251,1856$.

R. auriculata, Philippi, loc. cit., vol. II, p. 198, pl. xxvil, fig. 15, $15^{a}, 1844$.

- Mac-Andrew, Gcograph. distrib. of Testaccous Nollusca in the North Allantic and neighbouring seas, p. 17, 29, $26,41,45,47,18504$.

- E. Forbes, Mollusca and Radiata of the Egean sen, p. 141, 1844.

- C. Weinkauff, Calnlogue des coquilles marines, recueillies sur les côtes de l'Algérie, p. 567, 1862.

- G. Hidalgo, Catalogue des Mollusques testacés marins des côtes de l'Espagne et des iles Raléares, p. 109, 1867.

- Monterosato, Nuova Rivista delle Conch. Medit., p. 45, $10^{\circ} 760,1875$.

Testa minuta, ovata, inflata, alba, lavigata; spira brevi, acula; basi emarginata; columella triplicala, plicis acutis; labio expanso, adnato; labro marginato, calloso (Nénard). - Long. 5, 1 mill.; diam., 4 mill.

Hab. Océan : Norl de l'Espagne (Fischer), Asturies Coruña, Vigo, Cadix el Trafalgar (Mac-Andrew). Méditerranée : liahon, Concjira, Carthagène, Malaga et Gibraltar, Mlalte; assez abondanı, vit ì une profondeur de 20 à 40 brasses (Mac-Andrew, Llidalgo); Alger, trìs-commun dans le port, ou en dehors, près do l'entrie, dragué à une 
profonderr de 10 a 20 brasses (C. Weinkanff); Tarente (Monterosato).

Obs. Cette espèce, qui est très-voisine du R. buccinea, s'en distiugue par sa forme moins globuleuse, sa spire plus longue, sa callosité moins forte et sa surface garnie de stries régulières.

Nous n'avons pas cité, dans la synonymie, le nom de Voluta buccinata, Renier, parce qu'il est impossible de savoir à quelle espèce il doit s'appliquer, faute de descriplion et de figure.

25. Rivgicula conforsis, Monterosato (pl. V, fig. 15).

R. auriculala, Ménard, var. conformis, Monterosato, Nuova Rivista delle Conch. Nediterranee, p. 45, 1875. R. conformis, Monterosato, Journ. de Conchyl., vol. XXV, p. 44, pl. xı, fig. 4, 1877.

La forme et la disposition des dents sont différentes de celles du R. auriculata; l'ouverture est plus grimasante, et, en outre, le test n'est pas strié superficiellement. Dans quelques localilés, cette espèce présente, sur les premiers tours, une apparence de plis verticaux (Monterosato). Long. \& mill.; diam., 5, 4 mill.

Hab. Méditerranée, mais à une plus granile profondeur que le R. auriculata (Honterosato). L'espèce existe aussi dans l'Allantique : cap Breton (de Folin).

Obs. Celte forme, considérice d'abord comme une simp̣le variété de l'auriculata, a été élevée récemment au rang d'espece par l'auteur.

24. Ringicula ieptocilla, Brugnone (emend.) (pl. V, fig. 17). 
R. Ieptocheila, Brugnone, Miscellanea malacologica, p. 1i, pl. I, fig. 17.

- Monterosato, Nuova Rivista delle Conch.

Mediterrance, p. $45, \mathrm{n}^{\circ} 761$, 1875.

- Monterosato, Poche Note sulla Conchyliologia Mediterranea, p. 14, $\mathrm{n}^{\circ} 120$, 1875.

R. ventricosa, Jeffreys (non Sowerby).

Testa ovato-acuminata, ventricosa, tenui, nitidula, subtilissime transversim striato-punctata; spira parum exserta; anfractibus 5, convexis; apertura magna, subangulata; columella contorta, plicata; plicis 1-2, acutis; labro tenuiter marginato, intus lcevi, labro exilissimo, adnato (Brugnone). - Long. 5 mill.; diam., 4 mill.

IIab. Méditerranée, dans les grandes profondeurs (Monterosato). Atlantique et Nord de l'Atlantique (Jelfreys); Cadix, baie de Bilbao, par 14 brasses de profondeur, et fosse du Cap-Breton (de Folin).

25. Ringicula buccinea, Brocchi (pl. V, fig. 16).

Voluta buccinea, Brocchi, Conch. foss. subap., vol. II, p. $645, \mathrm{pl} . \mathrm{sv}$, fig. 9, 1814 .

A uricula buccinea, Sowerby, Min. Conch., vol. V, p. 100,

pl. ccccexv, fig. 2, 1 S2․․

- Deshayes, Encycl. mélh. Hist. nat. des Vers, vol. II, p. 95, 1850.

R. buccinea, Deshayes, Ilist. nat. des an. s. vert. (Lam.), $2^{\circ}$ édit., vol. VIIr, p. 544, 1858.

- Forbes, Mollusca and Radiata of the Egean - sen, p. 157-159, 1844. 
R. buccinea, Fischer, Faune Conch. marine du dép. de la Gironde et des côtes du S. 0. de la France, p. 211 (2。 supp.), 1874.

Testa minula, subovala, inflata, lavigata; spira brevis, acuta; columella triplicata, plicis acutis, labro expanso, adnato, labio marginuto, in medio inflato, non exarato (Brocchi). - Long. 4, 8 mill.; diam., 4 mill.

Hab. Côtes de la Gironde et des Landes, Cap-Breton, de $2 .:$ à 180 brasses (Fischer et de Folin); Asturies, au large de Gijon, par 18 brasses de profondeur (de Folin); Méditerranée (Forbes).

Obs. Cette espèce, bien voisine du R. auriculata, en diffère par sa coquille plus globuleuse, sa spire plus courte, sa callosité plus développée et sa surface toujours lisse et brillante.

B. Liste des espices fossiles.

1. Rivgicula Desilayesi, Guéranger,

R. Deshayesi, Guéranger, Essai Répert. Paléont. sur la faune de la Sarthe, p. 50, 1855.

Spire aiguë, composée de 5 tours et ne porlant aucuu ornement visible a la loupe. Bouche entourée d'un fort bourtel, extérientement tris-silllant, et garni de stries d'accroisicment. Le bord columellaire est garni de deux plis, l'inlérienr beaucoup moins accusé, placé obliquement sur le bord du canal (Gućranger). - Long. 7 mill.; diam., 4 mill. (mesure prise sur les dessins envoyés par M. Guéranger). 
Loc. Terrain crétacé. Le Mans, carrière des Perrais.

2. Ringicola Verneuili, d'Archiac.

1h. Verneuili, d'Archiac, Bull., Soc. Gćol. de France, ze sér., Desc. de quelques foss. nouveaux ou imparfaitement connus des env. des Bains de Rennes, vol. XI, p. 218, pl. IV, fig. $5 a, b .183 \%$.

Coquille ovalaire, pointue an sommet, composée de 5 tours, le dernier très-renflé, formant à lui seul les 2/3 de la hauteur totale; suture sub-canaliculée; surface couverte de stries décurrentes, régulières, plus rapprochées, vers le sommet et la base du dernier tour, qu'au milieu. Bord droit arqué, muni d'un bourrelet fort épais, qui, partant de la suture, se prolonge jusqu'à la base de l'ouverture, marqué au dehors de stries d'accroissement, lisse à sa partie antérieure et crénelé à son hord interne. Ouverture très-étroite vers le haut, élargie à sa partie moyenne, rétrécie de nouveau par un pli de la columelle, et se terminant par un canal très-court, peu profond, coupé obliquement en arrière. Bord gauche revètu d'une épaisse callosité, depuis sa jonction avec le bord droit, et muni, vers le bas, de leux plis très-prononcés, dont le second bórde le canal et recouvre l'extrémité du bourrelet du bord droit (d'Archiac). - Long. 6 mill., diam., \& mill.

Loc. Terrain crétacé. Mloulin Tisan (Aube).

Obs. Cette espèce, qu'il serait bien difficile de confondre avec le R. ringens, Desh. (Aur. ringens, Lam., Desh., vol. II, pl. vIII, fig. 16-17), n'en diffère, en réalité, que par les stries de la surface moins nombreuses, moins serrées et moins régulièrement espacces, par les crénelures internes du bord droit moins fines, par te canal de 
1a base moins profond, et faisant ainsi une sorte de passage an genre Ringinella, si toutefois ce dernier peut ctre conserví. C̈est, d’ailleurs, avec la précédente, la première espèce signalée lans la formation crélacée (Assises du grès vert, n. 5) (d'Ar'chiac).

5. Ringicula minor, Deshayes (pl. VI, fig. 1).

R. minor Deshayes, An..s. vert. du bassin de Paris, vol. II, p. 612, pl. $x \mathrm{~L}$, fig. 7-9, 1862 .

Tesia ovata, globosa, spira exsertiusculu, conica, apice acula; anfractibus quinis vel senis primis nitentibus, angustis, cuteris gradatim latioribus, convexiusculis, sutura subcunaliculatu, marginata distinctis, transversim profunde et regulariter striatis; ultimo inflato, globuloso, spiram superante; apertura elongato-angusta, labro in medio inflato, temuc crenulato, ad basin testam superante; columella breviuscula, inaqualiler triplicata (Deshayes). Long., 4 mill.; diam., 3 mill.

Loc. Eocène inféricur. Mercin, Hérouval, Louersines, Laon, Vrégny, Couvres, Relheuil, Cuise-Lamolhe. Assez rare (Deshilyes).

4. Rivgicula Bezançoxi, [. Morlet (pl. VI. fig. 5).

Testa ovata, crassa, gibbosa, temuissime el regulariter striata; anfractus $41 / 2$ convexiusculi, sutura simplici discreli; anfractus ullimus valde gibbosus, 3/4 longitudinis altingens, basi rotundutus; apertura lala; marginibus callo tenui junctis, callo penultimum anfractum. superante; columella callo crasso, superne valde dilatato munilu, triplicata; plicis lamelliformibus obliquis, ad centrum convergentibus; lubro allo et medio crasso, subden- 
ticulato, extus prominente. - Long., 3,2 mill.; diam., 2,4 mill.

Coquille ovale, épaisse, gibbeuse, striée très-finement et régulièrement. Les tours, au nombre de $51 / 2$, sont légèrement convexes et séparés par une sulure simple, le dernier tour, très-gibbeux, formant les $5 / 4$ de la coquille, est arrondi à sa base; l'ouverlure est large; les bords sont réunis par un dépôt calleux, qui remonte au delà de l'avant-dernier tour ; le bord columellaire, couvert d'une callosité très-forte, très-dilaté dans sa partie supérieure, est muni de 5 plis lamelliformes, obliques et se dirigeant vers le centre; le bord droit est assez épais, surlout vers le milieu, garni d'un léger bourrelet dentelé à l'intérieur et saillant à l'extérieur. (Collection de M. le docteur Bezançon, et la mienne.)

Loc. Eocène moyen. Marines (Sables de Beauchamp).

$O b s$. Cette espèce a quelques ropporls avec le R. ringens, mais elle en diffère par la longueur; ce dernier est plus long et moins ventru; la callosité est bien moins forte que dans notre espèce, et l'ouverture est moins large.

\section{Ringicula coarctata, Koenen.}

R. coarctata, Koenen, Die Fauna der unter-oligocänen Tertiårschichten von Helmstadt bei Braunschweig, p. $51 \%$, pl. xvi, fig. 6,1865.

On possède, provenant d'Helmstadt, un certain nombre d'échantillons bien conservés d'une Ringicule remarquable par son ouverture très-étroite. La spire se compose d'un tour embryonnaire, court et lisse, de 4 autres tours arrondis et comprimés, et l'un dernier tour. Les tours du milieu portent d'abord 5 , puis 4 ou 5 lignes peu 
profondes; sur le dernier tour, il s'en trouve, comme d'ordinaire, 12 et plus, et parfois celles du milieu sont les plus espacées. Le bord externe est fortement épaissi intérieurement et extérieurement; il est semblable à celui du R. striata, Phil., allongé en forme d'aile, à sa partie inférieure, et porte, en dedans, une protubérance allongée, épaisse, en forme de dent, qui se rétrécit brusquement en arrière, comme dans le R. auriculata ; toutefois, elle devient plus faible près de la sulure, où elle se continue; elie détermine là une callosité étroite qui remonte assez haut, comme on le remarque dans plusieurs Rostellaires.

Le bord columellaire s'élargit sur la coquille âussi loin que dans le R. auriculata et porte, sur le bord pen courbé, et vers la partie supérieure, une dent presque horizontale; près de cette dent, et la couvrant en partie, se présente une protubérance qui se prolonge presque parallèlement (Trad.). - Long., 5 mill.; diam., 2 mill. (mesure prise sur le dessin de Koenen).

Loc. Eocène moyen, Helmstadt.

6. Ringicula naja, L. Morlet. (PI. VI, fig. כ̈).

Testa minutissima, ovata, tenuis, regulariter striala; spiru brevis; anfructus b̈ convexiusculi, sensim cresconles, sulura simplicidiscreti; anfractus ultimus globosus, dilatatus, 2/3 tesla atlingens: apertura obliqua, lata; margine columellari arcuato, basi bidentato: callo inferne valde incrassalo; labro cum columella arcuatim juncto, medio dilatato, extus prominente. - Long. 2 mill.; diam., 1,2 mill.

Coquille trí-petite, ovale, mince, régulièrenent striće ; spire courte, composée de 5 tours légèrement converes, 
angmentant griduellement; suture simple; dernier tour globuleux, dilaté, arrondi et formant les $2 / 5$ de la coquille; ouverture oblique et assez large; le bord colımellaire est lrès-arrondi, garni, à sa base, de deux dents, la callosité très-forte dans la partic inférieure; le bord droit rejoignant la coquille par une courbe faible aux deux ertrémités, Irès-dilaté au milieu et saillant au dehors. (Ma collection).

Loc. Eoc. moyen. Marnes d'Ossun (Hautes-Pyrénées).

7. Ringicula ringens, Lamarck (pl. VI, fig. 2).

Auricula ringens, Lamarck, An. du tlus., vol. IV, p. 455, $11^{\circ} 5$, et vol. YIII, p. 54.5, pl. $\mathbf{L x}$, fig. 11, $a, b$, Deshayes, 1824.

- Deshayes, Lam., vol. II, p. 72, n² 10, pl. vili, fig. 16, 17, 1824.

- Ieshayes, Encycl. méth. vers., vol. II, p. 94, $\mathrm{n}^{\circ} 19,1830$.

Ringicula ringeus, Deslıajes, Lam., $2^{\mathrm{e}}$ édit., vol. VIIl, p. 541, $n^{\circ} 5,1858$.

- d'Orbigny, Prod., vol. III, p. 5k, $n^{0} 107,1852$.

- Deshayes,Trailé élémentaire conchyliologique, expl. des pl., p. 48, pl. Lxxvı, fig. 7, 8, 9, 1853.

- l'ictet, Triaté de Palćontologıe, vol. III, p. 100, pl. Lx, fig. $8,1855$. - Deshayes, An. s. vert. dı bassin de Paris, vol. II, p. 611, pl. vill, fig. $16,17,1862$.

Tesla ovalo-acuta. turgidula, transversim striata; aper 
tura marginibus calloso-marginatis; columella subtriplicata (Deshayes). - Long. 5 mill.; diam. 3 mill.

Loc. Eocène moyen. Grignon, Mouchy, Damery, Montmirail, Chaumont, Fontenay-Saint-P'ère, les Gaules, Vaudancourt, Chaussy, Chambord, Hermenonville, Boursault, Auvers, Valmondois, Sérons, le Fiayel, CheryChartreuve, Ver, le Guespelle, Beauval, Valognes, Hauteville? (Manche).

8. Ringicula Vasca, Tournouër. (PI. VI, fig. 4).

1R. Vasca, Tournoüer, surur quelques affleurements des - marnes nummuliliques de Bos-d'Arros, p. 9, $186 \%$.

- Tournouër, Congrès scientifique de France, $59^{\mathrm{e}}$ session, à Pau, p. 5, pl. vi, fig. 14$14 a, 1875$.

- Bouillé, Panléontologie de Biarritz et de quelques autres localités du bassin pyrénéen, p.40, pl. vı, fig. 14, $14 a, 1875$.

Diffère du R. ringens, par sa forme plus globuleuse, sa spire moins élancée, ses sillons beaucoup plus marqués et surtout par sa callosité columcllaire canaliculéc. (Tournouër), - Long. 4 mill.; diam. 5 mill.

Loc. Eocène moyen. P'eyrehorale (Basses-Pyrénées).

9. lingicula gracilis, Sandberger, Mlss. (I'l. VIII, (ii:. 4).

Testa parva, ovalo-elongata, tenuis, transversim et regulariter striala; spira elongala; anfractus 6 , fere planuluti, sutura simplici discreli; anfractus ultimus dimidium lesta paulo superans, busi rolundatus; aperlura 
angusta, marginibus callo tenui junctis; callo basin penultimi anfractus attingente; columella arcuata, plicis subagralibus instructa; labro fere rectilineo, medio incrassato et denliculis 5 munilo. - Long. 4 mill.; diam. 2,5 mill.

Coquille petite, ovale-allongée, mince, finement et régulièrement striée en travers; spire allongée, composée de 6 tours presque plans, séparés par une sulure simple, le dernier formant à lui seul un peu plus de la moitié de la coquille, arrondi à la base; onverlure étroite; borls réunis par un dépôt calleux, assez faible, s'arrêtant à la base de l'avant-dernier lour; bord columellaire légèrement arqué, garni de 5 plis presqu'égaux; labre presque droit, un pen épaissi au milieu et garni de $\mathbf{5}$ petils plis.

Loc. Miocène inféricur. Westeregeln.

Obs. Cette espèce se distingue des $\mathrm{R}$. ringens et Crossei, par sa taille plus petite, par sa forme plus allongée et par le petit nombre de plis qui ornent son labre.

10. Ringicula minotissima, Deshayes (pl. VI, fig. 7).

R. minutissina, Deshayes, An. s. vert. du bassin de Paris, vol. II, p. 612, pl. xl, fig. 10-12, 1862.

Testa minulissima, ovato-globosa; spira brevi, obtusiuscula; anfiractibus quinis, convexis, angustis, lente crescenlibus, sulura angustu, contabulata distinctis, transversim minutissime striatis, ultimo anfractu globuloso, spiram paulo superante, antice obluso; apertura angusta, labro crasso, in medio inflalo, levvigato, antice columellam paulo superante; columella triplicala, plica antica magna, lamellosa, prominenle (Deshayes). - Long. \& mill.; diam. $11 / 2$ mill. 
Loc. Niocène inférieur. Jeurres, Etrechy, Morigny, Versailles.

\section{Ringicula Semperi, Koch.}

R. Semperi, Koch, Neckl. Archiv. Ban!, XV, p. 202, 1866.

- Koenen, Das Mar. mill.-olig. Norddeutsch. Moll. Fauna, p. 71, 1867.

“'M. Koch m'a envoyé son unique exemplaire pour l'examiner et m'assurer s'il était compléterient adulte, attendu que les deux ailes d'expansion ne sont pas épaissies. Je considère comme très-possible, que nous ne possédlions qu'un jeune excmplaire de Ringicula acuta, Plil., attendu qu'il Ini ressemble beaucoup.» (Von Koenen.)

Loc. Oligocène moyen (Locène moyen), du Nord de l'Allemagne.

Obs. D'après les observations de Koenen, l'absence de diagnose et d'échantillons authentiques, nous proposons de placer cette espèce parmi les formes donteuses.

12. Ringicula stmata, Philippi. (PI. VIII, fig. 10).

R. striata, Philippi, Beiträge zur Kenntniss Jer Tertixrversteinerungen des Nordwestlichen Deutschlands, p. $28,61,76, \mathrm{pl}$. เv, fig. 23, 1843 .

- Beyrich, Die Conchylien des Norddentschen 'Tertixrgebirges, p. 5̋̈, pl. ı, fig. 19, $a$, $b, c, 1855$.

- Speyer, Dic Conchylien der Casseler Tertixrbil. rlungen, p. 17, pl. I, fig. 17, $a, b, c, d$, 1862. 
Coquille petite, ovale, légèrement ventrue, mince, finement et régulièrement striée en travers; spire assez longue, composée de 5 tonrs légèrement convexes, séparés par une sulure simple, le dernier tour formant, i lui seul, plus de la moitié de la coquille, un peu oblus à la base; bords réunis par un léger dépôt calleux; bord columellaire très-mince, à partir du pli supérieur, presque droit, garni de 5 plis, dont le supérieur est empâté darıs la callosité quni cesse tout-à-coup, ce qui lui donne la forme d'une protubérance, les deux autres plis ćpais et inclinés vers le sommet, surtont l'inférieur; labre presque droit, légèrement épaissi vers le milieu, rejoignant la coquille an milieu de l'avant-dernier tour, bord lisse a l'intérieur et pen saillant à l'extérieur. - Long. 5 1/2 mill.; diam. 2,2 mill.

Loc. Miocène inférieur. Kaufungen, Apollo-Berg, Fleden, Wilhemshöhe, Stemberg (Mecklembourg).

Obs. La diagnose de Philippi étant insuffisante, nous avons cru devoir en faire une nouvelle.

Outre sa forme générale, cette coquille présente un caractère distinctif bien marqué. Sa callosité s'arrête à la lhauteiur du pli supérieur.

Il y a une différence très-sensible dans la taille des échantillons de Kaufungen et de ceux de Stemberg : ces derniers sont plus petits.

\section{Ringicula subventricosa, d'Orbigny.}

R. ventricosa, Grateloup, Conch. foss. du bassin de l'Adour. Auricule, pl. I, n ${ }^{\circ} 11$, fig. 10, 1840.

R. subventricosa, d'Orbigny, Prod., vol. III, p. 6, $n^{\circ} 75$, 1852.

- $\quad$ - $\quad$ Pictet, Traité de Paléontologie, vol. III, p. 101, pl. Lx, fig. 10, 1853. 


\section{$-51-$}

R. sulventricosa, Speyer, Uber Tertiar Conchylien vou Westeregeln in Magdeburg, vol. IX, p. 110, 1862, 1864 .

Testa ovato-veniricosa, lucente, fragili, transverse substriata; columella biplicata (Grateloup).- Long. 7 mill,; diam. 4.

Loc. Miocène inférieur. Gaas.

14. Rivgicula Bocrgeoisi, L. Morlet (pl. Vili, fig. 5).

Testa ovato-clongata, crassa, subgibbosa, lavigata; anfractus 5 convexi, sutura simplici discreti, anfractus ultimus fere dimidium testa aquans, basi rotundalus; apertura angusta, marginibus callo junctis, margine columellari arcuato, incrassato, triplicalo; plica superna tenui, reliquis 2 crassis, parallelis; labro fere dextro, crasso pracipue ad medium, extus parum rellexo et medium unfractus penultimi attingente. - Long. 5,8 mill.; diam. 3,2 mill.

Coquille ovale-allongée, épaisse, légèrement gibbeuse, lisse; les tours, au nombre de ö, sont convexes et séparés par une suture simple, le dernier formant, à lui seul, près de la moitić de la coquille, arroudi à sa base; l'ouverture est étroite; les bords sont réunis par uII lépôt calleux, le bord columellaire est légèrement arqué, couvert d'une callosité épaisse, surtout à la partie inférieure, muni de 5 plis, le supérieur très-faible, les deux autres très-épais et parallèles entre eux; le labre est presque droit, trèsépais, principalement au milieu, légèrement renversé en dehors et se prolonge jusqu'au milieu de l'avant-dernier tour. 
Obs. Il existe deux variétés, l'une remarquable (pl. vili, fig. 5a) par sa spire très-pointue et ses tours très-globuleux et comme enclavés l'un dans l'autre; les 2 et 5 premiers tours sont finement striés; le dessous du dernier tour légèrement aplati._Long. 4, 9 mill.; diam. 2, 9 mill.

L'autre variété, qui est plus courte et plus globuleuse que la précédente, est complétement lisse, et les tours de spire sont légèrement canaliculés.

Loc. Miocène moyen. Pontlevoy, Paulmy et Ferrières l'Arçon, Manthelan et Mandillot.

15. Ringicula Bonellii, Deshayes (pl. VI, fig. 15).

Auricula punctilabris, Bonelli, Mus. zool. Torino, $n^{\circ} 567$, pl. v, fig. 12.

Pedipes punctilabrum, Michelotti, Rivista dei Gasteropodi, p. 6.

Ringicula Bonellii, Deshayes, Lam., $2^{\bullet}$ édit., vol. VIII, p. 544, $\mathrm{n}^{\circ}$ 546, 1858.

- - Michelotti, Desc. des foss. du tert. miocène de l'Italie septentrionale, p. 152, pl. v, fig. 11, 12, 1847.

- punctilabrum, Sismonda, Syn. méth., p. 52, 1847.

- Bonellii, Deshayes, Traité élémentaire Conch., expl.des pl., p. 48, pl. Lxxvir, fig.4, 6,1850 .

- - d'Orbigny, Prod., vol. III, p. 27, $n^{\circ} 546,1852$.

- - G. Cocconi, Enumerazione sistematica dei Molluschi Miocenici e Plioceniei delle provincie di Parmo e di Piacenza, p. 154, 1875. 
Testa ovato-abbreviata, turgiclula, eleganter striata, striis tenuibus, numerosissimis, angulis lateralibus imbricatis; columella triplicata; labro dextro incrassato, valde marginato (Bonelli). - Long. 10 mill.; diam. 8 mill.

Loc. Miocène moyen. Turin, Superga, Termo-Fourà, Baldiscero. - Minc. supérieur. Vence (Alpes-Maritimes, Tournouër). La variété se trouve à Peyrehorade, dans le Miocène moyen.

Obs. C'est la plus grande des espèces que nous connaissions : elle est ovale, globuleuse, à spire très-courte. Deux caractires la distinguent essentiellement : la surface extérieure est finement striée, et les stries sont en zig-zag très-fin et régulier; les deux bords de l'ouverture sont chagrinés d'une manière particulière par des points enfoncés, qui laissent en relief les petits intervalles qui les séparent (Bonelli).

Il existe une variété dont la bouche est un peu plus ouverte et le labre non granuleux (Collection Tournouër).

16. Ringicula costata, Eichwald (pl. VI, fig. 12.)

Marginella costata, Eichwald, Naturhist. Skizze, von Lithauen, Volhynien, u. s. w., p. 221, 1850.

- cancellata, Dubois, Conch. foss. du plat. Volhynien Podol. vol. I, p. 24, pl. I, fig. 17-18, 1851.

Ringicula costata, d’Orbigny, Prod., vol. IlI, p.57, n 5/45, 1852.

- - Eichwald, Lelhaea Rossica ou Paléontologie de la Russie, vol. III, p. 259, pl. $\mathbf{x}$, fig. 44, $a, b, c, 1855$.

- - Hörnes, Abhandl. Jer Kaiserl. König. geo- 
$\log$. Reichsanstalt, vol. I, p. 88, pl. 1x, fig. 5, $a, b, c, d, 1856$.

Ringicula costata, Pictet, Traité de Paléonlologie, vol. III, p. 101, 1855.

Testa minutissima, elongato-ovata, in ultimo anfractu ventricosa, costata, striis transversis ornata; columella triplicala, labro marginata, in medio inflata, non exarata (Eichwald). - Long. 2 mill.; diam. 1 1/2 mill.

Loc. Miocène moyen. Szuskowce (Volhynie). Bilka.

17. Ringicula elongata, L. Morlet (pl. VII, fig. 2).

Testa elongata, tenuis, regulariter striata; anfractus 51/2, parum convexi, sutura vix impressa discreti; anfractus ultimus dimidium teste superans, basi uttenuatus; apertura angusta; marginibus callo junctis; margine columellari parum arcuato, triplicalo; plica superna debili, valde obliqua; plicis infernis validis; labro vix arcuato, intus parum incrassato, ad basin angulato. - Long. 8 mill.; diam. 4 mill.

Coquille allongée, mince, régulièrement striée; les tours, au nombre de $51 / 2$, sont peu eonveres, séparés par une suture peı sensible, le dernier formant plus de la moitié de la coquille, atténué à sa base. L'ouverture est à peine dilatéc ; les bords sont réunis par un dépôt calleux; le bord columellaire est légèrement arqué, il est garni, à sa partie supérieure, d'un pli faible, très-oblique, et, à sa base, de deux plis très-forts; le bord droit est à peine cintré, muni d'un léger bourrelet en dedans, saillant en dehors, et forme presqu'un angle, à sa base, avec le bord columellaire. (Collection de l'Ecole des Mines.)

Loc. Miocène moỳen. Dax. - Miocène supérieur. Cacella près Lisbonne. 
Obs. Cette espèce ne pourrait se confondre qu'avec le R. Tournoueri, mais elle s'en distingue facilement, par sa longueur, par la forme desa bonche, qui est moins ouverte que dans le R. Tournoueri, et par sa callosité, qui est plus faible et moins étendue que dans cette dernière.

18. Ringicula levigata, Eichwald.

Marginella lævigata, Eichwald, Naturhist. Skizze, l.c., p. 121.

- eburnea, Lamarck, Pusch., 1 C.

Ringicula lævigata, Eichwald, Palaeontologica Rossica, vol. III, p. 259, pl. x, fig. 45, a, b, c, 1855.

Testa elongata, rufa. lavissima, ultimo anfraclu subventricosa, spiru maxime prominula (Eichwald). - Long. 4 mill.; diam. 3 mill. (ex icone).

Loc. Près de Zuskowce, de Zalisce, de Tarnaruda, de Kremenelz et à Korytnice, en Pologne.

Obs. M. Bronn a réuni cette coquille, mais à tort, je crois, avec le R. buccinea, comme petite variété. Sa forme est allongée, en forme de cône pointu, tandis que le R. buccinea est globuleux; ses tours sont un pen convexes et s'accroissent insensiblement, ils font une petite saillie en dessus du dernier tour; sa couleur est d'un brun roux uni, tandis que le $R$. buccinea est d'un brun clair. (Eichwald).

19. Ringicula Paulucciae, L. Morlet (pl. VI, fig. 6 , et $p l$. VIII, fig. 9).

Testa ovato-clongata, tenuis, regulariter et iransversim. striata, striis spiralibus 10-10̈ in ultimo anfractu, striis longitudinalibus sub lente conspicuis, decussatis; spira 
elongata; anfractus 6 convexi, regulariter crescentes, sutura simplici discreti; anfractus ultimus $2 / 3$ longitudinis aquuns, basiobtusus; apertura latiuscula, marginibus callo tenui junctis, margine columellari arcuato, triplicato, plica superna callo incrassato, brevi, plicis infernis crassis, horisontalibus, labro fere recto, brevi, crasso, superne arcuato, medium anfractus penultimi altingente, superne canaliculum formante, extus incrassatum. - Long. 4,8 mill.; diam. 3 mill.

Coquille ovale-allongée, mince, finement et régulièrement striée en travers, le nombre des stries variant de 10 à 15 sur le dernier tour; on remarque également, avec une forte loupe, de légères stries verlicales, coupant les côtes formées par les stries transversales; spire assez allongée, composée de 6 tours convexes, s'accroissant graduellement, séparés par une sulure simple; le dernier tour formant, à lui seul, les $2 / \overline{5}$ de la coquille, un peu obtus à la base; ouverture assez large, à borls réunis par un dépôt calleux généralement mince; bord columellaire arqué, garni de 5 plis, dont le supéricur, empâté dans la callosité et très-court, est incliné vers la base, les deux iaférieurs épais, horizontaux el légèrement tordus; labre presque droit, lisse, épais, formant une légère courbe à sa partie supérieure, ne dépassant pas le milieu de l'avant-dernier tour, formant, à cette jonction, une jetite gouttière, légèrement saillant en dehors.

Loc. Miocène moyer. Saucats, Dar.

Obs. Cette espèce se distingue du R. Tournoweri par sa taille, en général plus petite, ses tours de spire moins globuleux, sa caliosilé moins élendue et moins épaisse, ses plis columellaires plus épais, et son labre moins fort. 
20. Risgicula plicatula, Majer (pl. Vi, fig. 9).

Auriculina plicatula, Mayer, Journ. Conch., vol. XIX, p. 547, pl. 1x, fig. 8, 1871 .

Testa minutissima, ovato-elongata; spira elongata, acuta, anfractibus quinis, altiusculis, parum convexis, superne' angulatis, leviter contabulatis, longitudinaliter plicatulis, plicis tenuibus, approximatis, flexuosis, striis spiralibus temuissimis, inconspicuis, decussatis; ultimo anfractu spiru breviore, parum convexo, subquadrato; apertura oblonga, fere recta; columella tenui, incqualiter triplicata; labro leviter incrassuto (Mayer). - Long. 2 1/2 mill.; diam. 1 mill.

Loc. Miocène moyen. Saucats.

21. Ringicula ventricosa, Sowerby.

Auricula ventricosa, Sowerby, Min. Conch., vol. V. p. 99, pl. cccclxv, fig.1, 1825. Ringicula ventricosa, d'0rbigny, Prod., vol. III, p. 57. $\mathrm{n}^{\circ} 545,1852$.

- Searles Wood, Crag Mollusca,
vol. I, p. 22, fig. 1, $a, b$,
1847, et vol. XXV, p. 99,
1872.
- Speyer, Uber Tertiær-Conchylien,
von Westeregeln, in Magde-
burgischen, vol. IX, p. 110
(Dunker-llayer), 1862-1864.

Subovate inflated, transversely striated, spire short pointed, base notched; three sharp plaids upon the columella, left lip callous, a thick border upon the right lip (Sowerby). - Long. 6,8 mill.; diam. 5 mill. 
Loc. Miocène moyen. Sutton, Cor. Crag et Red Crag (Angleterre). Superga?

22. Ringicula acution, Mayer, ms. (pl. ViI, fig. 6).

Testa ovata, elongata, temis, nilida, eburnea, imperforata; anfractus 6, graciles, fere planulati, sutura parum impressa discreti; priores 4 striati; ultimus dimidium testce attingens, basi rotundatus; apertura angusta, marginibus callo junctis, columellari arcuato, tridentato, dente superno minuto, infernis 2 crassis, brevibus; margine dextro parum dilatato, crasso, superne canalem formante, et medium anfractus penultimi altingente. - Long., 5 mill.; diam., 3 mill.

Coquille ovale, allongée, mince, luisarte, éburnée, imperforée, lisse, excepté les 4 premiers tours, qui sont striés ; les tours, au nombre de 6 , sont élancés, presque plans, séparés par une suture peu marquée; le dernier, formant à lui seul la moitié de la coquille, est arrondi à sa base; l'ouverture est étroite, particulièrement à la partie supérieure; les bords sont réunis par un dépôt calleux, le bord columellaire est fortement arqué, et garni de "s dents, dont la supérieure, très-petite, est trèsrapprochée de la jonction du bord droit, avec le columellaire; les deux inférieures sont épaisses et courtes; ce bord se termine par une callosité trìs-épaisse, le bord droit est peu dilaté, très-épais sur toute son étendue, excepté à la partie supérieure, oì il forme, avec la coquille, un petit canal, et la callosité externe n'atteint qu'un peu l'avant-dernier tour (Collection du Blusée de Zurich).

Loc. Hiocène supérienr. Saint-Jean-de-Harsacq.

Obs. Cette espèce ne pourrait être confondue qu'avec le 
R. Bourgeoisi ; mais elle s'en distingue facilement par sa forme plus allongée, par sa spire plıs aiguë, par les plis du bord columellaire, plus faibles et sa callosité moins forte; ainsi que par le brillant de sa surface qui est plus clair.

\section{Ringicula Berthaud, Michaud (pl. VIJ, fig. 4).}

R. Berthaudi, Nichaud, Deser. Coq. foss. Hauterive, $5^{\circ}$ parlie, p. 16, pl. III, fig. 11, 1877.

Testa ovato-ventricosa, eleganter striata; spira acuta, canaliculata; columella triplicata, plicis irregularibus, inferne bis sinuata; labro exlus murginato; apertura ovata, superne angustiore (Michaud). - Long. 5-6 mill.; diam. 4 mill.

Loc. Miocène supéricur. Tersane (Drôme).

24. Ringicola Fiscueri, L. Morlet (pl. VII, fig. 5).

Testa elongata, tenuis, minute striata; anfractus 6 convexi, sutura notata discreti; unfractus ultimus 5/8 longitudinis aquans; apertura lata; marginibus callo tenui junctis; margine columellari triplicato; plica superna tenuiore; labro fere rectiusculo, superne curvato et subdivergente, intus incrassuto, extus prominente. - Long. 4,8 mill.; diam. 3 mill.

Coquille allongée, mince, striée finement; les tours, au nombre de 6 , sont convexes et séparés par une snture très-sensible, le dernier tour formant les $5 / 8$ de la coquille; l'ouverture est large, les bords sont réunis par un dépôt calleux assez mince; le bord columellaire est muni de trois plis, le supérieur très-faible el les inférieurs assez forts; le labre presque droit, s'éloignant vers le haut et 
formant, dans la partie supérieure, une courbe venant rejoindre la coquille, muni d'un bourrelet en dedans et saillant au dehors (Collection de l'École des Mines).

Loc. Hiocène supérieur. Korod (Transylvanie).

Obs. Cette espèce se distingue du R. Africana par sa forme plus globuleuse, par ses plis columellaires plus minces et plus droits, par sa callosité plus faible et par son labre moins épais.

25. Ringicula gigantula, Doderlein (pl. VII, fig. 7).

R. gigantula, Doderlein, ms., in C. Mayer, Desc. des coq. foss. des terraius tert. sup., in Journ. Conchyl., vol. XVII, page 85, pl. III, fig. 7, 1869.

Testa ovato-globosa, crassa et solida, lavi; spira brevi, conica; anfractibus quinis, convexis, angustis, velociter increscentibus, ultimo anfractu permagno, globoso, spiram fere ter superante; apertura postice canaliculata, antice dilutata; labro crassissimo, dilatato, foliaceo, anfractu penultimo adnato; columella triplicata; plica postica distante, tenui, media majore, untica obligua. (Mayer). Long. 14 1/2 mill.; diam. 10 mill.

Loc. Miocène supérieur. Sassuolo, Stazzano. (Collection de l'École des Mines; Musées de Turin et de Zurich.)

26. Ringicula Sandbergeri, L. Morlet (pl. VI, fig. 8).

R. acuta, Sandberger, Die Conchylien des Mainzer Terliærbeckens, p. 262, pl. xiv, fig. 11, $11 a$, 11, 1863. 
R. acuta, Speyer, Ueber Tertiær Conchylien von Westeregeln in Magdeburgischen, vol. II, p. 17 18-288, 1862-1864.

Testa ovato-ventricosa, spiru brevi, acuta, apice obtusula, mamillata; anfractus 5 , initiales 1 1/2 laves, cateri modice convexi, suturis linearibus disjuncti, cingulis longitudinalibus permultis (24), iniquis ornati; ultimus cateris omnibus paulo altior, inflatus. Apertura haud valde obliqua, labro dextro modico, media parte plica obtusa. nodiformi exornata; columella plicis duabus, latioribus, obliquis armata (Sandberger). - Long. 3 1/2 mill.; diam. 2 mill.

Loc. Miocène inférieur. Gaas, Weinheim, près Alzei, et Giemberg, près Waldbockelheim.

Miocène moyen. St-Paul-les-Dax, Mandillot, Léognan.

Miocène supérieur. Saubrigues.

Obs. Il existe déjà un R. acuta, décrit en 1849 par Philippi pour une coquille vivante de la mer Rouge et élabli. M. Sandberger ayant ultérieurement donné le même nom à une coquille fossile, nous sommes obligés de changer l'appellation de l'espèce fossile, que nous proposons de nommer R. Sanibergeri.

\section{Rivgicula Baylei, L. Morlet (pl. VI, fig. 11).}

Testa ovata, crassa, globulosa, regulariter striata; anfractus $61 / 2-7$, convexi, sutura simplici discreti; anfractus ultimus 3/4 longitudinis attingens, basi obtusus, superne incisus; aperturu lala, marginibus callo crasso junctis, callo penultimum anfractum superante, et canalem siphonnlem incrassante; maryine columelluri superne dilatato, triplicato, plica superna obliqua, fere marginata; media et inferna tenuibus; labro medio crasso, extus pro- 
minente et superne canalem ascendentem formante. Long. 8 mill.; diam. 5 mill.

Coquille ovale, épaisse, globuleuse, régulièrement striée; les tours, au nombre de 61,2 à 7 , sont conrexes, séparés par une suture simple quoique très-prononcée, le dernier tour, formant les $5 / 4$ de la coquille, est obtus à sa base et porte une entaille très-prononcéc, à la réunion des bords; l'ouverture est assez large, les bords sont réunis par un dépôt calleux très-fort, qui, d'une part, remonte au-delà de l'avant-dernier tour et, d'autre part, empâte le canal du siphon; le bord columellaire est dilaté dans la partie supérieure, garni de 5 plis, le supérieur oblique et presque marginé, les deux inférieurs très-dégagés et minces; le bord droit est très-épais, principalement au milieu, très-saillant audehors, formant à la partie supérieure un canal ascendant. (Collection de l'Ecole des Mines et la mienne.)

Loc. Miocène moyen. Dax, Saucats.

Miocène supérieur. Saubrigues, St-Jean-de-Marsacq.

Ots. Cette espèce se distingue du R. Grateloupi par sa forme plus aliongée, sa spire plus aiguë, ses strius plus espacées, sa bouche moins ouverte et les plis inférieurs de sa columelle plus épais et plus longs.

28. Ringicula Cacellensis, I. MorJet (pl. VII. fig. 9).

Testa ovata, crassa, globulosa, inferne parum planulata; spira brevis, acuta; anfractus 7 convexiusculi, sutura simplici discreti, priores \& spiraliter sulcati, reliqui laves, ultimus $3 / 4$ longitudinis attingens, basi subcanaliculatus; apertura constricta, marginibus callo junctis, callo amplo, crasso, ultrapenultimum anfractum superante; margine columellari arcuato, triplicato, plica superna valde 
crassa, media et inferna tenuibus: labro crassissimo, extus late marginato. - Long. 10,5 mill.; diam. 8 mill.

Coquille ovale, épaisse, globuleuse, légèrement aplatie en dessous, lisse, excepté les la premiers tours qui sont sillonnés; spire courte et aiguë, composée de 7 lours légèrement couveses, séparés par une suture simple, le dernier formant les $5 / 4$ de la coquille, subéchancré à la base; l'ouverture est resserrée; les bords sont réunis par un dépôt calleux très-étendı, épais et brillant, qui remonte aı delà de l'avant-dernier tour; le bord columellaire est fortement arqué, garni de $\tilde{5}$ plis dont le supérieur est trèsépais, les deux autres allongés et minces; le bord droit très-épais et garni d'un bourrelet très-saillant extérieurement.

Loc. Miocène moyen. Dax.

Miocène supérieur. Caceila, près Lisbonne.

Obs. Celte espèce se distingne du R. Baylei par sa grosseur, par sa forme qui est moins allongée ainsi que sa spire, par l'absence de stries sur les derniers tours et surtout par sa callosité qui couvre une très-grande partie du dernier tour, tandis que, sur le $\mathbb{R}$. Baylei, elle ne couvre qu'ì peine le dessous du dernier tour.

29. Rivgicula Crossei, I. Morlet (pl. VII, fig. 11).

Testa ovata, tenuis, transversim temuiter et eleganter strata; spira acula; anfractus 6 convexiusculi, sensim crescentes, sutura distincta discreti; anfractus ullimus subglobosus, basi rolundalus, $3 / 3$ longitudinis altingens; apertura obliqua, marginibus callo crasso junctis; margine columellari triplicato, superne paulo dilalato, plicis tenuibus; labrum dilalalum, inferne paulo depressum, in $4 / 3$ 
longitudinis crenulatum, intus plicatum, extus marginatum. - Long. 4 1/2 mill.; diam. $23 / 4$ mill.

Coquille ovale, mince, finement et élégamment striée ; spire aiguë, composée de 6 tours un peu convexes, s'accroissant graduellement, séparés par une suture bien distincte, le dernier tour formant les $\mathbf{3} / 5$ de la roquille: ouverture oblique; les bords sont réunis par un dépôt calleux assez fort; le bord columellaire, garni de 3 plis, est un peu dilaté à la partie supérieure, les plis sont trèsminces, le bord droit est dilaté, aplati légèrement en dessous, garni sur les 4/: de la longueur d'une crénelure très-fine, qui s'enfonce dans l'intérieur de la coquille, muni d'un léger bourrelet extérieurement.

Loc. Miocène moyen. Dax, Manthelan, Léognan.

Miocène supérieur. Saubrigues, Tortone, Vienne.

Obs. Cette espèce, qui se rapproche beaucoup du R. ringens, s'en distingue facilement par ses tours de spire plus globuleux, son ouverture qui est moins dilatée, par la crénelure du bord droit qui est plus étendue, plus fine, et par la coquille qui estmoins allongée, proportionnellement. Elle se distingue également du R. gracilis par sa taille plus forte, par sa forme moins allongée, et par la crénelure interne plus étendue et plus fine qui orne son labre.

50. Ringicula Ponteleviensis, L. Morlet (pl. VIII, fig. 8).

Testa brevis, crassa, leevigata; anfractus 3 1/2 convexiusculi, sutura simplici discreti; ultimus 4 lo longitudinis cequans, basi rotundatus; apertura angusta, marginibus callo valido, dorsum anfractus ultimi partim tegente junctis; margine columellari triplicato, plica superna obsoleta, immersa, plica media horizontali, crassa, plica inferna obliqua, valida; labro fere rectilineo, crasso, 
extus late reflexo, anfractum penultimum partim tegente. - Long. s̈ mill.; diam. 4 mill.

Coquille courte, épaisse, lisse; les tours, au nombre de $31 / 2$, sont peu conveses, séparés par une suture simple, le dernier formant à lui seul les $4 / 5$ de la coquille, arrondi à sa base; l'ouverture est très-resserrée; les bords sont réunis par un dépôt calleux très-fort, couvrant une grande partic de la base du dernier lour; le bord columellaire est garni de $\check{\jmath}$ plis, le supérieur est peu visible, étant presque couvert par la callosité, les deux autres trèsépais, le premier perpendiculaire à l'axe et l'inférieur obliquant vers le sommet; le labre est presque aroit, trèsépais, réfléchi en dehors et couvrant presque tout l'avant. dernier tour.

Obs. Cette espèce se rapproche lu $\mathrm{R}$. buccinea, mais elle est plus courte, moins globuleuse, la callosité n'est pas si élendue sur le dos du dernier tour et la position des dents n'est pas la mème. La partie supérieure de la callosité pourrait la faire confondre avec le R. marginata. Néanmoins, elle est plus faible, et ne cache pas le pli supérieur; la coquille est beancoup plus petite et ses tours de spire sont moins nombrenx et plus étroits.

Loc. Hiocine moyen. Tours, Pontlevey, Paulnay et Ferrières l'Arçon, Manthelan.

Miocène supérieur. Saubrigues.

51. Ringicula auriculata, Ménard.

Marginella auriculata, Ilénard, Ann. du Mus., vol. XVII, p. $351-552,1811$.

- Dubois, Conch. foss. du plat. Vol-
hynien P'odol, p. 24. pl. I, fig.

$15-16,1851$.


Marginella auriculata, Bronn, Italiens Tertiærgebilde, 1851 .

- $\quad$ - Philippi, Enumeratio Molluscorum Sicilix, vol. I, p. 251, 1851 ; vol. II, p. 197, 1856.

Ringicula - Philippi, Enum. Moll. Siciliæ, vol. II, p. 189, pl. xxvin, fig. 13, 1844 .

- $\quad$ - Beyrich, Dic Conch. des Norddeutschen Tertiærgebirges, $p$. 58, pl. 11, fig. 15, a, b, $c$, 1855 .

Speyer, Die Conch. des Casseler Tertiærbildungen, p. 18, pl. I, fig. 18, $a, b, c, 1862$.

$-\quad$ Weber Tertixer Conch.von
Westeregeln in Magdeburgi-
schen, 1862-1864.

- $\quad$ - Weinkauff, Die Conch. Mittel-
meeres, vol. II, p. 45, 1868.

- $\quad$ - Monterosato, Journ. Conch., vol. XXV, p. 44, 1877.

- - - Cat. delle Conch. fossili di Nonte Pellegrino e Ficarazzi, presso Palermo, p. 13, 1877.

Issel, Crociera del Violante, comandato dal capitano armatore Enrico, p. 10, 1878.

Testa minuta, ovata, inflata, alba, lcevigata, spira brevi, acuta, basi marginata, columella triplicata, plicis 
acutis, labio expanso, adnato, lcibro marginato, calloso (Ménard). - Long. 7 mili.; diam. $31 / 2$ mill.

Loc. Niocène moyen. Saucats, Superga.

Miocène supérieur. Sassuolo, Keilwangen, Eibergen (Hollande).

Pliocène inférieur. Anvers, Gênes, Viale près Asti,

Montafia, Massera, Villalvernia, Morée.

Pliocène supéricur. Monte Mario, Monte Pellegrino, Palerme, Rhodes.

Vit encore daus l'Océan et la Méditerranée.

52. Ringicula Brocchir, Seguenza, ms. (pl. VIII, fig. 2).

Testa ovatu, globulosa, tenuis, minute, regulariter et spiraliter striata; spira brevis; anfractus 5 1/2-6 convexi, reguluriter crescentes, sutura simplici discreti; anfractus ultimus 2/3 longitudinis aquans, basi rotundalus; apertura lala, marginibus callo junctis, cullo penultimum anfractum partim tegente; margine columellari arcuato, superne callo valido incrassato, triplicato, plica superna parva, plicis infernis obliquis, tenuibus; labro regulariter arcuato, crassiusculo, inferne subrotundato et canalem brevem simulante. - Long. 4,8 mill.; diam. 3,2 mill.

Coquille ovale, globuleuse, mince, fincment et régulièrement striéc; spire courte, composéc de $51 / 2$ à 6 tours convexes; s'accroissant régulièrement, séparés par une suture simple, le dernier formant les $2 / 5$ de la coquille, arrondi à la base; ouverture large; les bords sont réunis par un lépôt calleux assez fort, couvrant une partie de l'avant-dernier tour; le bord columellaire, fortement arqué, couvert dans la partie supérieure d’une callosité très. forte, garni de trois plis, dont le supérienr est très-faible, 
les deux inférieurs minces et obliques ; le bord droit régulièrement arqué, assez épais, presqu'arrondi à la partie supérieure, où il forme avec la coquille un petit canal.

Loc. Miocène moyen. Léognan, Saucats.

Miocène supérieur. Saubrigues.

Pliocène inférienr. Gênes, Altavilla, Rinolgo près

Sienne, Castellarquato, Masserano.

Obs. Cette espèce a beancoup le rapport avec le $\mathrm{R}$. Gaudryana, mais elle s'en distingue facilement par sa taille plus petite, ses tours de spire plus arrondis, sa suture simple, et son bord droit qui ne forme jamais, à la partie supérieure, un angle, comme dans le R. Gaudryana.

53. Ringicula buccinea, Brocchi (Pl. VIII, fig. 6). Voluta buccinea, Brocchi, Conch. foss. sub., vol. II, p. 95 , pl. Iv, fig. 9,1814 ; et vol. II, $2^{\mathrm{me}}$ édit., p. 519 , pl. Iv, fig. 9, 1845.

- pisum, Brocchi, Conch. foss. sub., p. 642, pl. xv, fig. 10, 1314.

Auricula buccinea, Sowerby, Min. Conch., vol. V, p.100, pl. cccclxv, fig. 2, 1825.

- - Deshayes, Expéd. scient. de Morée, vol. II, p. 170, 1855.

Marginella auriculata, Philippi, Enum. Moll. Siciliæ, vol. I, p. 251, 1831 ; vol. II, p. 198, pl. xxvil, fig. 151, $18 \overline{6} 6$.

Ringicula buccinea, Deshayes, Hist. nat. des an. s. vert. (Lam.), $2^{\text {me }}$ édit., vol. VIII, p. 244, 1858.

- - Searles Wood, Monog. of the Crag Mollusca, vol. I, p. 22 , pl. 1, 
fig. 2, $a, 4,1847$; vol. XXVili, p. 96,187 .

Ringicula buccinea, Deshayes, Traité élémentaire de Conch., expl. des pl., p. 48, pl. Lxxvir, fig. 10, 11, 12, 1855.

- _ Hörnes, Abhandlungen des Kaiserlich-Koniglichen Geologischen Reichsanstalt, vol. I, p. 86, pl. ix, fig. $5, a, b ; 4, a, b, c, d$, 1856.

- (Voluta) buccinea, Seguenza, Sulla formazione miocenica de Sicilia, p. 11, 1862.

- buccinea, Foresti, Cat. dei Moll. foss. Pliocenici delle colline Bolognesi, $1^{\text {re }}$ partie, p. 48, 1868.

- $\quad$ - Foresti, var. cincta, Foresti, I. c.

- $\quad$ - Issel, Appunti Paleontologici, p. 22, 1877.

Testa minuta, subovata, inflata, lavigata; spira brevi, acuta; columella triplicata, plicis acutis, labio expanso, adnato; labro marginato, in medio inflato, non exarato (Brocchi). - Long. 8,8 mill.; diam. 6,2 mill.

Loc. Miocène moyen. Mandillot, Bacedasco.

Miocène supérieur. Kilwangen, Sassuolo, Soo, Vöslau.

Pliocène inférieur. Antibes, Albenga, Gènes, Castelnuovo d'Asti, Altavilla.

Vit encore dans l'Océan et la Méditerranće.

Obs. L'échantillon que nous représentons étant plus adulte que celui figuré par Brocchi, on remarquera 
que le lahre est plus épais et la callosité plus forte. Nous avons cru devoir faire figurer l'espèce fossile, quoique l'ayant déjà fait pour l'espèce vivante, les échantillons fossiles étant généralement plus forts que ceux à l'état vivant.

M. Foresti, dans son Cat. Iei Moll. fossili Pliocenici, p. 48, crée une variété du R. buccinea qu'il nomme var. cincta : elle se distingue du type par des traces de côtes longitudinales que l'on aperçoit sur la partie dorsaie du dernier tour.

Loc. Niocène moyen. Bacedasco.

Miocène supérieur. Sassuolo.

54. Ringicula conformis, Monterosato.

R. auriculata, var. conformis, Monterosato, Nuova rivista delle conchiglie Mediterranee, p. 45, 1875.

- conformis, Monterosato, Journ. de Conchyliologie, vol. XXV, p. 44, pl. xı, fig. 4, 1877.
- - _ Cat. delle Conch. foss. di Monte Pellegrino et Ficarazzi, presso Palermo, p. 15, 1877.

La forme et la disposition des dents sont différentes de celle du R. auriculata ; l'ouverture est plus grimaçante ct, en outre, le test n'est pas strié superficiellement. Dans quelques localités, cette espèce présente, sur les premiers tours, une apparence de plis verticaux (Monterosato). long. 4 mill. ; diam. 3, 4 mill.

Loc. Mlocène moyen. Superga.

Pliocène inféricur. Borzoli, Zinola près Savone, Villalverma, Masserano, Viale près Montafia.

Pliocène supérieur. Honle Pellegrino, Ficarazzi, Rhodes. 
Vit encore dans la Méditerranće et I'Atlantique.

Obs. Cette forme, considérée d'abord comme une sim. ple variété de l'auriculata, a été élevée récemment au rang d'espèce par l'auteur.

5๊. Ringicula elegans, Pecchioli (PI. VII, fig. 8).

R. elegans, Pecchioli, Atti della Società ltal. di Scienze naturali, vol. VI, p. 508, pl. v, fig. $52.5 i$, 1864.

- _ Pecchioli, Desc. di alcuni nuovi fossili delle argille subappennine Toscane, p. 11, $n^{\circ} 6$, pl. v, fig. 52.54, 1864.

- - Foresti, Catalogo dei Mlolluschi fossili Pliocenici, p. 48, 1868.

Testa minuta, solida, ovata; spira brevi, acuta, exilıssime transversim striata, costellis raris, minutis, filiformibus longitudinaliter exornata ; labro incrassato, calloso, expanso, adnato; columella subquadriplicata (Pecchioli). - Long. 7 mill.; diam. 5 mill.

Loc. Miocène supérieur. Buccheri.

Pliocène inférieur. Cortandone près Asti, Sienne. Pliocène supérieur? Girgenti.

56. Ringicula exilis, Eichwald (Pl. VII, fig. 5).

Voluta exilis, Eichwald, Zoologia specialis potiss. Rossiæ et Poloniæ, vol. I. p. 298, pl. v, fig. $1 \%$, 1829.

Marginella exilis, Eichwald, Naturhist. Skizze von Lithauen, Vollynien, u. s. w., vol. I, p. 221, 1850 .

- auriculata, Dubois, Conch. foss. dı plat. Vo- 
Ihynien Porlol, rol. III, p. 24,

pl. I, fig. 15-16, 1851 .

Ringicula exilis, d'Orbigny, Prod., vol. III, p. $57, n^{\circ} 541$, 1852.

- - Pictet, Trailé de Paléontologie, vol. III, p. $102,1855$.

- buccinea, Eichwald, Lethaea Rossica (Palćontnlogie de la Russie), vol. III, p. 258 , 1855.

- (Voluta) exilis, Seguenza, Sulla formazione miocenia de Sicilia, p. 11, 1862.

Testa exigua, ventricosa, gibboso-ovata, transversim tenuissime striata, vertice acutissimo; apertura longiore; margine reflexo, incrassata, basi cmarginata, columellari margine triplicata. Var. B. cxilis, tenuissimis anfractibus, acutissimis, ultimo subito incrassato (Eichwald). - Long. 6 mill.; diam. 4,2 mill.

Loc. Miocène supérieur. Salles, Tortone, Stazzano, Sassuolo, Buïtur (B. de Vienne), Baden, Vöslau, Gainfaren.

Pliocène inférieur. Antibes, Castelnuovo d'Asti, Castell'A rquato.

Pliocène supérieur? Girgenti.

Obs. Quoique M. Eichwald identifie son exilis avec le II. buccinea, nous ne crojons pas devoir supprimer cette espèce, car les échantillons que nous avous examinés sont fortement striés, la spire assez allongée, le labre presque aroit, tandis que le R. buccinea est lisse, globuleux, à spire très-courte, à labre complétement arrondi et à callosité beancoup plus forte. 
57. Rivgicula Gaudrana, L. Morlet (PI. VII, fig. 12).

Testa ovata, piriformis, ventricosa, tenuis, tenuiter, regulariter et spiraliter sulcata; spira brevis; anfractus 6 , rapide crescentes, sutura fere canaliculata discreti; ultimus $5 / 8$ teste formans, basi obtusus, superne convexus, dilatutus et interdum subangulatus; apertura ampla, marginibus tenui callo junctis, margine columellari arcualo, triplicato, plica superna obsoleta, labro obliquo, extus marginato et incrassato, - Long. 8 mill.; diam. 6 mill.

Coquille ovale, piriforme, ventrue, mince, finement et régulièrement strice en travers; spire courte, composée de 6 tours convexes, s'accroissant rapidement, séparés par une sulure presque canaliculée, le dernier tour formant les $\check{5} / 8$ de la coquille, un peu obtuse à la base; la partie supérieure des tours est très-convexe, principalement celle du lernier, ce qui lui donne l'aspect d'une carène; ouverture large; les bords sont réunis par un mince dépôt calleux; le bord columellaire légèrement arqué, garni de jo plis dont le supérieur est très-faible, et les autres assez allongés, minces et torlus; le bord droit, oblique par rapport à l'axe de la coquille, est mince, formant, à la partie supérieure, un angle assez prononcé, extérieurement bordé et épaissi.

Loc. Miocène moyen. Léognan, Superga, Bacelasco.

Miocène supérieur. Saubrigues, Stazzano.

Pliocène inférieur. Biot, Antibes, Savone, Castell'

Arquato, Masserano, Castelnuovo d'Asti, Viale,

Borzoli, Sienne, environs de Bologne, Altavilla.

Obs. Celte espèce se distingue de ses congénères, non-seulement par sa forme globuleuse en général, mais 
surtout par sa dent supérieure, qui est presque nulle, et par la forme de son labre, qui est oblique et non arqué. Elle diffère du R. striata par sa grosseur, sa forme plus globuleuse, son ouverture dilatée en haut et sa spire beaucoup plus courte.

58. Ringicula Gratelodpi, d'Orbigny (PI. VIII, fig. 1).

Auricula ringens, Grateloup, Cat. zool. des An . du bassin de la Gironde, $n^{\circ} 65$, var. $A, n^{\circ} 85$, 1858.

Auriculina - var. major, Grateloup, Conch. foss. du bassin de l'Adour. Plicacés, $n^{\circ} 1$, pl. vi, fig. 6-7, 1840.

Ringicula Grateloupi, d'Orbigny, Prod., vol. III, p. 6, $n^{\circ} 76,1852$.

- $\quad$ - $\quad$ Pictet, Traité de Paléontologie, vol. III, p. 101, pl. Lx, fig. 9, 1855.

Testa majore, turgida; spira brevi; columella triplicata; labro marginato. - Long. 7,2 mill.; diam. 5,3 mill.

Loc. Miocène moyen. Léognan, Saucats, Superga, Baldissero.

Miocène supérieur. Salles, Saubrigues, St-Jean-deMarsacq, Sassuolo, Stazzano, Büitur, Baden. Pliocène inférieur. Perpignan.

59. Ringicdla intermedia, Foresli (PI. VIII, fig. $\overline{3}$ ). R. buccinea, Brochi, var. intermedia, Foresti, Catalogo dei Molluschịi fossili Pliocenici delle Colline Bolognese, $1^{\text {re }}$ partie, p. 48, pl. II, fig. 7, 8, 9, 1868.

- - Seguenza, Catalogo geologico d'Italia, vol.VI, p. 152,1875 . 
« Cette variété a été nommée par moi intermedia pour a indiquer qu'elle forme le passage entre la buccinca, Des" hayes, et l'elegans, Pecchioli. Les exemplaires de celte « variété ont la mème forme que les deux espèces précé"dentes; clle n'en diffère pas par les dimensions, par la " forme des tours et de la bordure, et par le nombre des a plis columellaires, mais on y irouve bien visibles les pe" tites côtes filiformes longitudinales qui ornent la R. ele" gans, sans présenter aucune strie transversale dans les " interstices, lesquelles sont lisses et luisantes, comme on "l'observe chez la R. buccinea. (Foresti.) "

Loc. Miocène moyen. Mandillot.

Hiocène supérieur. Saubrigues, Torlonc, Stazzano

Pliocène inférieur. Albenga Lugagnano, Sienne, Cortandona.

En raison des caractères constants qui distinguent la variété intermedia, et afin d'éviter toute confusion, nous proposons de l'élever an rang d’espèce.

40. Ringicula leptocheila, Brugnone.

R. Ieptocheila, Brugnone, Miscellanea malacologica, première parlie, p. 11, pl. I, fig. 18, 1875 . Seguenza, Comitato geologico d'llalia, vol. VI, p. 152, 1875 .

Monterosato, Cat. delle Conch. foss. di Monte Pellegrino e Ficarazzi presso Palermo, 1877.

Testa ovato-acuminata, ventricosa, tenui, nitidula, subtilissime transversim striato-punctata; spira parum exerta; anfractibus 5 , convexis ; apertura magna, subangulala, columella contorta, plicata; plicis 1-2acutis; labro tonui- 
ter marginato; intus lavi; labio exilissimo, adnato (Brugnone). - Long. 5 mill.; diam. \& mill.

Loc. Niocène moyen. Superga.

Pliocène supérieur. Ficarazzi, près Palerme.

Obs. Celte espèce se trouve vivante dans la Médilerranée et l'Océan Atlantique. M. Jeffreys la consirlère comme identique avec le $R$. ventricosa, Sowerby.

41. Ringicola marginata, Deshayes (Pl. VIII, fig. 7). Auricula marginata, Deshayes, Encycl. méth. Ver's, vol. II, p. $95, n^{\circ} 22,1850$.

Ringicula marginata, Deshayes, An. s. vert. (Lamk.), vol. VIII, p. 54.5, $n^{\circ} 4,1858$.

- - Sismonda, Syn. meth., p. 52. 1847.

- - D'Orbigny, Prod., vol. III, p. 168,
$n^{\circ} 72,1852$.

- $\quad$ - Pictet, Traité de Paléontologie, vol. III, p. 101, 1855.

Testa ovata, ventricosa, lavigata; spira acuta; sutura subcanaliculata; labro sinistro latissimo; columella triplicata, callo repando postice instructa, labro dextro sub callo marginato, in medio valde incrassato (Deshayes).-Long. 8 mill.; diam. 5 mill.

Loc. Miocène moyen. Superga.

Miocène supérieur. Salles, Saubrigues, Wurenlos près Zurich.

Pliocène inférieur. Perpignan, Savone, Cortan. dona près Asti, Val-d'Andole, Villalvernia.

42. Ringicula quadriplicata, L. Morlet. (PI. VII, fig. 1).

Testa ovata, ventricosa, crassa, longitudinaliler et sub- 
tiliter striata, spiraliter costulata; anfractus 6 convexi, sutura profunda discreti; an/ractus ultimns $2 / 3$ longitudinis attingens, rotundatus; apertura angusta, marginibus callo ascendente et anfractum perultimum superante junctis; margine columellari superne dila tato et biplica to, inferne plicis majoribus 2 munito; labro crasso procipue ad medium, et canalem ascendentem superne formante.Long. 12 mill. ; diam. 8 mill.

Coquille ovale, ventrue, épaisse, finement striće en long, côtelée en travers. Les tours, au nombre de $\mathbf{6}$, sont convexes et séparés par une suture profonde, le dernier, formant les $2 / 5$ de la coquille, est arrondi; l'ouverture est resserrée; les borda sont réunis par un dépòt calleux qui remonte au delà de l'avant-dernier tour; le bord columellaire est dilaté dans la partie supérieure, et garni de deux plis dont l'inférieur est marginé, la base de la columelle est garnie de deux autres plis plus forts; le bord Uroit très-épais, surtout au milieu, forme, à la partic supéricure, un petit canal ascendant.

Loc. Miocène moyen. Cabanes, Turin, Bacedasco.

Miocène supérieur. Angers, Saubrigues, St-Jeande-Marsacq, Sassuolo, Stazzano, Baden.

Pliocène inférieur. Biot, Antibes, Castelnuovod'Asti, Castell'Arquato, Albenga, Coroniana, Vallon Tenero, Valle de Fine, Falbiano, Zinola près Savone, Sienne, Morée.

45. Ringicura Tournoueri, L. Morlet. (PI. VI, fig. 10).

Testa tenuis, regulariter striata; anfructus 6 convexiusculi, sutura conspicua discreti; anfructus ultimus $3 / 3$ longitudinis attingens, basi rotundatus; spira elongata, sensim crescens; apertura angusta; marginibus callo crasso 
junctis; margine columellari arcuato, triplicato, plica superno parum distincta, plicis infernis validis et obliquis; labro fere arcuato, crassissimo pracipue ad medium, extus prominente. - Long. 5 mill.; diam. 3 mill.

Coquille mince, régulièrement striée : les tours, au nombre de 6 , sont un peu convexes et séparés par une suture assez sensible, le dernier formant les $5 / 5$ de la coquille et arrondi à la base; spire allongée, augmentant graduellement; ouverture rétrécie, à bords réunis par un dépôt calleux très-fort; le bord columellaire arqué, garni de 5 plis, le supérieur peu distinct et les inférieurs trèssaillants et obliques; labre presque droit, très-épais, surtout au milieu, et saillant en dehors.

Loc. Miocène moyen. Léognan, Manthelan, Mandillot, Saucats, Saint-Paul-les-Dax, Superga, Termo-Fourà, Kilwange.

Miocène supérieur. Saubrigues, Sassuolo.

Pliocène inférieur. Castelnuovo d'Asti, Anvers (Crag).

Obs. Cette espèce se distingue du R. elongata par sa taille plus courte, sa spire plus allongée en proportion, ses stries moins profondes et ses tours de spire moins enflés, sa callosité du bord columellaire plus forte et son bord droit plus détaché.

\section{Ringicula biplicata, Lea.}

Marginella biplicata, Lea, Contributions to Geology, p. 20I, pl. vi, fig. 216. 1855 .

Ringicula - Conrad, Check Lists of the Invertebrate fossils of North America, p. 9 $54, N^{\circ} 265.1866$.

Shell pyramidal, transversely striate, emarginated at 
base, substance of the shell thick; spire elevated, pointed, whorls four rounded, columella with two large folds, mouth small; outer lip very thick and minutely crenulated within (Isaac Lea).-Long. 3 mill.; diam. 21/2 mill. (ex icone).

Loc. Eocène moyen. Alabama.

45. Ringicula varia, Gabb.

Ring. varia, Gabb, Geological Survey of California (Palæontologie) vol. I, p. 112, pl. xxix, fig. 222, a, b, 1864, et vol. II, p. 251, 1869.

Shell small, elongate-ovoid, spire high; whorls six slightly convex; suture well-marked; body whorl broadly and regularly convex. Aperture wide, acute behind, narrowed in front, and with a deep, oblique notch. Outer lip nearly simple, the margine being not twice as thick as the shell behind it, and very narrow; inner lip covered with a small, circumscribed callus, bearing two small acute folds anteriorly. Surface variable, sometimes almost perfectly smooth and polished, at other times ornamented by sharp, impressed lines; and in still other specimens hoving square ribs of variable width, with the lines of growth strongly developed in the interspaces, and represented on the surfuce of the ribs by shallow undulations. (Gabb). Long. 12 mill.; diam. 7 mill. (ex icone).

Coquille petite, allongée, ovoïde ; spirc haute ; six tours légèrement convexes, suture marquée; le dernier tour largement et régulièrement convere. Ouverture large, acuminćc en arrière, étroite en avant et avec une échancrure profonde et oblique. La lèvre externe presque simple, le bord, n'ayant guère que deux fois l'épaisseur de la coquille, est très-étroit; la lèvre interne couverte d'une callosité 
petite, circonserite, portant 2 petits plis acuminés en avant. Surface variable, quelquefois parfaitement lisse et polie, d'autres fois, ornée de lignes nettement marquées ; dans d'autres spécimens, on observe des côtes carrées d'une largeur variable, avec les lignes d'accroissement fortement développées dans les intervalles et représentées, à la surface des côtes, par de légères ondulations.

Loc. Eocène moyen. Cow Creek, Shasta County, east of Shasta City.

46. Ringicula ?

Ring. ? d'A rchiac, Desc. des an. foss. de l'Inde, p. 285,

pl. xxvi, fig. 8, 1846.

- $\quad$ - Bulletin de la Société Géol. de France, $2^{\text {me }}$ série, vol. 11I, p. $5 \overline{5} 2, \mathbf{7 5} 8$, 1846.

Loc. Eocène moyen? Calc. jaune du Scinde.

Obs. M. d'Archiac cite, dans son ouvrage, une Ringicule dont il ne donne ni le nom ni la diagnose, mais seulement une figure de la coquille, vue de dos. Ne pouvant la dénommer, j'indique simplement la localité, afin d'attirer l'attention des géologues sur cette espèce.

47. linglcula semistriata, d'Orbigny.

Ring. semistriatu, d'Orbigny, Hist. de l'île de Cuba, par Ramon de la Sagra. Mollusques, Al. d'Orbigny, vol. II, p. 105, pl. $\mathrm{xxI}, 17-19,1855$.

- $\quad$ Gabb, Topography and Geology of Santo Domingo, p. 225, $187 \bar{~}$.

- tridentata, Guppy, Gcological Magazine, West Indian Tertiary fossils, vol, I, p. 406,1874 . 
Testa ovate conic, moderately thick, smooth, shining; spire conic. Whorls about 4. Aperture suboval: columella thickened and bearing two strong spiral plaits, the callus continued buckward, and carrying a stont tooth on the bodywhorl, the lutter separated by a deep notch, on canal from the thickened and somewhat everted outer lip. (Guppy). - Long. 2 mill.; diam. 1 mill.

Loc. Miocène moyen. Haïti.

Obs. Le R. tridentata, Guppy, doit être rapporté au R. semistriata, d’Orbigny. M. Guppy lui-même le fait remarquer, d'après la conclusion de M. Gabb, qui a pu vérifier les deux deux espèces.

Cette espece se trouve à la Jamaïque, à l'élat vivant.

48. Ringicula Africana, L. Morlel (Pl. Vit, fig. 10).

Testa ovato-elongata, lavis, crassa; spira acuta; anfractus $61 / 2$ convexiusculi, sutura canaliculata discreti; uitimus globulosus, basi rotundatus, 2/3 longitudinis attingens; apcrtura rotundata, marginibus callo tenui junctis, murgine columellari arcuato, triplicato, plica superna callo immersa, inferna contorta; labrum arcuatum, medio dilatatum, superne vix canaliculatum, extus valde crassum. - Long. 6 1/2 mill., diam. 4,6 mill.

Coquille ovale-allongée, lisse, épaisse, spire aiguë, composée de $61 / 2$ tours un pen converes, séparés par une suture canaliculée, le dernier globulenx, arrondi à sa base, formant les $2 / 3$ de la coquille : ouverture arrondie ; les borls sont réunis par une légère callosité; le bord columellaire est arqué, garni de 5 plis, dont le supérieur est sensiblement empâté dans la callosilé, el l’inférieur est tordu; le bord droit est légìrement arqué, un peu dilaté au milieu, formant une légère gouttière au sommet, à sa 
jonction, un peu au-dessous de la suture de l'avant-dernier tour : ce bord est très-épais à l'extérieur.

Loc. Pliocène inférieur. Douerah (Algérie).

\section{DISTRIBUTION GÉOLOGIQUE}

DES RINGIGULES EUROPÉENNES.

ESPÈCES APPARTENANT AUX TERRAINS CRÉTACÉS :

1. R. Deshayesi, Guéranger.

2. R. Verneuili, d'Archiac.

Obs. Ce n'est qu'avec doute que nous maintenons ces deux espèces dans le G. Ringicula, n'ayant pu les vérifier.

ESPÈCES APPARTENANT EN PROPRE:

A. A l'Eocène inférieur.

1. R. minor, Deshayes.

B. A l'Eocène moyen et supérieur (Oligocène inférieur).

1. R. Bezançoni, L. Morlet.

2. R. coarctata, Koënen.

5. R. nana, L. Hiorlet.

4. R. ringens, Deshayes.

ร. R. Vasca, Tournouër.

Pas d'espèces communes à l'Eocène et au Miocène.

ESPĖGES APPARTENANT EN PROPRE:

A. Au Miocène inférieur (Oligocène moyen).

1. R. gracilis, Sandberger. 
2. R. minutissima, Deshayes.

3. R. Semperi, Koch.

4. R. striata, Philippi.

5. R. subventricosi, d'Orbigny.

B. Au Miocène moyen.

1. R. Bourgeoisi, L. Morlet.

2. R. costata, Eichwald.

5. R. elongata, L. Morlet.

4. R. lævigata, Eiclıwald.

5. R. Pauluccix, L. Morlet.

6. R. plicatula, Nayer.

7. R. ventricosa, Sowerby.

C. Au Miocène supérieur.

1. R. aculior, Mayer.

2. I. Berthaudi, Michaud.

5. R. Fischeri, L. Norlet.

4. R. gigantula, Doderlein.

ESPÈCE COMMUNE AUX TROIS ÉTAGES DU MOCÈNE:

1. R. Sandbergeri, L. Morlet.

ESPĖCES COMMUNES AU MOCÈNE MOYEN ET AU MOCÈNE SUPÉRIEUR :

1. R. Baylei. I. Norlet.

2. R. Cacellensis, L. Morlet.

5. R. Crossei, L. Morlet.

4. R. Ponteleviensis, L. Morlet.

5. R. buccinea, Brocchi, var. cincta, Foresti.

6. R. Bonellii, Deshayes. 
ESPÈCES COMMUNES AU MIOCÈNE ET AU PLIOCÈNE:

1. R. auriculata, Ménard.

2. R. Brocchii, Seguenza.

5. R. buccinea, Brocchi.

4. R. conformis, Mlonterosato.

5. R. elegans, Pecchioli.

6. R. exilis, Eichwald.

7. R. Gaudryana, L. Morlet.

8. R. Gratcloupi, d'Orbigny.

9. R. intermedia, Foresti.

10. h. Jeptocheila, Brugnone.

11. R. marginata, Deshayes.

12. R. quadriplicata, L. Morlet.

15. R. Tournoueri, L. Morlet.

En résumé, il y a 45 espèces de Ringicules fossiles européennes, actuellement connues.

Sur ces 45 espèces, 2 appartiennent aux terrains crétacés ; 6 appartiennent à l'Locène; 22, plus la var. cincta, appirtiennent au Miocène; 13 appartiennent au Miocène et au Pliocène.

Quatre espèces, qui datent du Miocène, se trouvent encore, à l'état vivant, dans les mers européennes:

R. auriculata, Ménard, Océan, Méditerranée.

R. buccinea, Brocchi.

R. conformis, Monterosato, Méditerranée, Atlantique.

R. Ieptocheila, Brugnone.

En dehors de l'Europe, nous ne trouvons que cinq espèces de Ringicules fossiles, signalées par les auteurs.

2, dans le terrain Eocène de l'Alabama: le R. biplicata, l.ea, et, en Californie, le R. varia, Gabb. 
1, dans le terrain nummulitique du Scinde, sans nom spécifique (d'A rchiac).

1, dans le terrain pliocène l'Mlgérie, le R. Africana. L. MIorlet.

1, dans le terrain miocène d'Haïli, R. semistriata, d'Orbigny, qui vit encore dans la mer des Intilles.

\section{espèces a SUPPRiMer dU geNRE Rixgicula.}

Parmi tontes les espèces rapportées à tort au genre Ringicula, nous trouvons les suivantes, que l'on doit éliminer:

R. incrassata, Geinitz, qui est un Avellana.

R. pyramidalis, Desor, qui est un Auricula.

li. simulata, Philippi, qui est un Ácteon.

R. Iurgida, d'Orbigny, qui est un Ringinella.

Avant de terminer, nous prions tous les naturalistes qui ont bien voulu nous prêter leur concours et nous communiquer les matériaux qu'ils avaient à leur disposition, de vouloir bien agréer nos remercîments les plus sincères.

$$
\text { I. M. }
$$


EXTRAIT DES NUMÉnos D'AVRIL ET DE JUILlET 1878 du

\section{DOURNAT DE CONCHYYLOLOGIE,}

PUBLIÉ PAR H. CROSSE,

RUE TRONCHET, 25,

PARIS. 


Journal de Conchyloologie. 1878

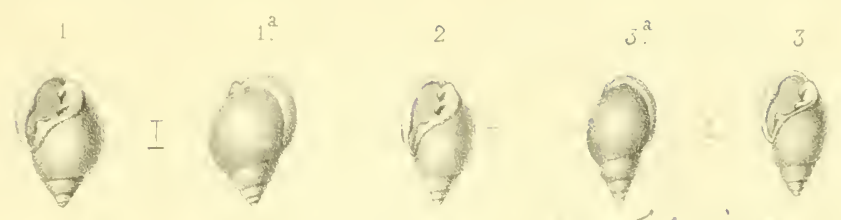

suignii.m yoismatica Toliner WI.

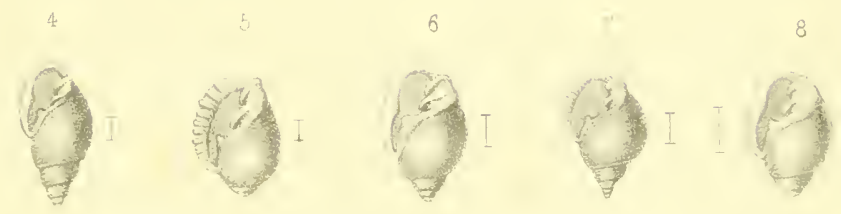

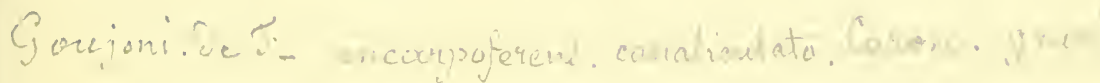

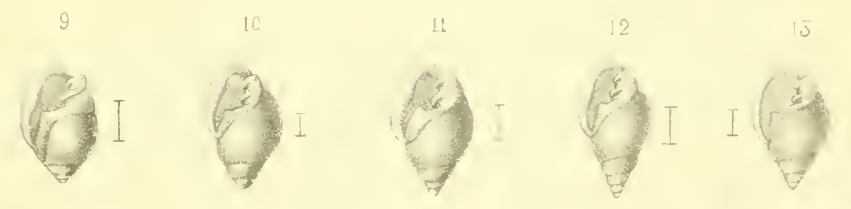

arclal $x$

$$
\begin{aligned}
& \text { fosbur ta. } \\
& \text { Mey is }
\end{aligned}
$$$$
\text { destrabis Somere. }
$$
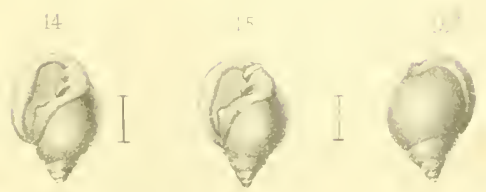

16

araculatio. 

ournal de Conchyliologie. 18\%

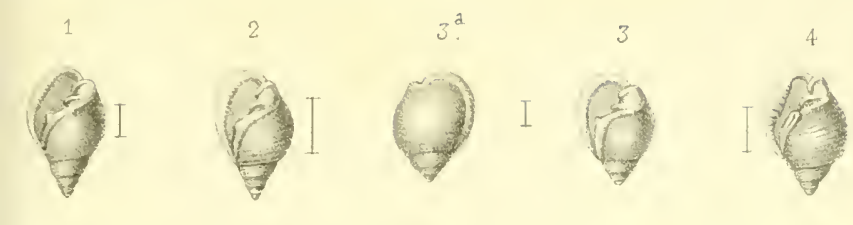
misicer
U.esh 3. 3.
2.3
ingens. 2 am,$C) 2$.

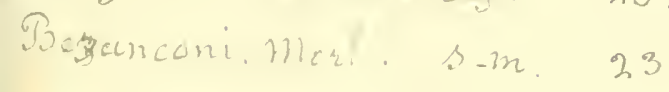

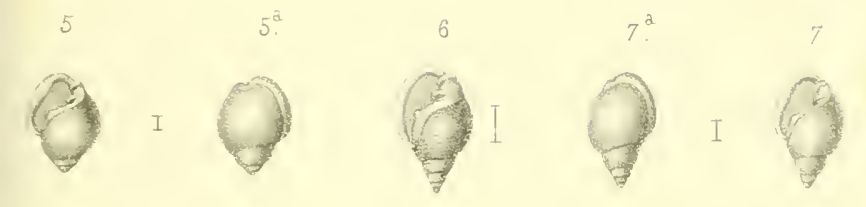
vasca

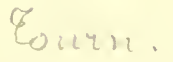
Eoc malu
24.
coc moy 25.
natra. Mnouk.
joakligioe hion.
mioc moy 35.
8
$8^{a}$
8
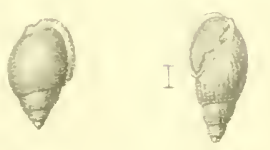
minutisisice
$\because$ ish
sandoergere
moadet
Mazer

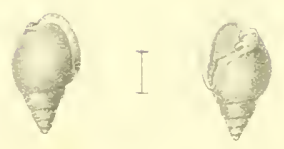
joicatila.

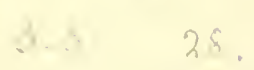
ilice. 40.
mioe moy 34 .

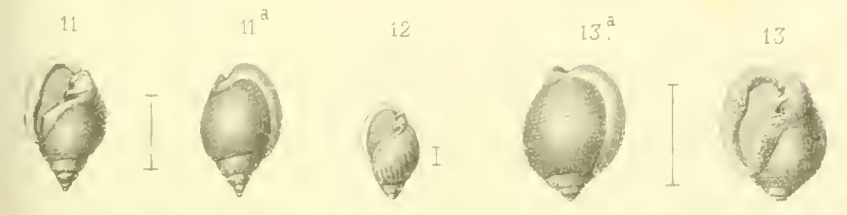

sil dat

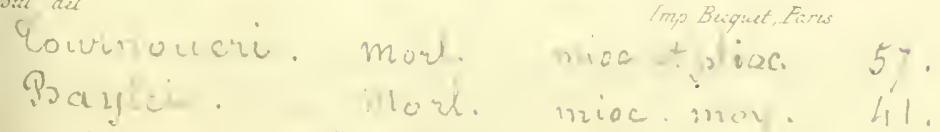

costata.

do cicharalo. inzioc inery. 41 . mioc macyen. 33. 



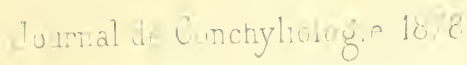

1

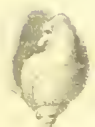

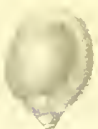
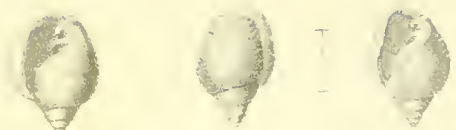

! Pr. quacriplicata

elongata.

Sischeri.

$3^{2}$
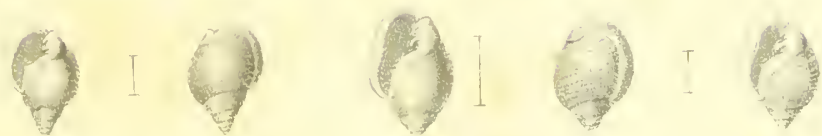

Soertrarde

e.xili

$(x \cdots e+0)$

michauis.

mioc 44.30 .

Eichuies

mive etplice \&

mayer

mioc. selp

38

11

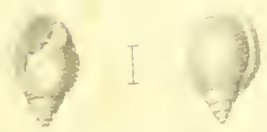

$-$

yigantix..e

¿ elegarus

a cozeliensis.
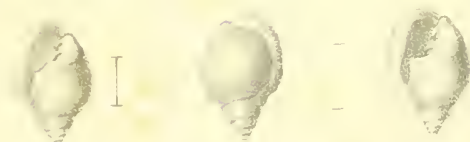

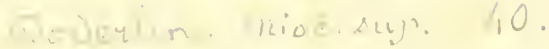

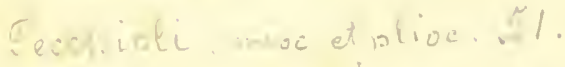
too $0=4$. wive iny. 41

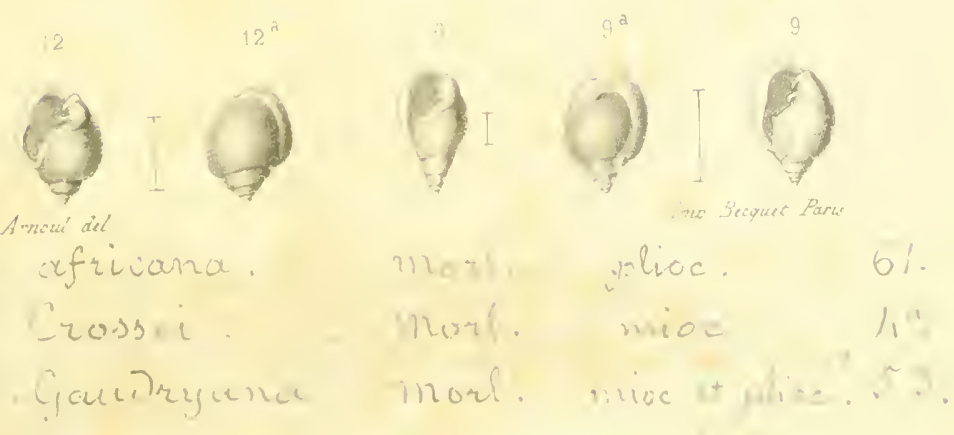



Journal de Conchyliologie. 1878.

PI. VIII

3

$3^{2}$

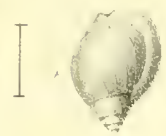

$2^{2}$

2

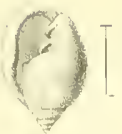

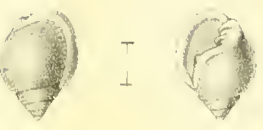

1. Pr cirateloujir. dorb. miocetplios.54.

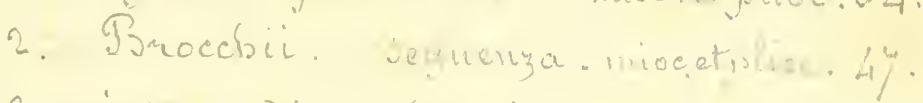

3. intermedia. Toresti. mior etplis. 54.

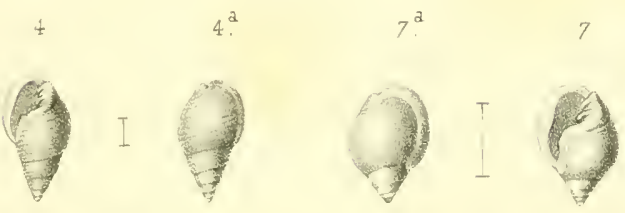

4. grexcills. Sance mioc inf. $2_{i}^{2}$

5. Sourgeoisi. Mot. mioc ing. 31.

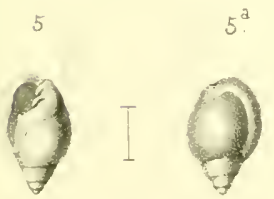

$5^{b}$

$8^{2}$

8

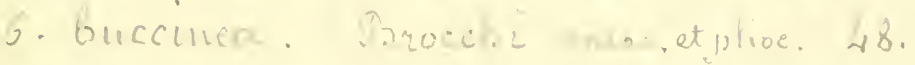

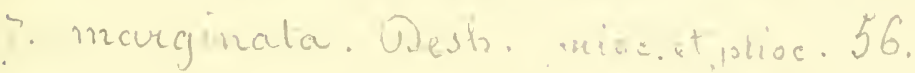

8. Pontefriconsis. Mrorl. mioc. 44

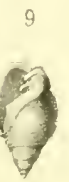

Ainoul del
$9^{2}$

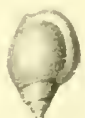

6

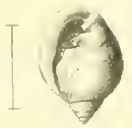

10

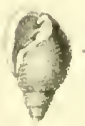

Irno Becquet. Par's

D. Tauluccioe mork. mioc. mill.

10. itriater. Thilijsoi.

mos $=$ in.

ag. 




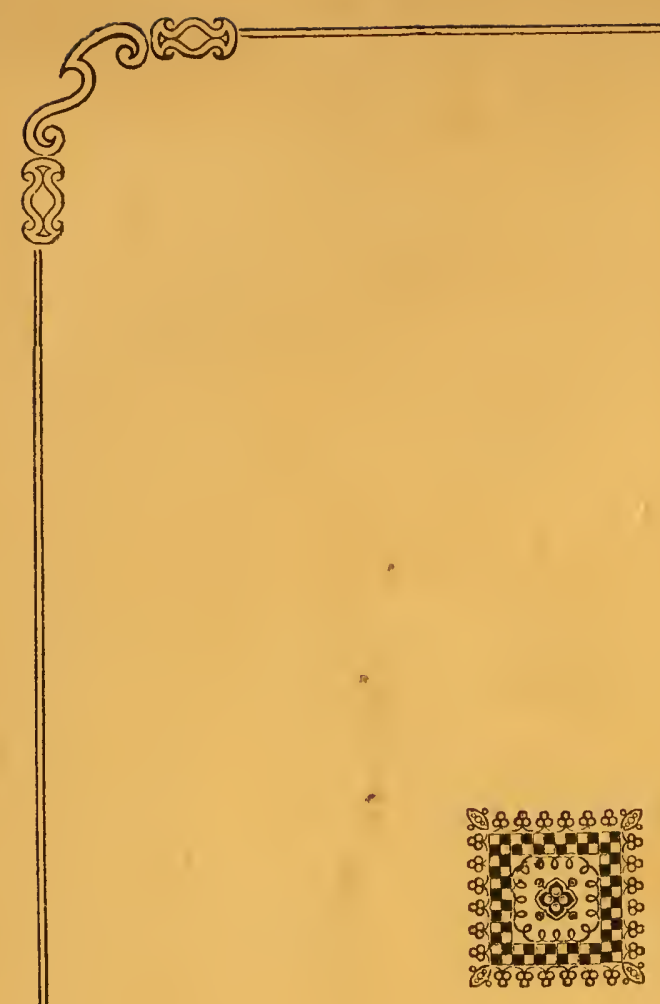

PARIS. - IMPRIMERIE DE M $^{\text {m }} \mathrm{V}^{\mathrm{e}}$ ROVCHARD-HUZARD, RUE DE L'ÍPERON, 5 ; J. TREMBLAY, gendre et successeur, 


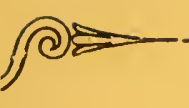

\section{SUPPLÉMENT}

A LA

\section{MONOGRAPIIIE DU GENRE RINGICULA,}

DESHAYES,

PAR

LE COMMANDANT L. MORLET.

\section{PARIS \\ CIIEZ L'AUTEUR,}

RUE DE VincenNes, 84, A montreuld-SOds-bois (SEine),

A PARIS, CIIEZ F. SAVY, LIBRAIRE, BOULEVARD SAINT-GERMaIN, 77. 
AIRIE deS SCIENCES

ERALES. H. BeCUS

rue M. le Prince

's surles sciences

te el achat de

otheques, etc

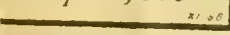




\section{SUPPLÉMENT}

A LA

\section{HONOGRAPIIE DU GENRE RINGICLLA,}

DESHAYES,

PAR

LE COMMANDANT L. MORLET.

En 1878, j'ai publié, dans le Journal de Conchyliologie (1), la Monographie du genre Ringicula, Deshayes. Depuis cette époque, j'ai pu me procurer de nouveaux matériaux, qui me permettent, aujourd'hui, de faire connaitre des espèces inédites, de figurer celles que je ne possédais pas alors, ou qui ne m'avaient pas été communiquées; enfin, d'indiquer des habitats non encore signa-" lés pour les espèces vivantes, ainsi que de nouvelles localités, pour les espèces fossiles (2).

\section{A. Espèces vivantes.}

5. Ringicula prismatica, de Folin.

Hab. Mers de Chine; Kua-Kué, Ouagap, côte est de

(1) Journal de Conchyliologie, vol. XXVI, p. 113 et 25I, 1878.

(2) Les numéros d'ordre se rapportent i ceux de la Monographie ou viennent à la suite. 
Nouméa, à 12 mètres de profondeur : sable grossier (Morlet); Bornéo, Nossibé (de Folin).

4. Ringicula Folini, L. Morlet.

Hab. Baie de Suez, mer Rouge (Iorlet).

5. Ringicula Goujoni, de Folin.

Hab. Bornéo (de Folin); très-répandue sur les côtes de la Nouvelle-Calédonie, de 7 à 12 brasses de profondeur (Morlet).

6. Ringicula canaliculata, de Folin.

IIab. Singapore (Morlet).

22. Ringicula auricolata, Mlénard.

Hab. Cap Férat, Méditerranée (Jeffreys).

25. Ringicula conformis, Monterosato.

Hab. Cadix, Espagne (de Folin).

24. Ringicula leptocieila, Brugnone.

Hab. Baie de Biscaye, Océan Atlantique, de 220 à 1,093 brasses de profondeur : Voyage du Porcupine, en 1870 , de Falmouth à Gibraltar (Jeffreys).

26. Rivgicula Mariei, L. Morlet.

Testa minutissima, ventricosa, elongata, sublicvigata, ad basin striis spiralibus 4-5 ornata; anfractus 4 1/2 convexi, sutura impressa discreti; anfractus ultimus dimidium teste paulo superans, basi subangulatus; spira elevata; apertura angusta, marginibus callo crasso junctis ; margine columellari arcuato. plicis 3 aqualibus, aqui- 
distantibus et convergentibus ornato; labro fere rectilineo crasso, tuberculo medio dentiformi et plica inferna basali, munito. - Long. 1 1/2 mill.; diam. 1 mill.

Var. minor. Long. 1 mill., diam 0,7 mill.

Coquille très-petite, ventrue, allongée, presque lisse, ornée seulement de 4 à כ̆ stries spirales, à la base du dernier tour; les tours, au nombre de $4 \mathbf{1} / \mathbf{2}$, sont convexes et séparés par une suture profonde, le dernier formant, à lui seul, un peu plus de la moitié de la longueur totale de la coquille, un peu anguleux à la base; spire élevée, augmentant graduellement; ouverture étroite : les bords sont rćunis par un dépôt calleux très-épais; bord columellaire très-arqué, garni de 5 plis à peu près semblables, á ćgale distance et convergeant l'un vers l'autre, le labre presque droit, épais, garni, an milieu, d'une protubérance dentiforme, d'un petit pli, entre cette dent et l'échancrure de la base, el saillant en dehors.

Hab. Nossibé (de Folin).

Obs. Cette espèce, qui est une des plus pelites que nous connaissions, ne peut être confondue, par son oruementation, qu'avec le $\boldsymbol{R}$. prisinatica de Folin, mais elle en diffère par sa laille plus faible, sa forme moins ventrue, par son deuxième pli sur le labre, et sa suture non sillonnée; elle se dislingue du R. Goujoni, de Folin, par son ornementation, sa suture plus profonde et son deuxième pli plus accentné.

\section{Ringicula Salleana, L. Morlet.}

Testa parva, brevis, ventricosa, crassa, nitens, striis spiralibus profundis, regularibus ornata; anfractus 6 convexi, sutura lineari discreti; ultimus $4 / 5$ longitudinis wquans, basi rotundatus; spira brevissima; apertura an- 


\section{$-4-$}

gusta, marginibus callo crasso junctis, margine dextro superne canalem formante; margine columellari arcuato, quadriplicato; plicis supernis 2 crassis, brevibus, ad basin oblique vergentibus; plicis infernis 2 transversis, labro arcuato, intus crasso, procipue ad basin; superne angustiore, extus varicoso et $3 / 4$ anfractus penultimi tegente.Long. 5,2 mill., diam. 4,5 mill.

Coquille petite, courte, ventrue, épaisse et luisante, ornée de stries spirales, profondes et régulières; les tours, au nombre de 6 , sont conveses et séparés par une suture simple, le dernier formant a lui seul les 4/5 de la Inngueur totale de la coquille, arrondi à la base; spire très-courte, augmentant rapidement; ouverture étroite; les bords sont réunis par un dépôt calleux très-épais, formant un bourrelet, dans la partie supérieure, et formant un canal à sa joaction avec le bord droit; bord columellaire fortement arqué, garni de 4 plis, les 2 supérieurs épais' et courts, et incliné obliquement vers la base, les 2 inférieurs transverses et formant une goultière à l'extrémité; le labre légèrement cintré, très-épais, surtout dans la partie inférieure, s'amincit tout à coup et va rejoindre le bord columellaire avec lequel il se prolonge jusqu'au $5 / 4$ de l'avant-dernier tour, très-saillant en dehors.
Hab.
Nossi-Bé
(de Folin).

Obs. Cette espèce est caractérisée par sa forme trèsglobuleuse el courte, par les 4 plis qui ornent le bord columellaire et par l'épaisseur de la callosité columellaire, bordée par un sillon distinct.

28. Ringicula Caledonica, L. Morlet (pl. v, fig. 1).

Testa minutissima, conica, tenuicula, nitens, spiraliter striata; anfrachus 5 convexiusculi, subgradati, sutura li- 
neari discreti; anfractus ultimus dimidium tester requans, basi rotundatus; spira elongata; apertura angusta; marginibus callo crasso junctis; margine columellari arcuato, triplicato, plicis validis, superna obliqua, media horizontali, inferna contorta, labro fere recto, crasso, medio prominente, subdentato, extus incrassato. - Long. 2 mill., diam. I mill.

Coquille très-petite, conique, assez mince, légèrement striée en travers; les tours, au nombre de š, sont convexes, subétagés, séparés par une suture simple, le dernier formant à lui seul la moitié de la longueur totale de la coquille, arrondi à la base; spire allongée, augmentant graduellement; ouverture élroite, les bords sont réunis par un dépôt épais; bord calleux columellaire arqué, garni de 5 plis très-forts, le supérieur incliné vers la base, celuj du milieu horizontal et l'inférieur légèrement relevé et tordu, le labre presque droit, épais, surtout au milieu, où il existe une protubérance dentiforme très-forte, saillant à l'extérieur el descendant plus bas que le bord columellaire.

Hab. Nouvelle-Calédonie; plage de la baie Pouen, sur le sable grossier, à 12 mìtres de profondeur.

Obs. Celte espèce a beaucoup de rapport avec le $\mathbf{R}$. prismatica, de Folin; mais elle s'en dislingue par sa surface brillante et couverte de stries spirales, tandis que celte dernière espèce n'est siriée que sur la moitié de sa surface, et par son ouverture plus étroite. Elle se rapproche également du R. Goujoni, le Folin ; elle en diffère par son test brillant, ses stries moins serrées et l'absence du deuxième pli sur le labre. 
29. Ringicula Noumeensis, L. Morlet (PI. V, fig. 3 ).

Testa parva, ovato-elonguta, striis remotis ornata: anfractus 5 convexi, sutura lineari discreti; ultimus $2 / 3$ longitudinis cequans, basi rotundatus; apertura lata, marginibus callo crassiusculo, parum expanso junctis; columellari arcuato, triplicato; plica superna crassa, brevi; intermedia horizontali; inferne ascendente, labro regulariler urcuato, superne tenui, medio incrassato, prominente, subdentato, extus parum reflexo, callo basali crasso, extus reflexo. - Long: 3 1/2 mill., diam. 2 mill.

Hab. Nouméa, Nouvelle-Calédonie.

Coquille petite, ovale allongée, ornée de stries trèsespacées; ces tours, au nombre de cinq, sont convexes, séparés par une suture simple, mais bien distincle, le dernier formant, à lui seul, près des deux tiers de la longueur totale de la coquille, arrondi à la base; l'ouverture est large; les bords sont réunis par un dépôt calleux assez épais, mais neu étendu, qui s'arrête à la base de l'avant-dernier tour; le bord columellaire est arqué, garni de trois plis, dlont le supérieur très-épais et court, le deuxième, horizontal, et, l'inférieur, remontant vers le sommet, tous deux épais et tordus; le labre régulièrement cintré, mince dans la partie supérieure, et assez épais, à partir du milieu où il y a une légère proéminence dentiforme, peu saillant à l'extérieur, la base de la colımelle est couverte d'une callosité très-forte et saillante extérieurement.

Une petite variété de cetle espèce se trouve sur les plages de Gouenen et de Pouen (Nouvelle-Calédonie).

50. Ringicula OEhlertie, L. Morlet (PI. V, fig. 4). Testa parva, tenuis, globosa, regulariter et temue striu- 
ta; anfractus 4 1/2-5 convexi, sutura subcanuliculatu discreti; spira brevis, acuta, subgradata; apertura lata; marginibus callo junctis; callo medium penultimi anfractus attingente; margine columellari urcuato, triplicato, p'ica superna brevi, verticali et cum callo angulum rectum formante; plicis infernis tenuibus, ascendentibus, contortis; columella basi granoso-rugata; labro parum arcuato, medio subprominente, superne canaliculato, extus incrassato. - Long. 4.2 mill., diam. 3,6 mill.

Hab. Mers de Chine (Morlet); mers du Japon, de 50 à $\breve{4}$ brasses (Saint-John).

Coquille petite, mince, globuleuse, régulièrement et finement strice; les lours, au nombre de quatre et demi à cinq, sont très-convexes, séparés par une suture subcanaliculée; spire courte, aiguë et subélagée; ouverture large; bords réunis par un dépôt calleux assez fort, s’arrêlant au milieu de l'avant-dernier tour; bord columellaire fortement arqué, garni de trois plis, le supérieur court et formant avec la callosité une arête à angle droit se prolongeant vers le sommet; cette arête forme une goutlière profonde et arrondie jusqu'à sa jonction avec le bord droit, les deux autres plis sont minces, tordus et inclinés vers le sommet: entre ces deux plis on remarque une granulation très-forte, qui se prolonge jusqu’à la base de la columelle, et la callosité est, pour ainsi dire, côtelée un peu au-dessus; labre peu cintré, ayant une légère prolubérance dentiforme au milien, échancré dans sa parlie supérieure en forme de canal, saillant à l'extérieur et descendant au-dessous du bord colımellaire.

Obs. Cette espèce se rapproche beancoup du R. canalieulata, de Folin ; elle en diffère : par ses plis plus minces 
et tordus, son labre plus mince, ainsi uue son test, sa callosité moins forte et moins étendue.

51. Ringicula Passieri, L. Morlet (Pl. V, fig. 5).

Testa subventricosa, crassa, subelongata, regulariter striata (striis transversis, impressis, distantibus); anfractus 7-71/2, convexi, sutura lineari, marginata discreti, anfractus ultimus $2 / 3$ longitudinis cequans, basi rotundatus; spira elongata, sensim crescens; apertura superne angusta, inferne dilatata; marginibus callo junctis; columella arcuata, triplicata; plica superna verticali, plica inferna sinuosa; labro crasso, extus prominente, intus parum sinuoso, infra rolundato, supra anfractum penultimum partim tegente et canalem formante. - Long. $51 / 2$ mill., diam. $31 / 2$ mill.

Hab. Fosse du Cap Breton (de Folin).

Coquille légèrement ventrue, épaisse, un peu allongée, régulièrement striée en travers par des sillons très-prononcés et assez espacés; tours au nombre de sept à sept et demi, convexes, séparés par une suture bordée; le dernier, formant à lui seul les deux tiers de la coquille, est fortement arrondi à la base; spire allongée, augmentant graduellement; ouverture étroite dans la partie supérieure et large à l'inférieure ; bord droit réuni par un léger dépôt calleux ; columellaire fortement arqué, garni de trois plis minces, le supérieur droit, dirigé verticalement vers la base et garni à sa naissance d'un très-petit pli, l'inférieur fortement sinueux et formant un siphon très-prononcé au-dessus de la réunion du bord droit; le labre est épais, saillant en dehors, légèrement sinueux en dedans, il est très-arrondi à la base, presque droit jusqu'à sa jonction 
avec l'avant-dernier tour qu'il recouvre en partie et où it forme un léger canal.

Obs. Cetle coquille ne peut être comparée à aucune des espèces vivantes des mers d'Europe; elle a quelque analogie avec le $R$. quadriplicata du miocène et du pliocène, mais il sera toujours facile de l'en distinguer par sa taille beaucoup plus petite, son nombre de tours de spire plus grand, sa callosité plus mince et moins étendue et par son labre plus faible et moins saillant.

52. Ringicula pulchella, Jeffreys (Pl. V, fig. 6).

Testa parva, tenuis, forma variabilis, plus minusve elongata; anfractus 5 convexi, sutura profunda discreti, sublcevigati, superne tenuiter sulcati; anfractus ultimus 2/3 longitudinis cequans, lineis spiralibus 2 supernis, juxta suturalibus ornatus, deinde lavigatus, medio et inferne transversim punctato-liratus, basi rotundatus, marginibus callo tenui junctis; apertura umpla; margine columellari vix arcuato, triplicato, plicis minutis; labro regulariter arcuato, tenui, extus vix prominente. - Long. 3,2 mill., diam. 2 mill.

Hab. Ouest de l'Irlande, draguée de 1180 à 1215 brasses (1869); entre Falmouth el Gibraltar, draguée de 227 à $79 \breve{~ b r a s s e s ~}(1870)$; voyage du Porcupine de 1859 et 1870 (Jeffreys).

Coquille petite, mince, variable dans sa forme, tantôt allongée, tantôt courte et globuleuse; les tours, an nombre de cinq, sont convexes et séparés par une suture profonde; ils sont ornés, à la partic supérieure seulement, de trois stries profondes, finement crénelées; le dernier forme les deux tiers de la longueur totale, il est orné de stries spirales ponctuées, excepté sur un tiers de 
sa surface environ et à la partie supérieure de sa face dorsale, où il est lisse ; l'ouverture est grande; les bords sont réunis par un dépôt calieux et très-mince, qui ne dépasse pas le dernier tour; le bord columellaire est peu arqué, garni de trois plis très-petits, le supérieur se prolongeant sur la columelle, les deux autres placés perpendiculairement; le labre est régulì̀rement cintré, mince, à peine saillant en dehors, descendant au-dessous des plis de la columelle.

5j. Ringicula Terquemi, L. Morlet (PI. V, fig. 7).

Testa parva, globosa, tenuis, regulariter striata, striis anfractus ultimi in facie aperturali conspicuis, in dorso inlerdum obsoletis 3-8, quarum 3 basalibus; anfractus 4.1/2, globosi, sutura canaliculata discreti; anfractus ultimus dimidium testce superans, basi rotundatus; spira brevis, rapide crescens; apertura lata, marginibus callo tenui junctis, margine columellari inferne arcuato, triplicato, plicis crassis, brevibus; plica superna callum tortuosum simulans; plica inferna plicam mediam superans, labro regulariter arcuato, medio parum calloso ei subdentato, extus prominulo. - Long. 3 mill., diam. $1,1 / 2$ mill.

Hab. Baie de Smyrne (sable vaseux), à 20 mètres de profondeur (Terquem).

Coquille petite, globuleuse, mince, régulièrement striée; excepté sur le dernier tour dont les stries ne sont bien visibles que du côté de l'ouverture; on en voit néanmoins un certain nombre sur le dos; chiffre variable de trois à huit, mais généralement trois à la base du dernier tour ; lours au nombre de quatre et demi, globuleux, séparés par une suture formant canal, le dernier formant, à lui 
seul, un peu plus de la moilié de la coquille et fortement arrondi à la base; spire courte, augmentant fortement, onverture large; bords réunis par un dépôt calleux faible ; bord columellaire fortement arqué à la base, garni de trois plis épais et courts, surtout celui du sommet, formant une callosité tortueuse, celui de la base, un peu pias grand que l'autre; labre cinlré régulièrement et garni d'une callosité au milieu formant une dent, légèrement saillant en dehors.

Dans le précédent article, nous avons fait connaître la disposition des espèces vivantes, en profondeur et dans les diverses régions. En y ajontant les espèces nouvelles que nous venons de décrire, elles se groupent aujourd'bui de la manière suivante:

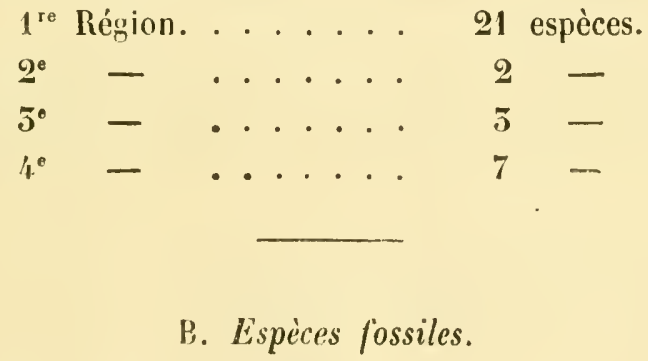

7. Rivgicula Rivgexs, Deshayes.

Loc. Eocène moyen : Orglandes (Nanche).

14. Ringicula Bourgians, L. Morlet.

Loc. Viocène moyen : Ferme de Breil-foin, près Genneteil (Maine-et-Loire).

17. Ringicula elongata, Eichwald.

Loc. Miocène moyen : Matella, près Lisbonne, Büiterr 
(Bassin de Vienne). Pliocène inférieur : Altavilla (Sicile).

19. Ringicula Pauluciale, L. Morlet.

Loc. Miocène moyen : moulin de Cabannes, près Dax (Landes), Mandillot (Gironde).

21. Ringicula ventricosa, Sowerby (PI. V, fig. 2).

Obs. Je fais figurer cette coquille qui n'est pas représentée dans mon premier travail et qui provient du Crag de Sutton.

24. Ringicula Fiscieri, L. Morlet,

Loc. Pliocène inférieur : Astésan (Italie).

27. Ringicula Baylei, L. Morlet.

Loc. Miocène moyen : Bernachon, près Saucats (Gironde). - Miocène supérieur: Saubrigues, Largileyre, près Salles (Gironde); San Paul d'Ordal, province de Barcelone.

29. Ringicula Crossei, L. Morlet.

Loc. Miocène inférieur : Gaas (Landes).

30. Rungicula Pontelenviensis, L. Morlet.

Loc. Nliocène moyen : Ferme de Breil-foin, près Genneteil (Maine-et-Loire).

51. Ringicula auriculata, Ménard,

Loc. Pliocène inférieur : La Calle, près Nice, propriété Bernard et moulin de l'Abadie, près Cannes (Alpes-Maritimes). 
55. Ringicula buccinea, Brocchi.

Loc. Mliocène moyen : Sutton, Cor. Crag et Read Crag (Angleterre).

53. Ringicula elegans, Pecchioli.

Loc. Miocène moyen : Saint-Paul-lès-Dax; La Capagne et moulin de Lagus, près Saucats (Gironde).

56. Rivgicula exilis, Eichwald.

Loc. Miocène moyen : Le Coquillat, à Léognan, Cestas, Pont-Pourquey, près Sancats (Gironde). - Miocène supérieur : Largileyre, près Salles (Gironde), Mlutella, près Lisbonne.

57. Ringicula Gaudruana, L. Morlet.

Loc. Miocène supérieur : San Pau-d'Ordal, province de Barcelone. - Pliocìne inférieur : Orciano (Toscane).

58. Ringicula Gratelouri, d'Orbigny.

Loc. Miocène supérieur: Largileyre, moulin Debat et Ninoy, à Salles (Gironde).

42. Ringicula Quadriplicata, L. Morlet.

Loc. Pliocène inférieur : Lucardo (Toscane).

45. Rixgicula Tounnoueri, L. Morlet.

Loc. Nliocène moyen : Mérignac, Cestas, Pont-Pourquey, Giraudeau, Bernachon, la Capagne (Gironde); moulin de Cabannes (Landes). - Miocène supéricur : Orthez (Basses-Pyrénées), Mutella, près Lisbonne. 
48. Ringicula Africana, L. Morlet.

Loc. Pliocène inférieur : Sidi-Daho, près Oran (Algérie).

49. Ringicula simplex, Briart et Cornet.

R. simplex, Briart et Cornet, Desc. des foss. du Calc. grossier de Nons, $5^{\mathrm{e}}$ partie. Supplément, p. 48, pl. xvı, fig. 4, $a, b, c, d, e, f, 1878$.

Testa minutissima, ovata, globulosa; anfractus 3-4 sutura lineari discreti, lavigati, nitentes, haud striati; anfractus ultimus amplus, basi rotundatus; apertura ovata, obliyua, antice dilatata, postice acuta; labro intus et extus incrassato, medio inflato; margine columellari callo so, plicis validis instructo, antico validiore. (Trad.) Long. 3,5 mill., diam. 1,7 mill.

Loc. Eocène inférieur : Mons (Belgique).

Très-petite coquille, ovale, globuleuse, composée de trois ou quatre tours légèrement arrondis, senroulant sous un angle assez aigu, séparés par des sulures linéiires peu profondes, mais bien marquées. Ces tours sont lisses et brillants sans le moindre ornement, le dernier trèsdéveloppé, à base arrondic ; ouverture ovale, oblique aiguë en arrière, dilatée en avant, le bord droit saillant antérieurement, fortement renflé en un bourrelet solide à l'intérieur comme à l'extérieur, principalement vers le milieu; le bord gauche fortement infléchi à la base de la colunelle, calleux, portant deux plis très-saillants, l'antérieur très-fort, projeté en avant et dessinant avec lı bord droit une espèce d'échancrure assez large, le postérieur moins fort, séparé du premier par un assez large sillon arrondi, et du tour précédent par un sillon plus faible également arrondi (Briart et Cornet). 
50. Ringicula Cossmanni, L. Morlet (Pl. V, tig. 8).

Testa ovata, tenuis, tenuiter et regulariter striata; anfractus 5, parum convexi, sutura subcanaliculata discreti, subgraduti, ultimus dimidium testa paulo superans; apertura lata, marginibus callo tenui, ultru penultimum anfiactum ascendente junctis, margine columellari subobliquo, triplicato, plicis brevibus, tenuibus, cequidistantibus; labro arcuato, intus lavi, extus prominu!o.-Long. 4 mill., diam. פ,7 mill.

Loc. Eocène inférieur? Abbecourt (Oise). - Eocène moyen : Ferme de l'Orme (Seine-ct-Oise).

Coquille ovale, mince, finement et régulièrement striće ; les tours, au nombre de cinq, sont convexes, séparés par une suture un peu canaliculée, ce qui donne à la spire l'air d'être étagée, le dernier formant à lui scul un peu plus de la moitié de la coquille; l'ouverture est large; les bords sont réunis par un léger dépôt calleux, qui remonte seulement un peu au-dessus du dernier tour; le bord columellaire est légèrement oblique, garni de trois plis courts, minces et à peu près à égale distance; lc labre est légèrement cintré, uni en dedans et un peu saillant en dehors.

Obs. Celte espèce, qui se rapproche par sa forme du R. ringens, Lamarck, s'en distingue par sa taille plus pelitc, par sa suture des tours de spire plus accentuée, son labre plus cintré et non garni de dents, à l'intéricur.

51. Ringicula Dugasti, L. Morlet (PI. V, lig. 9).

Testa ovata, globulosa, crassa, tenuiter el regulariter striata; spira brevi; anfractus 3 1/2 convexi, sulura profundu discreti; ultimus fere 2/3 longitudinis cequans, basi rotundatus; aperturu anguslu, marginibus callo crasso ad 
partem superiorem anfractus penultimi ascendente junctis; margine columellari arcuato, triplicato; plica superna brevissima, reliquis crassis, contortis, approximutis: labro arcuato, crasso, medio prominente, dentem simulante, extus incrassato, superne canalem ascendentem formante. - Long. 4,8 mill., diam. 3, š mill.

Loc. Eocène moyen : Beauchamp (Seine-et-0isc).

Coquille ovale, globuleuse, épaisse, finement et régulièrement striée; spire courte; les tours, au nombre de cinq et demi, sont convexes et séparés par une suture profonde, le dernier formant à lui seul presque les deux tiers de la coquille, très-arrondi à la base ; l'ouverture est étroite; les bords sont réunis par une forte callosité, qui remonte jusqu'à la partie supérieure de l'avant-dernier tour; le bord columellaire est arqué, garni de trois plis, le supérieur très-court, les deus autres longs, épais et tordus, très-rapprochés l'un de l'autre; le labre est cintré, très-épais, surtout au milieu où il existe une forte proéminence en forme de dent, qui se prolonge dans l'intérieur de la coquille, très-saillant à l'extérieur et forme, à sa jonction à la partie supérieure, un petit canal ascendant.

Obs. Cette espèce ne peut être confondue avec aucune de ses congénères du Bassin de Paris, par sa forme générale, l'épaisseur de la callosité sur la columelle, celle du labre et enfin par l'absence decrénelure sur la partie intérieure du bord droit.

52. Ringicula Raincourti, L. Morelet (PI. VI, fig. 5).

Testa parva, tenuis, globulosa, tenuiter el regulariter striata; anfractus 4 1/2 convexi, superne subcarinati, sutura lineari discreli; ultimus 2/3 longitudinis aquans, 
basi subangulatus; aperturu lata, marginibus callo tenui ultra ultimum anfractum non altingente junctis; margine columellari triplicato, superna plica brevissima, reliquis crassis, inferna contorta, truncala, labro fere rectilineo, superne et inferne arcuato. - Long. 3 mill., diam. 2 mill.

Loc. Eocène moyen : Ferme de l'Orme et Septeuil (Seine-et-0ise).

Coquille pelite, mince, globuleuse, très-finement et régulièrement striée; les tours, an nombre de $4 \mathbf{1 / 2}$, sont convexes et un peu carénés dans là partie supérieure, séparés par une suture simple; le dernier formant à lui seul les $2 / \bar{\partial}$ de la coquille est subanguleux à sa base; l'ouverture est large; les borls sont réunis par un mince dépôt calleux, qui ne remonte pas au-delà du dernier tour; le bord columellaire est garni de 5 plis, le supérieur trèscourt, les 2 autres plus longs, épais, el l'iuférieur fortement tordu, formant une troncature échancrée; le labre presque droit, simple, dépassant de beaucoup, à sa base, le bord columellaire et formant, ì sa partie supérieure, une légère courbe pour rejoindre la coquille.

Obs. Cette espèce ne peut être confondue avec aucune de ses congénères du Bassin de Paris, si ce n'est arec le R. Bezançoni, L. Horlet, mais eile est plus courte, moins globuleuse, et le labre n'est pas dentelé comme dans cetle dernière.

ə̋. Ringicula Bardini, I. Morlet (PI. VI, fig. 1).

Testa purva, ovata, conoidea, crassa; anfractus 6 convexi, sutura subcanaliculatu discreti, primi spiraliter et tenerrime striati; ultimus $3 / 4$ longitudinis cequans, rotundatus; upertura angusta, marginibus callo junctis; callo in anfractum penultimum ascendente: margine colu 
mellari basi arcuato, triplicato; plica superna callositate immersa, infernis validis, contortis; labro vix arcuato, extus parum dilalato. - Long. 4 1/2 mill., dium. 2,9 mill.

Loc. Miocène moyen : Ferme de Breil-Foin, près de Genneteil (IIaine-et-Loire).

Coquille petite, ovale, conoïle, épaisse, garnie de stries très-fines, sur les 5 premiers tours seulement; Ics tours, au nombre de 6 , sont convexes et séparés par une suture légèrement canaliculée, le dernier, formant à lui seul près des $5 / 4$ de la coquille, est arrondi; l'ouverture est étroite; les bords sont réunis par un dépot calleux qui recouvre l'avant-dernier tour; le bord columellaire, arqué à sa base, est garni de 5 plis, dont le supérieur est fortement empâté dans la callosité, et les deux inférieurs, trèsforts et tordus; le labre est presque droil, peu dilaté extérieurement.

Obs. Cette espèce se rapproche beaucoup du R. marginata, Deshayes, par sa forme générale et sa forte callosité recourrant une grande partie du ventre de la coquille, mais elle s'en distingue, par sa spire plus allongée, ses tours plus convexes, ses plis plus proéminents, et le manque de canal à la jonction du labre avec le bord columellaire.

54. Ringicula Hermitei, L. Morlet (PI. VI, fig. 4).

Tesla ovata, crassa, globulosa; anfractus 5 , convexiusculi, sutura subcanaliculata discreti; primi 2 sublente tenerrime striati altimus obsolete costatus, hfo longitudinis aquans, bası rotundaius; apertura sut lata, marginibus callo crasso junctis; callo in unfractum penultimum ascendente; margine columellari triplicato, plica super- 
na tenui, infernis crassis, contortis; labro fere rectilineo, medio crasso et subdentato; callo columelluri lato, $\varepsilon x-$ panso ei partem anfractus ultimi occultante; margine dextro superne cum columellari canalem formante. Long. 5 mill., diam. 4 mill.

Loc. Miocène moyen: Ferme de Breil-foin, près de Genneteil (Ilaine-et-Loire).

Coquille ovale, épaisse, globuleuse; on aperçoit, avec un fort grossissement, de légères stries, sur les 2 premiers tours, et des traces de côtes longiludinales sur le dernier; les tours, au nombre de 5 , sont légèrement convexes, séparés par une suture un peu canaliculée, le dernicr formant, à lui seul, les $4 / 00$ de la coquille, arrondi à la base; l'ouverture est assez ouverte; les bords sont réunis par un dépôt calleux très-fort, recouvrant toute la surface interne de la coquille et remontant an sommet de l'avant-dernier tour; le bord columellaire est garni de 5 plis, le supérieur très-faible et les autres très-épais et tordus, le labre presque droit, très-épais, surtout au milieu où il forme une dent, dont l'épaississement se continue dans l'intéricur de la coçuille; la rallosité est tris-forte et recouvre une grande partie dit dernier tour; le bord droit forme, à sa jonction à la partie supérieure, un canal très-prononcé, lequel est arrêté sur la columelle par la dent supérienre.

Obs. Cette espèce ne peut se confondre qu'avec le h. Ponteleviensis, L. Morlet, mais il sera toujours facile de l'en distinguer par sa forme plus conique, sa spire plus allongée et aiguë, ses tours plus nombreux et plus convexes, par ses stries sur les 2 premiers tours et ses côtes longitudinales sur le dernier. 
55. Ringicula Munieiı, L. Morlet (Pl. VI, fig. 5).

Testa ovata, elongata, crassa, apice elongata; anfractus 7-71/2 convexiusculi, sensim crescentes, sutura canaliculata discreti, primi 5 tenuiter striati; ultimus longitudinuliter costulatus, striis remotiusculis basi munitus, 2/3 longitudinis cequans, inferne rotundatus; apertura lata, murginibus callo crasso, medium penultimi anfractus attingente junctis, margine columellari quadriplicato, plicis supernis callositate incrassatis, plicis infernis cras. sis, brevibus, contortis; labro fere rectilineo, crasso, extus prominente, antice et postice canalem cum margine columellari formante. - Long. 9 mill., diam. 5,4 mill.

Loc. Hiocène moyen : Thorigné, St-Clément-de-laPlace, ferme de Renaubeau, près de Brigné (Maine-etLoire) (L'abbé Bardin).

Coquille ovale, allongée, épaisse, finement striée sur le 5 premiers tours; le dernier marqué de côles longitudinales et orné, à la base, de stries assez espacées, variant de 5 à 5 ; spire allongće; les tours, au numbre de 7 à 7 1/2, sont convexes, augmentant graduellement, séparés par une suture canaliculée, le dernier formant les $2 / 3$ de la coquille, arronıli à la base; l'ouverture est large; les bords sont réunis par un dépôt calleux très-fort, qui remonte jusqu'au milieu de l'avant-dernier tour; le bord colımellaire est fortement arqué à la base, garni de 4 plis, les 2 supérieurs très-empâtés dans la callosité qui les recouvre extérieurement, et qui s'étend sur toute la partie inférieure de la coquille, les 2 inférieurs épais, courts et tordus; le labre est presque droit, très-épais sur toute son étendue, très-saillant en dehors, dépassant à sa base le bord columellaire et forme, à sa jonction, un petit canal, ainsi qư'à sa partie supérieure. 
Obs. Cette espèce, qui se rapproche beaucoup dn R. quadriplicata, L. Morlet, s'en distingue par sa forme générale plus allongée, ses tours plus nombrenx, l'ouverture plus large, la callesité plus forte et plus étendue; l'ornementation du dernier tour diffère par son petit nombre de stries, à la base seulement. Elle diffère également du R. Baylei, L. Morlet, par sa forme qui est un peu plus ventrue, par sa spire plus longue, le dernier tour plus arrondi, la callosité plus forte dans la partie supérieure et moins étendue dans la partie inférieure et aussi par le nombre de plis.

57. Rivgicula Almera, L. Morlet (PI. VI, fig. 6).

Testa ovata, crassu, subgibbosu, spiraliter costata, costis incequaliter remotis; spira brevis, acuta; anfraclus 6-7 convexi, sutura subcanaliculata discreli; anfractus ultimus 3/4 longitudinis cequans, basi rotundatus; apertura angusta, marginibus callo crasso junctis; callo infra leve dimidium testa, infra el postice anfractum penultimum tegente; margine columellari arcuato, quadriplicato, plicis callositute immersis, supernis parvis, infernis validis; columella basi conica; labro arcuato, crasso, medio prominulo, postice canalem aum margine columellari formante, extus prominente.-Long. 6,3̈ mill., diam. 4,3 mill.

Loc. Hiocène supérieur: San-Pan-d'Orual, province de Barcelone.

Coquille ovale, épaisse, légèrement gibbeuse, ornée de côtes transversales irrégulièrement espacées; spire courte el aigü̈, composée de six à sept tours convexes, séparés par une suture légèrement canaliculée, le tlernier formant à lui seul les trois quarts de la longuenr tolale, arrondi à 
la base; l'ouverture est resserrée; les bords sont réunis par un dépồt calleux, très-fort, qui recouvre environ la moitié de la coquille en-dessous et remonte, d'autre part, jusqu'au sommet de l'avant-dernier tour ; le bord columellaire est légèrement arqué, garni de quatre plis, les deux supérieurs très faibles, les deux autres assez forts, l'inférieur très-épais à la base; ces quatre plis sont fortement empàtés dans la callosité, qui est très-épaisse, sur tout à la base; columelle conique à sa base; le labre saillant en dehors, légèrement cintré, épais, ayant au milieu une légère protubérance, s'amincissant légèrement vers le haut et formant une légère gouttière, à sa jonclion avec le bord columellaire.

Ois. On trouve des spécimens dont les côtes sont réunies par deux, l'une contre l'autre, ce qui donne à la coquille un aspect tout particulier.

Cette espèce se rapproche du R. quadriplicata, L. Morlet, mais elle en differe par sa forme plus allongée, par son ornementation qui se compose de costulations et non de stries, enfin, par ses plis épais et courts, tandis qu'ils sont minces, chez le R. quadriplicata.

Elle se distingue du R. Cacellensis, L. Morlet, par le nombre de ses plis, sa taille plus petite, sa forme plus allongée, son ornementation et sa callosité moins forte et moins étendue.

58. Ringicula Mayeri, L. Morlet (PI. VI, fig. 7).

Testa ovalo-elongata, tenuis; anfractus 6 parum convexi, primi tenuiter striati, reliqui tantum in parte inferiore sulcati; sutura canaliculata; anfractus ultrmus 3/4 longitudinis aquans, busi rotundatus; spiru elongata, sensim crescens; apertnra sat ungusta, marginibus callo crasso junclis, callositate ad mediam purtem penultimi 
anfractus productu; margine columellari obliquo, incrassato, quudriplicato: plicis supernis approximatis, brevibus; plicis infernis longioribus; labro fere rectilineo, medio latiore, supcrne attenuato, extus prominente.-Long. 5,8 mill., dıam. 3,8 millim.

Loc. Niocène supéricur : Saubrigues, Saint-Jean-deNarsacq (Landes).

Coquille ovale allongée, mince; les premiers tours striés finement et les autres seulement jusqu'au milieu; les tours, au nombre de six, sont peu convexes, séparés par une suture légèrement canaliculée, le dernier formant à lui seul près des trois quarts de la longueur totale de la coquille, arrondi à la base; spile allongée, augmentant sensiblement; ouverture assez rétrécie; bords réunis par un dépôt calleux assez fort, qui remonte jusqu'au milieu de l'avant-dernier tour, bord colnmellaire oblique, recouvert d'une callosité épaisse, muni de quatre plis, les deux supérieurs très-rapprochés et courts, les deux autres plus longs el relevés à la partie extrème; le labre est presque droit, épais ; à partir du milien, il s'amincit jusqu'au sommet, saillant en dehors, et forme à la base un petil canal, à sa jonction avec le bord columellaire.

Obs. Cette espece pourait être conlondue avec le R. Bardini, L. Morlet, mais elle s'en distingue : par sa forme plus allongée, sa callosité plus épaisse sur le bord columellaire, son ornementation et son quatrième pli; on la distingue igalement du R. Baylei, L. Morlel, par sa taille plus petite, sal callosité moins étendue et moins épaisse, son ornementation et son quatrième pli.

58. Risacula Douvilua, L. Moriet (PI. VI, fig. 2).

Testa ovalı, crassa, lenuiter et regulariler striuta; 
spira brevis; anfractus 6 convexi, sutura profunda discre ti, ultimus dimidrum longitudinis superans, basi rotundatus: apertura angusta, marginibus callo crasso, penultimum anfractum attingente junctis, margine columellari arcuato, triplicato, plica superna mediocri, callositate immerso, infernis crassis, contortis, labro leviter arcuato, medio incrassato, extus prominente. - Long. 4 1/2 mill., diam. 2,9 mill.

Loc. Miocène inférieur: Stemberg (Mecklembourg).

Miocène moyen: Salles, Le Coquillat à Léognan, la Capagne et lloulin-de-Lanus près Saucats (Gironde), Saint-Paui-lès-Dax et Mimbaste (Landes).

Pliocène inférieur : Moulin de l'Abadie, près Cannes (Alpes Maritimes).

Coquille ovale, épaisse, finement et régulièrement striée; spire courte; les tours, au nombre de six, sont convexes, séparés par une suture profonde, le dernier formant à lui seul un peu plus de la moitié de la coquille, arrondi à sa base; ouverture étroite; les bords sont réunis par un dépôt calleux épais, couvrant presque l'avant-dernier tour; bord columellaire fortement arqué, garni de trois plis, le supérienr médiocre, très-empâté dans la callosité, les deux autres épais et tordus ; le labre est légèrement cintré, très-épais, surtout au milieu, très-saillant en dehors.

Obs. Cette espèce ne peut être confondue avec aucune autre de ses congénères, par sa forme générale, et surtout par l'épaisseur de sa callosité et de son labre.

59. Ringicula Baunovi, L. Morlet (PI. VI, fig. 8).

Testa ovata, ventrosa, interdum spiraliter striatula, tenerrime et longitudinaliter striata; spira brevis, coni- 
ca; anfractus 5 1/2 convexi, rapide crescentes, sutura lineari discreti; ultimus $3 / 4$ longitudinis aquans, basi rotundatus; apertura mediocris; marginibus callo crasso, expanso junctis; margine columellari parum arcuato, quadriplicato, plicis supernis 2 brevissimis, crassis, approximatis, callositate immersis; infernis 2 crassis, contortis; lubro reguluriter arcuato, medio crassiusculo, superne canalem formante, extus prominente. - Long. з mill., diam. 3,8 mill.

\section{Loc. Pliocène inférieur : Asti.}

Coquille ovale, ventrue, ornće de stries longitudinales, assez espacées et profondes, et parfois de fines stries spirales; spire courte et conique, composée de cinq tours et demi, convexes, s'accroissant rapidement, séparés par une suture simple, le dernier formant à lui seul près des trois quarts de la roquille, arrondi à la base; les bords sont réunis par un fort dépôt calleux très-étendu; le bord columellaire peu arqué, garni de quatre plis, les deux supérieurs très-courts, épais et rapprochés, empâtés dlans la callosité, les deux anires, épais et très-tordus; le labre régulièrement cintré, épais, surtout au milieu où il est garni d'une callosité saillante et occupant un tiers environ du labre, forme une légère gouttière à la partie supérieure, et saillant en dehors.

Obs. Celte espèce ne peut être rapprochée que du R. marginata, Deshayes, mais elle s'en distingue : parsa forme moins globuleuse, l'ouverture de sa bouche plus grande, la callosité du bord columellaire moins anguleuse et le nombre de plis ì l'intérieur. 
60. Rivgicula Deponvallaeri, L. Morlet (PI. Vl, fig. 9).

Testa parva, globulosa, tenuis; anfractus 5 convexi, primi 3 eleganter striati, reliqui ad partem inferiorem tantum striati, striis 6-9; sutura simplaci; anfractus ultimus 3/4 longitudinis cequans, basi rotundatus; spira brevis, rapide crescens; apertura lata; murginibus callo tenui junctis, callo 3/4 longitudinis penullimi anfractus altingente; margine columellari urcuato, triplicato, plica superna ad basin decurrente; callositate immersa; plicis infernis horizontalibus; labro valde arcualo, medio crassiusculo, superne depresso, extus prominente. - Long. 4. mill., diam. 2,6 mill.

Loc. Pliocène inférieur : Moulin de l'Ábadie, près Cannes (Alpes-Nlaritimes).

Coquille petile, globuleuse, mince; le trois premiers tours striés très-élégammeni, les deux autres striés seulement sur la partie inférieure, ces stries variant de 6 à $\mathbf{9}$; les tours, au nombre de cinq, soni très-convexes et séparés par une suture simple, mais bien prononcée, le dernier formant, à lui senl, les trois quarts de la longueur totale de la coquille, arrondi à la base; spire courte el augmentant rapidement; onverture large; bords réunis par un dépôt calleux faible, recouvrant les trois quarts de l'avant-dernier tour; bord columellaire arqué, garni de trois plis épais, le supérieur incliné vers la base, empâté dans la callosité, qui est très-forte à cet endroit, les deux autres longs, horizontaux et formant une gouttière à leur partie extrême; le labre est très-cintré, légèrement épaissi au milieu et ayanı, dans la partie supérieure, une dépression très-prononcée, saillant au dehors. 
Obs. Cette espèce se rapprocherait dn R. semistriata, d'Orbigny, mais elle s'en distingue par sa forme plus courte, plus globuleuse et sa callosité plus faible.

Nous avons fait connaitre, dans la Monographie, la distribution gẻologique des espèces fossiles : nous allons ajouter les modifications à apporter dans cette classification.

Nous n'avons rien à signaler parmi les espèces des terrains crétacés.

A. A l'Éocène inférieur :

R. simplex. Briart et Cornet.

B. A l'Éocène inférieur ct à l'Éocène moyen :

R. Cossmanni, L. Horlet.

C. A l'Éocène moyen :

R. Dugasi, L. Morlet.

R. Raincourli, L. Morlet.

B. Au lliocine moyen :
R. Bardini, L. Morlet.
R. Hermitei, L. Norlet.
R. Munieri, L. Morlet.

C. An Wiocène supérieur :
R. Almere, L. Norlet.
R. Maycri, L. Horlet.

Espèces communes au Miocène et au Pliocène :
R. Douvillei, L. Ilorlet.
R. elongata, L. Horlet.
R. Fischeri, L. Morlet. 
A. Au Pliocène inférieur :

R. Baudoni, L. Morlet.

R. Depontaillieri, L. Morlet.

RÉSuné.

Les 55 espèces de Ringicules fossiles européennes se stibdivisent de la manière suivante :

2, appartiennent aux terrains crétacés; 10 à l'Éocène ; 27 au Niocène; 14 au Miocène et au Pliocène et 2 au Pliocène.

Parmi les espèces européennes, une, le R. quadriplicata, se trouve en Afrique, sur la rive gauche de l'OuedNalor.

L.es 88 espèces vivantes ct fossiles contenmes dans ce genre, peuvent être groupées, comme il suit, d'après leurs caractères conclyyliologiques :

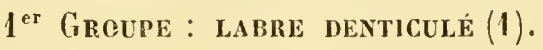

"R. Besançoni, Caron, * Crossei, denticulata, encarpofe. rens, "gracilis, "minor, " minutissima, " ringens, "Vasca.

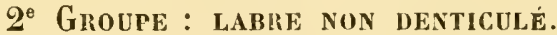

a. Bord columellaire à deux plis.

"R. biplicata; "* leptocheila; "subven/ricosa: "varna; *Vernevili.

(1) Les noms précédés d'une astérisque indiquent que l'espèce est fossile; ceux précédés de deux astérisqucs indiquent que l'espèce est à la fois vivante et fossile; enfin les noms sans aucun signe indiquent les espèces vivantes. 
b. Bord columellaire à trois plis.

B. acuta; "acutior; "Africana; "arctata; * auriculata; Australis;" Bardini; " Baylei; "Berthaudi ; "Bonellii; "Bourgeoisi; ; Brocchii; ; buccinea; " Cacellensis; Caledonica; canaliculuta; " coarctata; " costalu; "Cossmanni; "Depontaillieri; " Deshayesi ; doliaris; "Douvillei; " Dugasti; " elegans; " elongata, exserta; " exilis; "Fischeri; Folini; fossulata; "Gaudryana; "gigantula; Goujoni; * Grateloupi; grandinosa; " IIermitei; * intermedia; vigata; "marginata; Morilsi; " nena; nitidu; Noumeensis; OEhlertice; Passieri; " Pauluccice; "Nariei; " plicatula; " Ponteleviensis; prismatica; propinquans; pulchella; "Raincourti; "Sandbergeri; Savignyi; "* semistriala; "Semperi; " simplex; Someri; "striata; suturalis; Terquemi; "Tournoueri; "ventricosa.

c. Bord columellaire à qualre plis.

"R. Almerce; "Baudoni; " conformis; " quadriplicata; Mayeri; "Munieri; Salleana.

Obs. La Ringicule signalée dans le calcaire jaune du Scinde, n'ayant pas été dessinée du côlé de l'ouverture, n'a pu être classée dans aucun groupe.

Ayant omis, dans la Monographie du genre Ringicula, de faire comnnaître les collections dans lesquelles se trouvaient les types des espèces que nous avons fait figurer, nous nous empressons de reclifier cette erreur, et nous y ajoutons la même mention, pour celles qui sont comprises dans notre Supplément. 
a. Espèces vivantes.

Ringicula arclata, Gould (coll. Crosse).

- auriculata, Ménard (coll. Bonterosato).

- Australis, Hinds (coll. Morlet).

- buccinea, Brocchi (de Folin).

- Caledonica, L. Morlet (coll. Morlet).

- canaliculala, de Folin (coll. Morlet).

- Caron, Hinds (coll. Crosse).

- conformis, Monterosato (coll. Monterosato).

- encarpoferens, de Folin (coll. de Folin).

- Folini, L. Morlet (coll. Morlet).

- fossulala, de Folin (coll. Crosse).

- Goujoni, de Folin (coll. de Folin).

- grandinosa, Hinds (coll. Norlet).

- Leptocheila, Brugnone (coil. Monterosato).

- Moritzi, de Folin (coll. de Folin).

- Noumeensis, L. Morlet (coll. Morlet).

- OEhlertia, L. Morlet (coll. Morlet).

- Passieri, L. Morlet (coll. de Folin).

- prismalica, de Folin (coll. Crosse).

- pulchella, Jeffreys (coll. Norlel).

- Savignyi, L. Morlet (coll. Moriel).

- Someri, de Folin (coll. de Folin).

- Terquemi, L. Morlet (coll. Morlet).

\section{b. Espèces fossiles.}

Ringicula acutior, Nayer (coll. du Musée de Zurich).

- Africana, L. Morlet (coll. de l'École des Mines).

- Almera, L. Morlet (coll. Morlel).

- Bardini, L. Morlet (coll. Morlel).

- Baudoni, L. Morlet (coll. Morlel). 
Ringicula Baylei, L. Morlet (coll. de l'École des Mines). Bezançoni, L. Mlorlet (coll. Bezançon).

- Bonellii, Deshayes (coll. du Musée de Zurich).

- Bourgeoisi, L. Morlet (coll. Crosse).

- $\quad$ - var., L. Morlet (coll. Crosse).

- Brocchii, Seguenza (coll. Crosse).

-. buccinea, Brocchi (coll. Crosse).

- Cacellensis, L. Morlet (coll. de l'Ecole des Mines).

- Cossmanni, L. Morlet (coll. Morlet).

- costala, Eichwalı (coll. du Musée de Zurich).

- Crossei, L. Moriet (coll. Crosse).

- Depontaillieri, L. Morlet (coll. Morlet).

- Douvillei, L. Morlet (coll. Morlet).

-- Dugasti, L. Morlet (coll. Morlet).

- elegans, Pecchioli (coll. Tournouër).

- elongata, L. Morlet (coll. de l'Ecole des Mines).

- exilis, Eichwald (coll. du IJusée de Zurich).

- Fischeri, L. Morlet (coll. de l'Ecole des Mines).

- Gaudryana, L. Moriet (coll. Crosse).

- gigantula, Doderlein (coll. du Musée de Zurich).

- gracilis, Sandberger (coll. Sandberger).

- Grateloupi, d'Orbigny (coll. Crosse).

- Mermitei, L. Morlet (coll. Morlet).

- intermedia, Foresti (coll. Foresti).

- marginala, Deshayes (coll. de l'licole des mines).

- Mayeri, L. Morlet (coll. Morlet).

- minor, Deshayes (coll. Bezançon).

-_ minutissima, Deshayes (coll. Bezançon).

- Munieri, L. Morlet (coll. Morlet).

- nana, L. Niorlet (coll. Morlet).

- Pauluccia, L. IIorlel (coll. Crosse). 
Ringicula plicalula, Mayer (coll. du Musée de Zurich).

- Ponleleviensis, L. Morlet (coll. Crosse),

- quadriplicala, L. Morlet (coll. Crosse).

- Raincourti, L. Morlet (coll. Morlet).

- ringens, Deshayes (coll. Crosse).

- Sandbergeri, L. Morlet (coll. Crosse).

- striata, Philippi (coll. Sandberger).

- Tournouëri, L. Morlet (coll. Crosse).

- Vasca, Tournouër (coll. Tournouër).

- ventricosa, Sowerby (coll. Morlet).

\section{Errata :}

5. Ringicula minor, Deshayes, Monographie du genre Ringicula, page 25, Loc. lisez : Lowersines et non Loversines.

25. Ringicula gigantula, Doderlein, $l$. c. page 40, lisez : $n^{0} 25$ et non 25.

L. M.

EXTRAIT DU NUMÉRO D'AVRIL 1880

du

JOURNAT DE CONCHYLIOHOGLE

PUBLIÉ PAR H. CROSSE,

RUE TRONCHET, 25,

PARIS.

Paris. - Imprimerie de madame veuve Bouchard-Huzard, rue de l'Éperon, 5 J. TREMBLAY, gendre et successeur. 
Jouma de anchylolog, 1 \$30

PI i

1

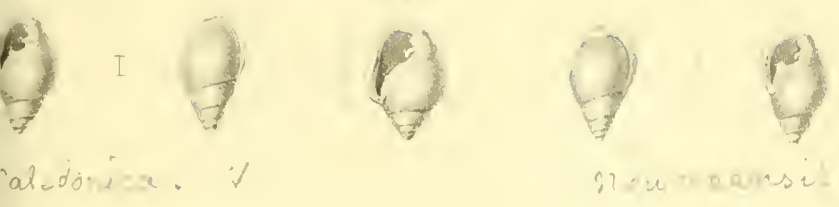

aledonitar. Y
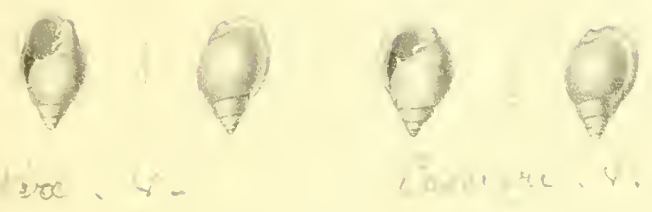

, $50 x^{2}, 42,4$.

liv $3, x, y-$

5

6

7

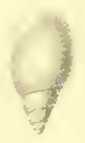

.) Ila : .
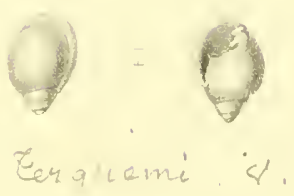

C
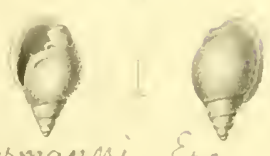

$\varepsilon_{0}=$

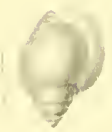

Eerallemi \&.

$$
\begin{gathered}
\text { Monograplic iv genre Panglauia } \\
\text { ( Supplement) }
\end{gathered}
$$

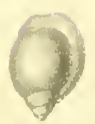

on ontol prove 



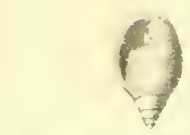

Pinini

mice , in.

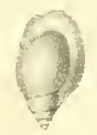

- sither.

rive int.
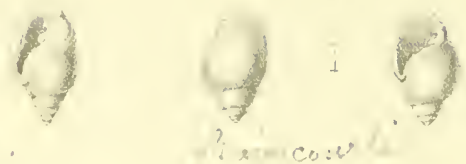

ror andy
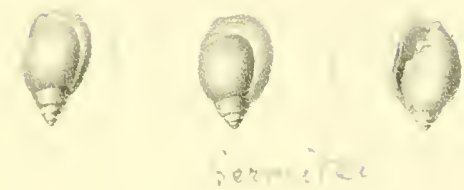

$3222^{2}+12221$
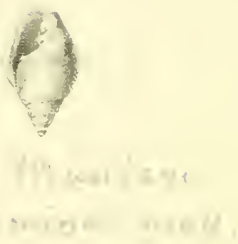

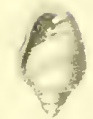

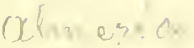

$\operatorname{man} e-i x x_{0}$.

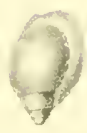

$$
\text { . }
$$
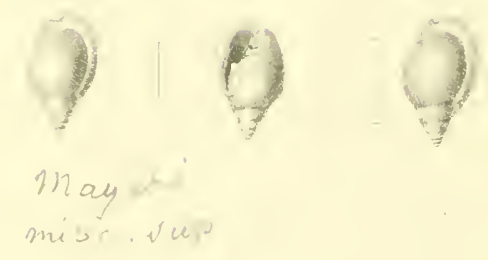

8

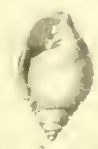

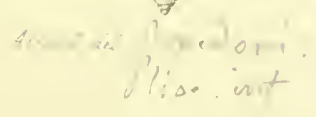

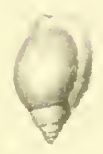

Vonographi. du gener Rungicula

(Supp-ment)

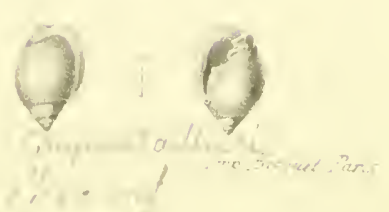





\title{
DEUXIËME SUPPLÉMENT
}

A LA

\section{HONOGRAPHII DU GENRE RINGILULA,}

\author{
DESHAYES,
}

PAll

LE COMMANDANT L. MORLET.

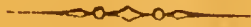

PARIS

\section{CHEZ L'AUTEUR,}

IIUE DE VINCENNES, 8\%, A MONTREUL-SOUS-BOIS (SEINE),

A PARIS, CHEZ F. SAVY, LIBRAIRE, HOLLIVVARI SAINT-GERMAIN, 77. 



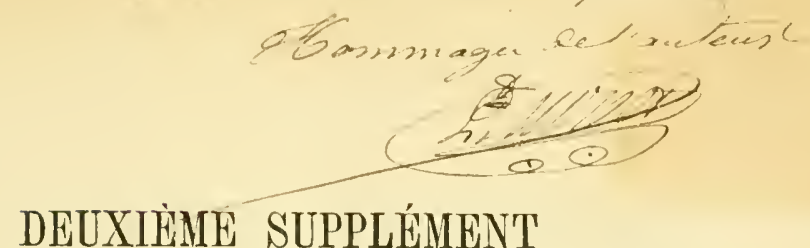

A LA

MONOGRAPHIE

DU GENRE RINGICULA

(DESHAYES)

PAR

Le Commandant L. MORLet

Depuis la publication de la Monographie du genre Ringicula (1) et du Supplément (2), le nombre des espèces vivantes et fossiles s'est encore augmenté, et justifie l'apparition d'un deuxième Supplément, contenant les descriptions des espèces nouvelles, soit vivantes, soit fossiles que j’ai pu éludier.

D'autre part, une importante Monographie des Ringicules fossiles de l'Italie a été publiée récemment par M. Seguenza et nous a fait connaître plusieurs espèces nouvelles. Enfin H. G. Vasseur a découvert, dans les terrains tertiaires de la Bretagne, une forme inćdite très remarquable, appartenant à ce genre.

(1) Nonographie du genre Ringicula, Journal de Conchyliologie, vol. XXVI, p. $113 \in \mathrm{e} 251,1878$.

(2) Supplément, Journal de Conchyliologie, vol. XXVIII, p. $150,1880$. 
En réunissant tous ces documents, on complétera nos listes antérieures. Nous avons conservé les numéros d'ordre distinct pour les espèces vivantes et pour les espèces fossiles.

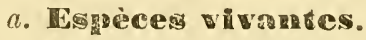

54. Rivgicula Cabrai, L. Morlet (PI. IX, fig. I).

T'esta minutissima, subventricosa, crassa; anfractus 4 1/2 convexiusculi, sutura canaliculata discreti, sulcis spiralibus profundis ornati, tum sulco superno et sulcis raris inferis, tum sulcis xquidistantibus omnino exarati, anfractus ultimus $3 / 5$ longitudinis xquans; apertura magna, marginibus callo crasso junctis; margine columellari valde arcuato, plicis 3 minutis ornato, plica superna crassissima, plicis inferis tenuibus et horizontalibus; labro arcuato, crasso, extus prominente, intus el medio callo planato et dente infero parvo munito. - Long. 2,5 mill.; diam. 1,8 mill.

Coquille très petite, légèrement ventrue, épaisse; les tours, au nombre de $41 / 2$, sont un peu convexes, séparés par une suture canaliculée, ornés de sillons profonds d'une manière irrégulière, quelquefois d'un sillon à la partie supérieure et de quelques sillons à la base, d'autres fois de sillons couvrant toute la surface et régulièrement espacés; dernier tour formant les $5 / 5$ de la longueur totale. L'ouverture est grande; les bords sont réunis par un dépôt calleux épais, qui ne dépasse pas le dernier tour; le bord columellaire est très arqué, garni de trois plis irès petils, le supérieur très épais et incliné vers la base, les deux autres très minces et horizontaux; le labre très légèrement ciutré, épais, très saillant en dehors et dépassant un peu le bord columellaire, est garni, à l'intérieur 
et au milieu, d'une callosité plane et, au-dessous, d'une petite dent. (Coll. du marquis de Folin.)

Hab. Ner Rouge?

Obs. Cette espèce se rapproche du R. Goujoni, de Folin, par sa dent placée à la partie inférieure du labre, mais elle s'en distingue par sa taille plus petite, par son système d'ornementation, par la callosité du labre plus pro. noncée el par ses dents plus forles.

53. Ringicula Senegalensis, L. Morlet (PI. IX, fig. 2).

Testa parva, globulosa, brevis, crassa; anfracius 5 convexi, sutura profunda discreti; primi striatuli; ultimus radiatim costellatus, transversim in dorso non striatus, 2/3 longitudinis xquans, basi rotundatus; apertura coarctata, marginibus callo crasso junctis, callo basin anfiactus ultimi occupante; columella triplicata; plica superna valida, basi dilatata, supra canalem formante, media brevi, inferna tenai, contorta; labro parum arcuato, crasso, medio callo prominenic, longo, ad extremitates subdentato munito. - Long. 3 mill.; diam. 2,3 mill. (Coll. Morlet).

Coquille petite, globuleuse, courte, épaisse; tours au nombre de 5, convexes, séparés par une suture très prononcée, les premiers tours striés légèrement, le dernier orné de petites côtes, mais sans stries sur le dos seulement, formant à lui seul les $2 / \bar{\jmath}$ de la longueur totale, très arrondi à la base; ouverture peu resserrée; bords réunis par un dépôt calleux, épais et s'étendant sur la partie inférieure du dernier tour; bord columellaire garni de trois plis, le supérieur très fort, élargi à sa base et formant un petit canal à la partie supérieurc, les deus autres 
courts ; l'inférieur mince el lordu ; labre peu cintré, très épais, garni, au milieu, d'une callosité forte, étendue, présentant une petite dent ì chaque extrémité.

Hab. Côtes du Sénégal à 72 mètres de profondeur, fond vaseux (Schlumberger).

Obs. Cette espèce ne peut être confondue avec aucune de ses congénères, dont elle se distingue par sa forme très globuleuse, sa striation et surtout par la callosité proéminente qui orne son labre.

56. Ringicula a dmirabilis, L. Morlet(PI. IX, fig. 5).

Testa globosa, crassa, tenuiter striata et costellata (striis transversis 3-4 in anfractibus supernis, numerosis, densis in anfractu ultimo; costellis in dorso anfractus ultimi minus conspicuis); anfractus $51 / 2$ convexiusculi, su. tura impressa discreti, ultimus $3 / 5$ longitudinis xquans, basi rotundatus; apertura constricta; marginibus callo crasso junctis; margine columellari quadriplicato, plicis superis 2 crassis, brevibus; tertia brev, contorta; infera tenui, horizontali; labro parum arcuato, medio crasso et cxtus reflexo. - Long. 3,5 mill.; diam. 2,5 mill.

Coquille globuleuse, épaisse, très fineınent striée et côtelée; tours au nombre de 5 1/2 légèrement convexes, séparés par une suture très prononcée, le dernier formant à lui seul les $5 / 5$ de la longueur tolale, arrondi à sa base; ouverture resserrée; bords réunis par un dépôt calleux très épais; bord columellaire garni de 4 plis, le supérieur épais, court, anguleux et se prolongeant vers la partie supérieure; le deuxième très court et épais; le troisième court, épais et tordu; le dernier mince et tordu, tous denx placés horizontalement; labre peu cintré, très épais, surtout au milieu, et réfléchi en dehors ; toute 
la coqnille est striée horizontalement : les premiers tours portent 5 et 4 stries seulement, mais, sur le dernier, les stries sont très serrées; il en est de mème pour les côtes longitudinales, qui sont beaucoup plus visibles sur le côté ventral de la coquille que sur le dos (Collection Morlel).

IIab. Méditerranće.

Obs. Cetto espice se rapproche par sa striation du R. elegans, Pecchioli, du miocène el du pliocène; mais elle s'en distingne par sa forme plus allongée, ses stries plus fines el plus serrées el son pli inférieur horizontal, tandis que, dans le $R$. elegans, ce pli est relevé vers le sommet.

57. Rivgicula Schlumbergeri, L. Morlet (PI. IX, fig. 4).

Testa brevis, glubulosa, crassa; anfractus 5 convexi, sutura impressa discreti, striis spiralibus profundis, regulariter distantibus, in 3/4 anfractus ultimi conspicuis ornati, anfractus pemultimus costellis longitudinalibus munitus, ullimus $2 / 3$ longitudinis xquans, basi rotundatus; spira brevis; apertura constricta, marginibus callo crasso, cum labro canalem formante junctis, margine columellari arcuato, quadriplicato, plica superna tenui, media marginata, inferis 2 tenuibus, contortis, horizontalibus; labro arcuato, crasso, medio tuberculo dentiformi, plus minusve prominente munito. - Long. 4 mill.; diam. 3 mill.

Coquille courte, globuleuse, épaisse; les tours au nombre de š sont convexes, séparés par une suture trìs prononcée, ornés de stries profondes, régulièrement espacées, mais ne couvrant que les $5 / 4$ du tour, l'avant-lernier garni de quelques côtes longitudinales, le dernier formant 
à lui seul les $2 / 5$ de la longueur totale et fortement arrondi à la base; spire courte. L'ouverture est resserrée; les bords sont réunis par un dépôt calleux très épais, formant avec le pli supérieur un canal très prononcé, à sa jonction avec le labre ; bord columellaire fortement arqué, garni de 4 plis, le supérieur mince et incliné vers la base, le deuxième marginé et les deux inférieurs minces, tordus et horizontaux; le labre légèrement cintré est très épais, surtont au milieu, où il est muni d'une protubérance dentiforme plus ou moins forte (Coll. L. Morlet).

IIab. Méditerranée.

Obs. Cette espèce ne peut être confondue avec aucune autre de ses congénères, à cause de sa forme courte, de son ornementation consistant en stries et en côtes qui sé croisent, et de son quatrième pli, à l'intérieur.

Outre ces espèces, nous devons signaler une coquille malheureusement incomplète, draguée par les naturalistes de la deuxième expédition du Travailleur (1881). Cette coquille est mince, globulense, de grande taille, ornée de stries transverses et de côtes longitudinales très fines et très serrées; le labre a une forme particulière.

Nous donnons provisoirement à cette espèce le nom de R. abyssorum.

\section{b. Espèces fossiles.}

4. Ringicula Bezançoni, L. Morlet, var. Herouvalensis (PI. IX, fig. 5).

Parmi les échantillons de Ringicules d'llérouval que nous avons examinés, nous en avons remarqué qui s'éloignent sensiblement du R. minor et se rapprochent du M. Bezançoni de l'éocène moyen sans être identiques; leur forme est plus globuleuse, la callosité et le labre sont 
plus épais; la denticulation du labre est plus forte, s'étendant dans l'intérieur, où l'on remarque un petit bourrelet interne; l'ouverture est moins large à la base.

Nous ne croyons pas ces caractères suffisants pour créer une espèce, mais nous proposons pour ces formes, le nom de R. Bezançoni, variété Herouvalensis (Coll. de M. le marquis de Raincourt).

Long. 5, 2 mill.; diaut. 2,5 mill.

Loc. Eocène inférieur, Hérouval.

61. Ringicula Langlassei, L. Mortet (PI. IX, fig. 6),

Testa parva, ovata, crassa, tenuiter et regulariter striata; anfractus 5 convexi, sutura simplici discreti; anfractus ultimus $3 / 5$ longitudinis xquans, basi rotundatus; apertura coarctala, marginibus callo crasso, penultimum anfractum attingente junctis, margine columellari urcuato, plicis 3 crassis, brevibus, fere equidistantibus munito; plica superna versus basin obliqua, reliqquis ho. rizontalibus contortis, labro arcuato, in medio incrussato et tenue denticulato, superne attenuato.—Long. 3,2 mill.; diam. 1,7 mill.

Coquille petite, ovale, épaisse, finement et régulièrement striće; tours au nombre de 5 , convexes, séparés par une suture simple, le dernier formant à lui seul les $\tilde{5} / \partial \ddot{~ d e}$ la longueur totale et arrondi à la base; ouverture resserrée; bords réunis par un dépôt calleux, épais, dépassant légèrement le dernier tour; bord columellaire arqué, garni de $\bar{s}$ plis épais et courts, et à peu près à égale distance, le supérieur incliné vers la base, les deux autres horizontaux et tordus, principalement l'inférieur; labre légèrement cintré, épais au milieu el s’amincissant fortement, dans la partie supérieure, garni sur toute la parlie 
épaisse d'une fine denticulation (Collection du $\mathrm{D}^{\mathrm{r}} \mathrm{Be}$ zançon).

Loc. Eocène moyen, Septeuil.

$O b s$. Cette espèce se distingue du R. ringens, Lamarck, par sa forme plus allongée, sa taille plus petite, son labre moins détaché et plus droit, ses plis plus courts et plus épais.

69. Ringicula Leognanensis, L. Morlet (PI. IX, fig. 7).

Testa purva, elongata, crassa, striis æquidistantibus ornata; anfractus $51 / 2$ regulariter crescentes, sutura simplici discreti; ultimus dimidium testx paulo superans, obsolete costulatus, basi angulatus; apertura latb, marginibus callo crasso junctis; margine columellari parum arcuato, plicis 3 brevibus, crassissimis; labro rectilineo, superne tenui, medio incrassato et dente prominente munito, inferne coarctato et extus reflexo. - Long. 3 mill.; diam. 1,7 mill.

Coquille petite, allongée, épaisse, ornée de stries régulièrement espacées; tours au nombre de 5 1/2 augmentant graduellement, séparés par une suture simple, le dernier formant à lui seul un pen plus de la moitié de la longueur totale, portant quelques traces de côtes longitudinales, anguleux à la base; ouverture large, à bords réunis par un dépôt calleux très épais qui s'arrête à la hauteur du dernier tour; bord columellaire peu arqué, garni de 5 plis courts et très épais, surtout les inféricurs; labre droit, fortement détaché et mince à la partie supérieure, épais principalement an milieu, où il est muni d'une dent proéminente, se resserrant à la base et légæ̀rement réfléchi en dehors. 
Loc. Miocène moyen, Léognan.

Obs. Cette espèce ne peut être confondue quavec le R. Tournoueri, mais elle s'en distingue par sa taille plus petite, sa callosité plus épaisse, ses plis plus courts et plus épais, son ouverture plus triangulaire et sa suture plus simple.

65. Ringicula semidecorata, L. Morlet (PI. IX, fig. 8 ;.

Testa parva, globulosa, tenuis, striis spiralibus, profundis, infra medium testx conspicuis ornata; anfractus 5 sutura canaliculata discreti; ultimus $3 / 5$ longitudinis xquans, basi subangulatus; apertura dilatata, marginibus callo tenui junctis; margine columellari arcuato, triplicato, plicis brevibus, crassis, rquidistantibus, plica infera contorta, versus basin obliqua, labro parum arcuato el reflexo, uniformi. - Long. 2,5 mill.; diam. 1,7 mill.

Coquille petite, globuleuse, mince, ornée de stries transverses, profondes, occupant seulement la moitié inférieure de chaque tour; tours au nombre de 5 , séparés par une suture canaliculée; le dernier formant à lui seul les $5 / 5$ de la longueur totale, légèrement anguleux à la base ; ouverture élargie; borls réunis par un dépôt calleux très mince; bord colımelliaire fortement arqué, garni de $\tilde{z}$ plis courts, épais et placés à peu près à égale distance, l'inférieur fortement tordu et incliné vers la base ; labre peu cintré, peu réfléchi et uniforme, dépassant un peu le bord columellaire (Collection L. Morlet).

Loc. Eocène moyen? Saint-Etienne-d'Orthe (Landes) (R. Tournouër).

Obs. Cette espèce ne peut être confondue avec aucune 
autre de ce genre; elle se distingue par sa forme générale et son ornementation.

N'ayant pu nous procurer l'ouvrage intitulé : "Ringicole Italiane, ” et publié en 1880-1881, dans les Mémoires de la * Reale Accademia dei Lincei », dans lequel M. Seguenza a publié sa Monographie des Ringicules des terrains tertiaires de l'Italie, et n'ayant pu recevoir les renseignements que nous avions demandés, nous devons les prendre dans le tirage à part qui en a été fait.

15. Ringicula Bonelli, Deshayes.

R. Bonelli, Seguenza, Ringicole Italiane $n^{\circ} 22$, p. $\mathbf{4 1}$, 1881.

Loc. Miocène moyen, Collines de Turin (Bellardi, Michelotti, Rovasenda).

16. Ringicula costata, Eichwald.

R. costata, Seguenza, Ringicole Italiane $\mathrm{n}^{\circ}$ 25, p. 42, pl. II, fig. 9, $9 a, 9 b, 10,10 a, 1881$.

Loc. Miocène supérieur, Romelta (Prov. de Messine), var. 1, Ciminna (Prov. de Palerme), var. 1 et 2.

17. Ringicula elongata, L. Morlet, var. MessaNensis, Seguenza.

R. elongata, Seguenza, Ringicole Italiane $n^{\circ} 17$, p. $5 \pi$, pl. II, fig, 5 , ऽ̌ $a, 1881$.

Loc. Miocène supérieur, Gravitelli, près Messine.

25. Ringicula gigantea, Doderlein.

R. gigantea, Seguenza, Ringicole Italiane $n^{\circ} 5, p .17$, 1881. 
Loc. Miocène supérieur, Monte Gibio, près Sassuolo (Coppi).

Obs. C'est par suite d'une erreur que M. Ie professeur C. Mayer a désigné cette espèce sous le nom d'Auriculina gigantula (Journ. Conchyl., vol. XVII, p. 85, 1869), et que j'ai moi-même employé cette dénomination spécifique dans ma Monographic du genre.

\section{Ringicula Baylei, L. Morlet.}

R. Baylei, Seguenza, Ringicole Italiane $\mathbf{n}^{\circ}$ 18, p. 58, 1881 .

Loc. Mlocène moyen, Turin (Bellardi).

29. Ringicula Crossei, L. Morlet.

R. Crossei, Seguenza, Ringicole Italiane $n^{0} 20$, p. 40, 1881 .

Loc. Miocène supérieur, Tortona (L. Morlet).

5̇l. Ringicula auriculata, Ménard.

R. auriculata, Seguenza, lingicole Italiane $n^{\circ} \mathbf{1 1}$, p. 50 , pl. I, fig. 9, $9 a$, pl. II, fig. I, $1 a, 1881$.

Loc. Pliocène inférieur : Mlodenese (Coppi, Bellardi), Osterla, Altavilla, Siena (Pantanelli), Gallina (Reggio). - Pliocène supérieur : Vallebiaia (Issel), Monte Pellegrino (Brugnone), Fte Oreto (Bruguone), Militello (Brugnone), Fonte Giannetello, près Caltanissetta (Brugnone), Menosterace. -Quaternaire : Messine, Reggio (Calabre), Catanza (Lovesato).

52. Ringicula Broccin, Seguenza.

R. Brocchii, Seguenza, Ringicole Italiane $n^{0} 14, p .54$, 1881. 
Loc. Pliocène inférieur: Nodenese (Coppi), Piacentino, Osterla, Cornare, Altavilla (Ciofalo, Brugnone), Calatabiano, Patli, Buccheri (Brugnone), Siena (Pantanelli), Pliocène supérieur : Mlonte Mario (Rigacci).

55. Ringicola boccinea, Brocchi.

R. buccinea, Segnenza, Ringicole $n^{\circ} 5$, p. 20, pl. I, fig $, \bar{\jmath}, \overline{5} a, \bar{\jmath} b, \bar{\jmath} c, \overline{5} d, \bar{\jmath} e, 1881$.

Loc. Miocène moyen : Superga (Bellardi). — Miocène supérieur : Honte Gibiol Ciminna (Ciofalo). - Pliocène inférieur: Savona, Gênes (Issel), Cornare, Villavernia, Astigiano (Bellardi), Osterla, Masserano, Piacentino ( $D^{r}$ Aragona), Modenese (Coppi, Bellardi), Bolognese (Foresti, Segnenza), Siena (Pantanelli), Orciano (Lawley), Livourno (Caterini), Altavilla (Ciofalo), Gallina.

53. Ringicula conformis, Monterosato.

R. conformis, Seguenza, Ringicole Italiane $n^{0}$ 2, p. 16, pl. I, fig. 2, 1881 .

Loc. Pliocène inférieur: Altavilla, Piacentino ( $D^{r}$ Arilgona). - Pliocène supérieur : Ficarazzi (Brugnone). Quaternaire: Boveto.

56. Ringicula exilis, Eichwald.

R. exilis, Seguenza, Ringicole Italiane $n^{0} 16$, p. 56 , 1881 .

Loc. Miocène moyen : Superga (Bellardi). — Miocène supérieur : Stozzano (Bellardi), Miodenese (Coppi), Ciminna (Ciofalo). — Pliocène inférieur : Modenese (Bellardi). 
37. Ringicula Gaudryana, L. Morlet.

R. Gaudryana, Seguenza, Ringicole Italiane $n^{\circ} \mathbf{1 5}, p . \overline{5} \overline{5}$, pl. II, fig. S, Sa, 1881 .

Loc. Miocène supérieur : Stozzano (Bellardi). - Pliocène inférieur : Hodenese (Coppi), Bolognese (Foresti), Peccioli, Orciano (Lawley), Livorno (Caterini), Savona, Genova (Issel), Osterla, Hasserano, Altavilla (Brugnone), Ponte Granetello, IIonte Santo Giuliano, près Caltanissetta (Brugnone).

58. Ringicula Grateloupl, d'Orbigny.

R. Grateloupi, Seguenza, Ringicole Italiane ${ }^{\circ} 10$, p. 29, p. II, fig. 12, $12 a, 1881$.

Loc. Miocène moyen : Superga (II.), Baldissero (M.). - Miocène supérieur : Monte Gibio (Coppi, Bellardi), Tortonese (Bellardi), Ciminna (Ciofalo). - Pliocène inférieur: Modenese (Bellardi).

40. Risgicula leptocheila, Brugnone.

R. Ieptocheila, Seguenza, Ringicole Italiane $n^{\circ} 5$, p. 45, 1881.

Loc. Pliocène inférieur : Rometta (prov. de Messine), Gallina (près Reggio). - Pliocène supérieur : Ficarazzi (Brugnonc), Monte Pellegrino (Brugnone), Fiume Oreto (Brugnone).

41. Ringicola marginata, Deshayes.

R. marginota, Segnenza, Ringicole Italiane $n^{\circ} 6$, p. 25, pl. I, fig. 5, 5ै a, 1881. 
Loc. Mliocène supérieur : Benestare, Calabria. - Pliocène inférieur : Astigiano (Bellardi).

45̄. Ringicula Tournoueri, L. Morlet.

R. Tournoueri, Seguenza, Ringicole Italiane $\mathbf{n}^{\circ} \mathbf{2 1}, \mathrm{p} .40$, pl. II, fig. $4,4 a, 4 b, 1881$.

Loc. Miocène moyen : Stilo (prov. di Reggio). - Miocène supérieur : Ciminna (prov. de Palerme), var. 1,5 (Ciofalo), Rometta (prov. de Messine), var. 2.

48. Ringicula africana, L. Morlet.

R. africana, Seguenza, Ringicole Italiane $\mathrm{n}^{\circ} 9$, p. 28, 1881.

Loc. Pliocène inférieur : Astigiano, Piacentino ( $\mathrm{D}^{\mathrm{r}}$ Aragona), Altavilla, Buccheri (Brugnone). — Pliocène supérieur : Vallebiaia (Issel), Monte Mario (Rigacci).

64. Ringictla crassa, Seguenza.

R. crassa, Seguenza, Ringicole Italiane $n^{\circ}$, p. 15, pl. I, fig. 1, $1 a, 1 b, 1881$.

Loc. Nliocène supérieur : Sassuolo, Tortonese (Bellardi). — Pliocène inférieur : Astigiano (Issel).

63. Ringicdla Hoernesi, Seguenza.

R. Hoernesi, Seguenza, Ringicole Italiane $\mathrm{n}^{\circ} 4$, p. 18, pl. I, fig. $4,4 a, 4 b, 1881$.

Loc. Miocène supérieur : Baden Monte Solliano, près Sassuolo.

66. Ringicula doliformis, Seguenza.

R. doliiformis, Seguenza, Ringicole Italiane $\mathrm{n}^{\circ} \mathbf{7}$, p. $\mathbf{5 6}$, pl. 1 , fig. $6,6 a, 6 b, 1881$. 
Loc. Miocène moyen : Sciolze (près Turin).

67. Ringicula Calabia, Seguenza.

R. Calabra, Seguenza, Le formazioni terz. nella prov. di Reggio (Calabria), p. 101, pl. xı, fig. $5,1879$.
- $\quad$ - Ringicole Italiane $\mathrm{n}^{\circ} 8, \mathrm{p} .27, \mathrm{pl} . \mathrm{I}$, fig. $7,7 a, 7 b, 8,8 a, 1881$.

Loc. Miocène moyen : Sciolze (près Turin). - Miocène supérieur : Norlenese (Coppi, Bellardi) avec les var. 1 et 2. Stazzano (Tortonese) (Bellardi), Benestare (Calabria), avec les diverses variétés. - Pliocène moyen : Mlodenese (Bellardi).

68. Ringicula Placentina, Seguenza.

R. Placentina, Seguenza, Ringicole Italiane ${ }^{\circ} 12$, p. 52, pl. 11, fig. 2, 2a, 2b, 1881 .

Loc. Pliocène inférieur : Piacentino ( $\mathrm{D}^{\mathrm{r}}$ Aragona).

69. Ringicula Taurinensis, Seguenza.

R. Taurinensis, Seguenza, Ringicole Italiane n 15, p. 56 , pl. II, fig. $\overline{5}, \bar{\jmath} a, \bar{z} b, 1881$.

Loc. Miocène moyen: Collines de Turin (Bellardi).

70. Ringicula Marie, Seguenza.

R. Mariæ, Seguenza, Ringicole Italiane $n^{\circ} 19$, p. 59, pl. II, fig. 6, 6a, 7, 7 a, 1881 .

Loc. Nliocène moyen : Turin (Bellardi).

71. Ringicula cancellaroides, Seguenza.

R. cancellaroides, Seguenza, Ringicole Italiane $\mathbf{n}^{\circ} \mathbf{2 4}$, p. 44, pl. 11, fig. 11, 11 a, 1881 . 
Loc. Miocène supérieur : Sassuolo (Modenese).

79. Ringicula calabro-sicula, Seguenza.

R. calabro-sicula, Seguenza, Le formazioni terziarie nella prov.'di Reggio (Calabria), p. 252, pl. xvI, fig. 15, $15 a, 1880$.

- $\quad$ - Ringicole Italiane $\mathrm{n}^{\circ} 26$, p. $46,1881$.

Loc. Pliocène inférieur : Gallina, près Reggio (Calabria), Calatabiano (Sicilia).

II. G. Vasseur cite, dans sa thèse pour le doctorat ès sciences, une Ringicule nouvelle, d'une forme tout à fait inédite. Quoique cette espèce ne soit encore que manuscrite, nous croyons devoir la signaler.

75. Ringicula Morleti, G. Vasseur, ms.

Loc. Terrains tertiaires de la Bretagne.

L. II.

EXTRAIT DU NUMÉRO DE JUILLET 1882

du

JOURNA. DE CONCHYLIOLOGIE

PUBLIÉ PAR H. CROSSE,

RUE TRONCHET, 25,

PARIS.

Paris. - Imprimerie de Mme veuve Bouchard-Huzard, rue de l'Éperon, 5 ; J. TREMBLAX, gendr et successeur. 
Journal te Cumnjlogog 1802
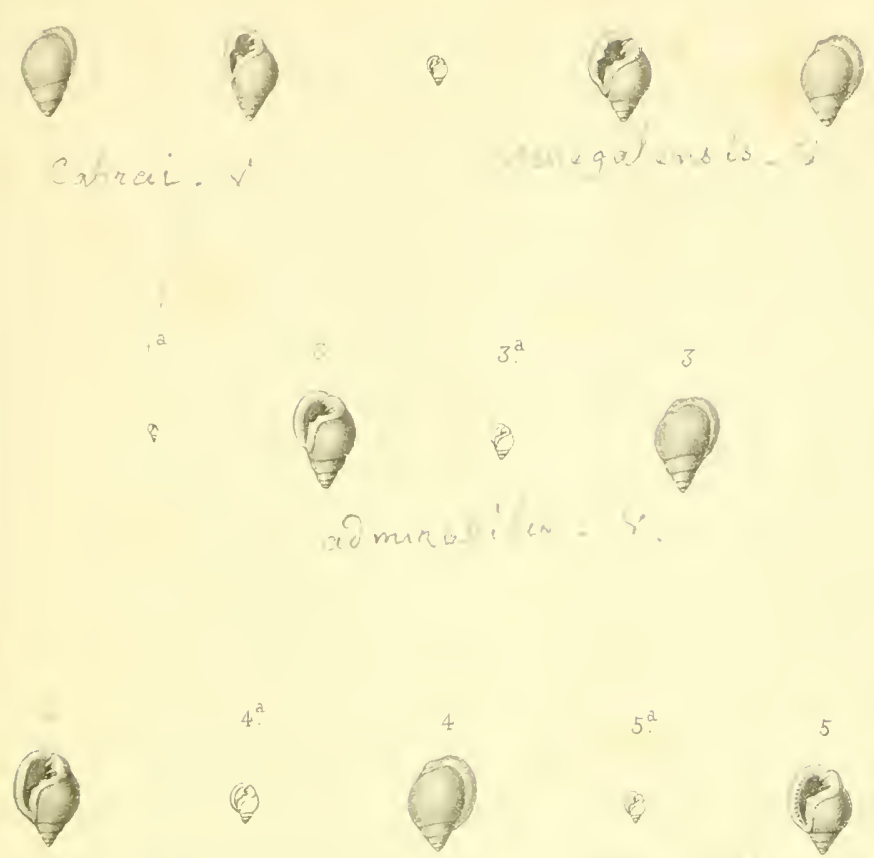

Ir'Jumi cotakre
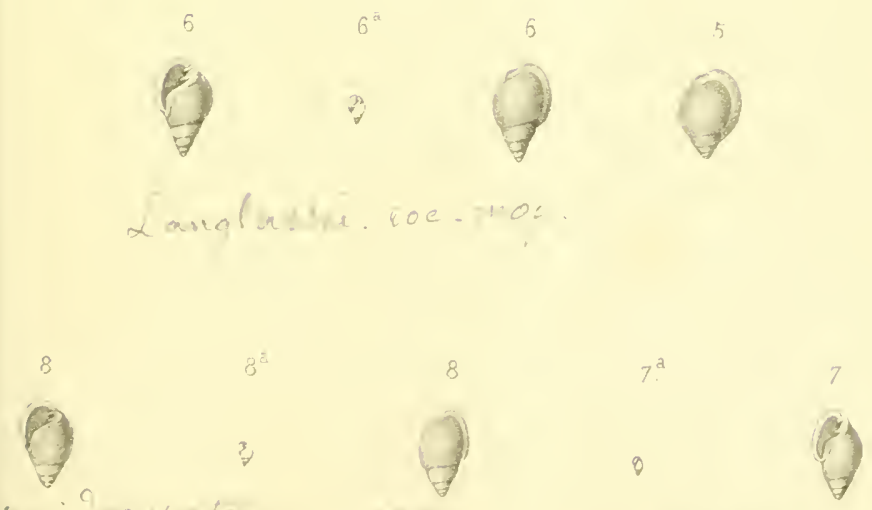

A $26 e-2+6^{\circ}$

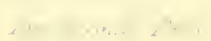

A Libral Awaet Seriegatinais Mo.t. admrabilis irorict Schlumberqen in or et

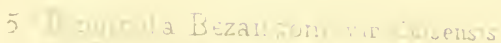

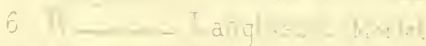

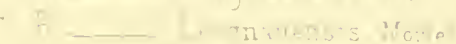

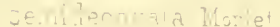








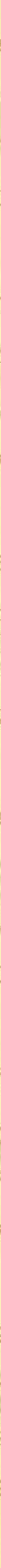



